\title{
New Burke Museum \\ Fire and Life Safety Overview and Atrium Design Analysis
}

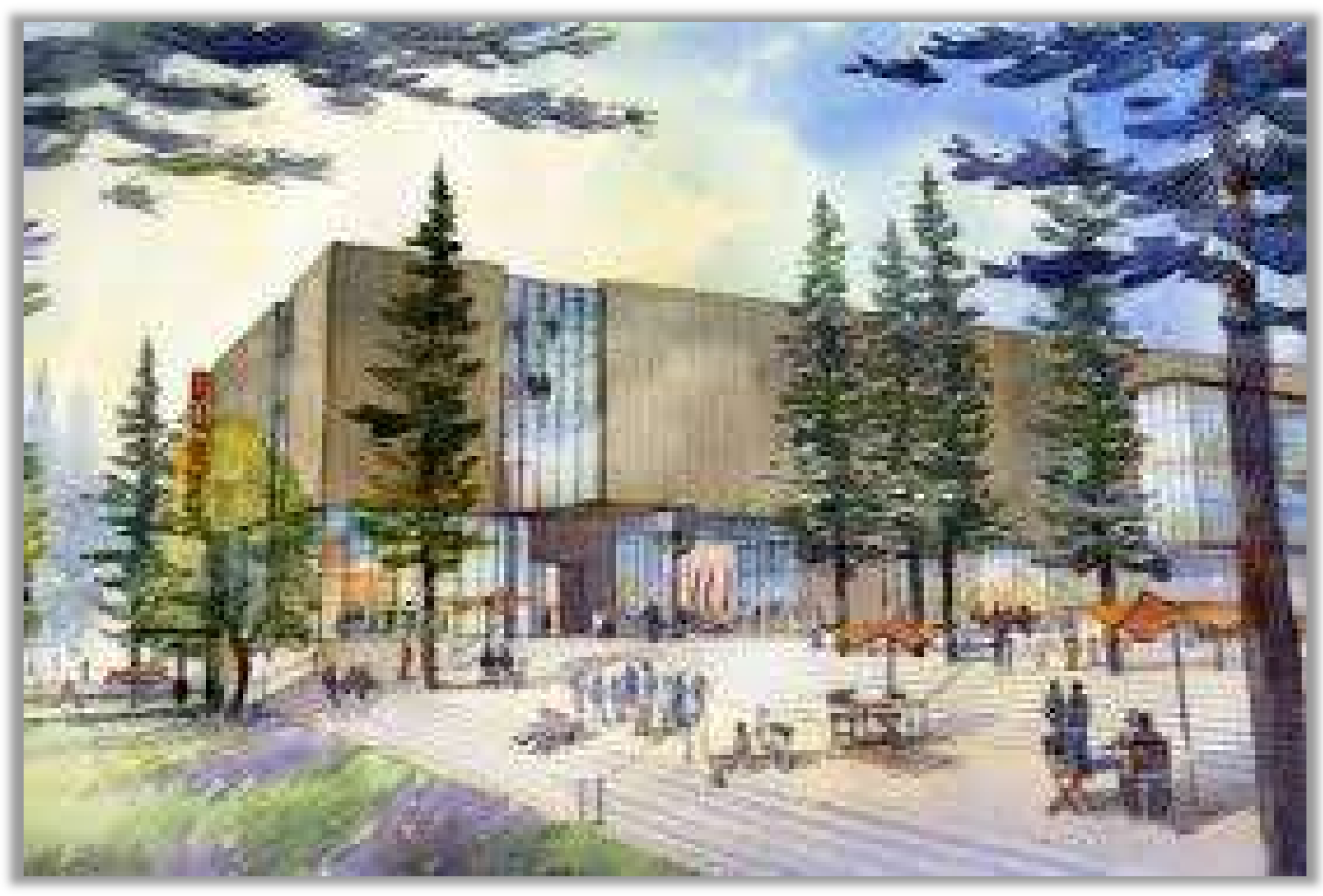

Justin Schmidt

Californian Polytechnic State University, San Luis Obispo

FPE Culminating Project

June $9^{\text {th }} 2016$ 


\title{
$\underline{\text { Statement of Disclaimer }}$
}

This project report is a result of a class assignment; it has been graded and accepted as fulfillment of the course requirements. Acceptance of this report in fulfillment of the course requirements does not imply technical accuracy or reliability. Any use of information in this report is done at the risk of the user. These risks may include, but may not be limited to, catastrophic failure of the device or infringement of patent or copyright laws. California Polytechnic State University at San Luis Obispo and its staff cannot be held liable for any use or misuse of the project.

Keywords: Atrium, Smoke Control, Separation, Horizontal Shutter, Alternate Means and Method

\begin{abstract}
:
This paper compares two design approaches for a 4-story atrium. The subject is the New Burke Museum building that is currently under construction in Seattle, WA. Under normal conditions, this building has four levels that are connected by different horizontal and vertical openings. The building design utilizes a series of vertical and horizontal acting fire doors to create separation and eliminate the atrium condition. The building's alternate design is compared to a traditional atrium design meeting the requirements of section 404 of the IBC with an active smoke control system designed using NFPA 92B. In order to complete the analysis of the two designs a study of the entire Burke Museum building and how it meets current building code requirements is also summarized. This includes the buildings construction type, occupancies, fire and smoke protection features, egress requirements and fire protection systems.

The comparison is based on code compliance, fire and life safety performance and impact to the building design. It is found that both designs meet the building code. The alternate design to create separation has the least impact to the design. When designed and maintained properly, an active smoke control system will maintain tenability longer than creating separation.
\end{abstract}




\section{$\underline{\text { Table of Contents }}$}

1 Introduction

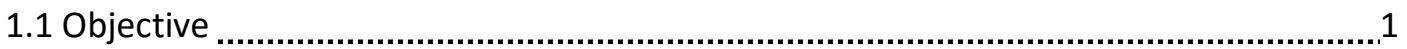

1.2 Personal Association with the Building .................................................................. 1

1.3 Building Description ...................................................................................... 2

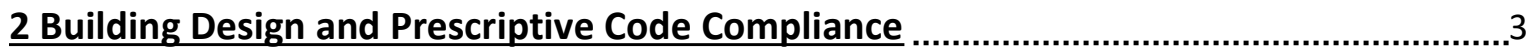

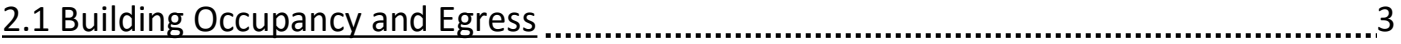

2.1.1 Building Occupancy ....................................................................................

2.1.2 Occupant Load ......................................................................................

2.1.3 Exit Capacity and Configuration ............................................................... 8

2.2 Building Height and Area .........................................................................................

2.2.1Construction Type ............................................................................. 11

2.2.2 Allowable Height and Area ..............................................................11

2.2.3 Fire Resistance Ratings ...........................................................................13

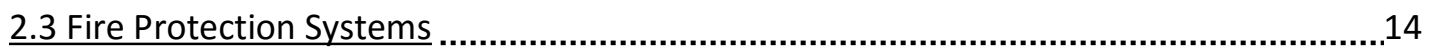

2.3.1 Fire Alarm Detection System .................................................................14

2.3.2 Fire Alarm Secondary Power Supply .......................................................16

2.3.3 Fire Alarm Testing and Maintenance .....................................................16

2.3.4 Fire Sprinkler System .................................................................. 17

2.3.5 Building Occupancy Classification ..........................................................18

2.3.6 Sprinklers at Windows ........................................................................ 19

2.3.7 Sprinkler System Design Calculations ......................................................20

2.3.8 Sprinkler System Inspection, Testing and Maintenance .............................20

3 Atrium Design Comparison and Performance Based Analysis .........................................22

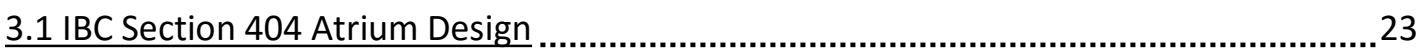

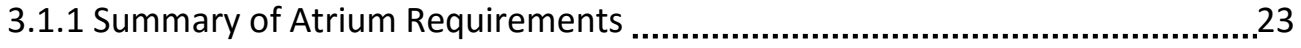

3.1.2 Travel Distance ............................................................................. 25

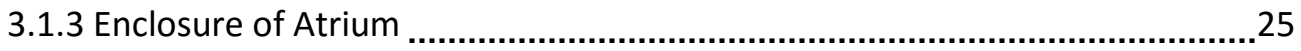

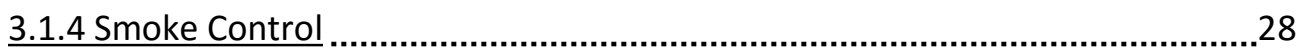

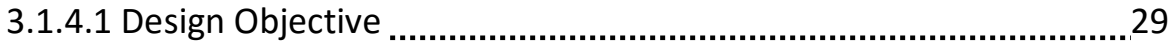

3.1.4.2 Design Fire Fuel Sources ........................................................... 31

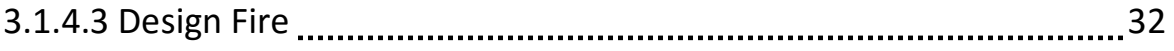

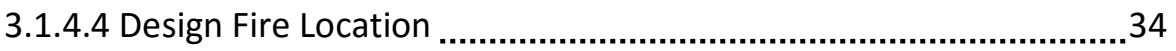

3.1.4.5 NFPA 92B Mechanical Exhaust Calculations .................................34

3.1.4.6 CFD Smoke Control Design ......................................................... 35

3.1.4.7 CFD Smoke Control Design Results ........................................... 38

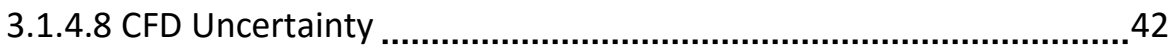

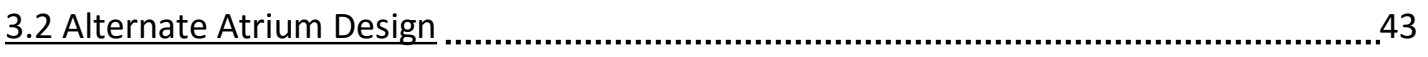

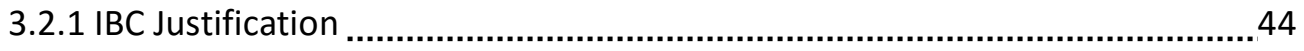

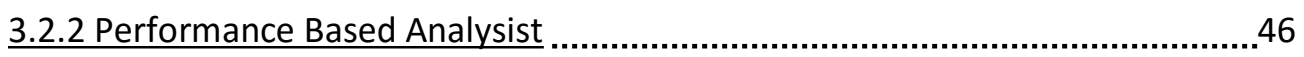

3.2.2.1 Required Safe Egress Time ......................................................46 
3.2.2.2 CFD Model 47

3.3 Atrium Design Comparison .................................................................................. 49

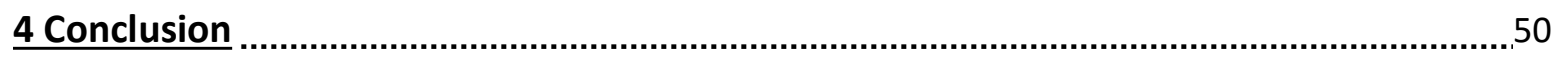

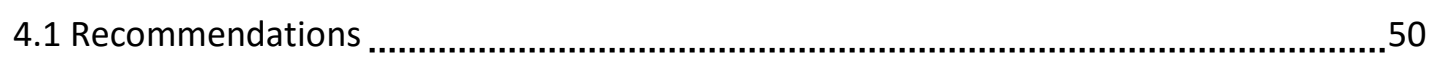

5 References 


\section{Introduction:}

\subsection{Objective:}

This report will provide a review of The New Burke Museum (Burke) building and how it meets current building code requirements. The Burke is currently under construction in Seattle, WA. The review will include the buildings construction type, occupancies, fire and smoke protection features, egress requirements and fire protection systems.

The Burke has four levels that are connected by different horizontal and vertical openings. A focus of this report will be to compare two design approaches for this 4-story atrium. The final building design utilizes a series of vertical and horizontal acting fire doors to create separation and eliminate the atrium condition. A portion of this design includes the use of an alternate means and method per IBC 104.11. The Burke's use of this alternate design will be compared to a traditional atrium design meeting the requirements of section 404 of the IBC. An emphasis will be put on the active smoke control system that would be required in a traditional atrium design.

The analysis of the building and atrium designs will utilize the following building codes and standards:

- 2012 International Building Code (IBC)

- 2013 NFPA 13

- 2013 NFPA 72

- 2009 NFPA 92B

- 2012 NFPA 252

- 2012 NFPA 288

\subsection{Personal Association with the Building:}

I work as a product specialist for a specialty subcontractor. My primary role is to be a fire and life safety code consultant for architects and provide them with innovative design solutions using the products that my company supplies and installs. One of the products we work with is a horizontal fire shutter that is used on this project. I helped the architect write the code appeal that was used to get the final design approved. I chose to do this report to discover what it would have taken to use a smoke control system and to compare it to the final design. 


\subsection{Building Description:}

The Burke Museum is a 105,000 GSF natural history and cultural museum. Construction will start on this project May of 2016. The project is on track to be LEED Gold and is designed to break down the traditional museum barriers. In addition to open exhibit areas, the building is designed to give visitors a view of collections and research labs of a working museum.

The building consists of 3-stories over a partial basement. The primary exhibit area consists of three levels with 20' ceilings and three large floor openings that provide daylighting from the skylight above and connectivity between each level. A large communicating stair connects the floors to further promote exploration of the museum. As shown in Figure 1, a primary design goal was to provide an open and natural environment.

The museum will consist of exhibit halls, classrooms, event rooms, labs, storage rooms, offices and a café. $60 \%$ of the building will be accessible or viewable to visitors.

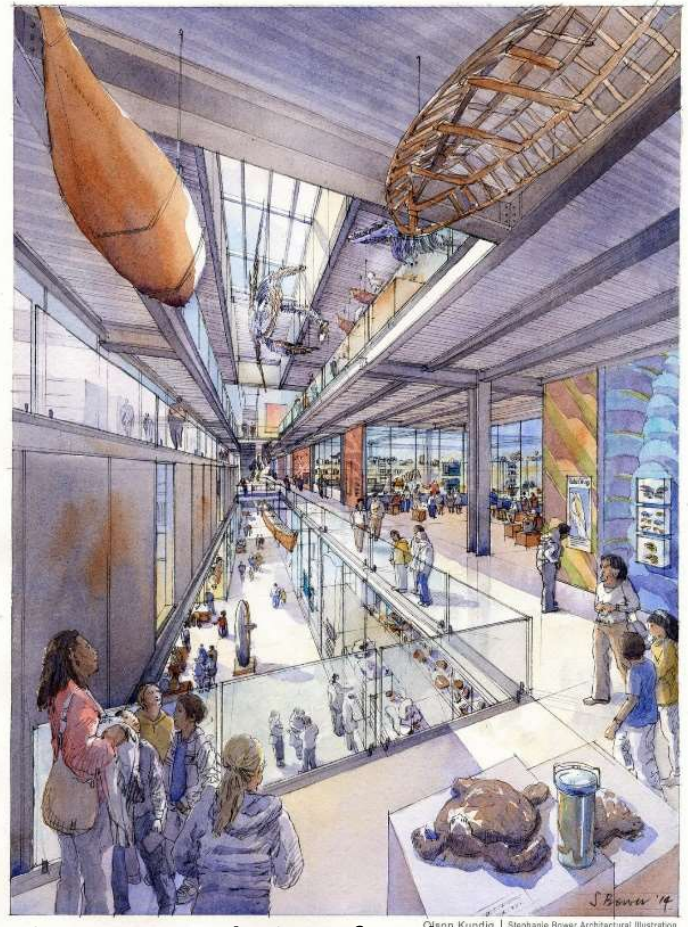

Figure 1: Rendering of Burke Museum Atrium Space

The building is equipped throughout with a compliant fire sprinkler and alarm system. The construction is type IIB with some building components designed with a fire resistance as required in different areas of the IBC. The occupancy is mixed use with the primary occupancy being A-3. The occupancies are non-separated with the exception of a room that is classified as $\mathrm{H}-3$. The $\mathrm{H}-3$ occupancy is separated from the rest of the building by 2 -hour construction. A complete overview of the Burkes design and prescriptive code compliance will now be provided. 


\section{Building Design and Prescriptive Code Compliance}

\subsection{Building Occupancy and Egress}

\subsubsection{Building Occupancy}

The Burke Museum is a mixed use occupancy building. The primary use of this building and most restrictive non-separated occupancy is A-3. Below is a summary of the non-separated and separated occupancies in this building:

- $\quad$ Non-Separated (per IBC Section 508.3)

- A-3: Assembly, Museums, Lecture Halls (Primary Occupancy)

- A-2: Assembly, Food and Drink Consumption

- B: Business, Administration Areas

- E: Educational Areas

- S-1: Storage, Moderate-Hazard

- S-2: Storage, Low-Hazard

- M: Mercantile

- Separated Accessory (2-hour separation per IBC Table 508.4)

- H-3: Hazardous, containing class IB Flammable or Comestible Liquids

To better clarify the layout of the building and its different occupancies Figures 2 thru 5 show floor plans of the building with the different occupancies identified. The exit and exit access points are also shown on the drawings. 


\section{Occupancy, Basement Level}

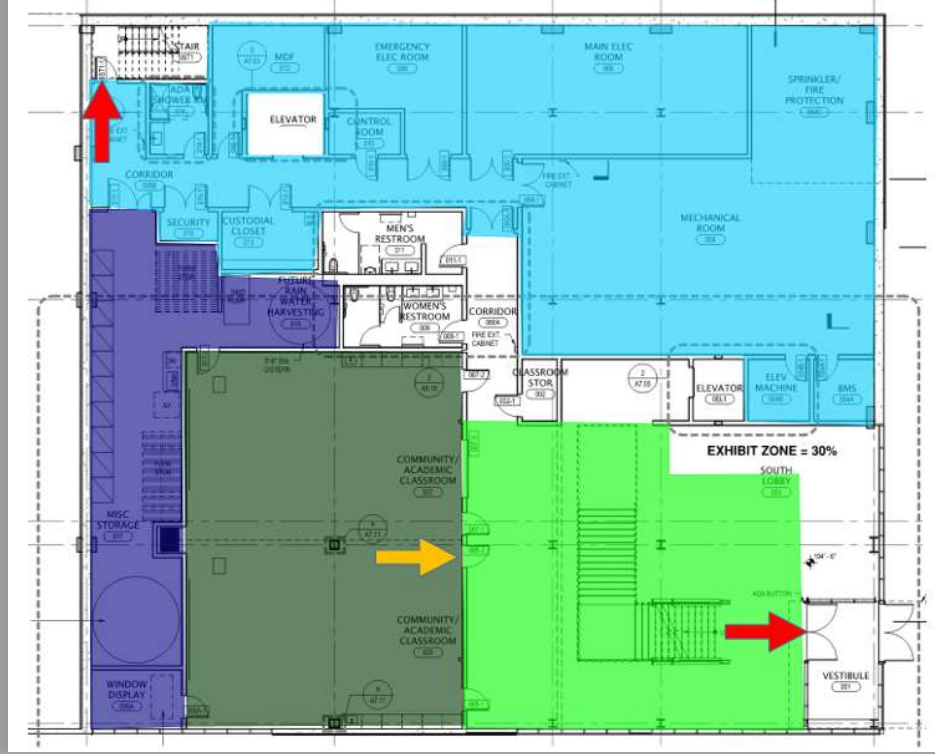

\section{Exit Exit Access}

A-3

A-2

$B$

$\mathrm{E}$

S1

S2

H3

$\mathrm{M}$

Figure 2: Basement Level Occupancy Classifications Exit Components

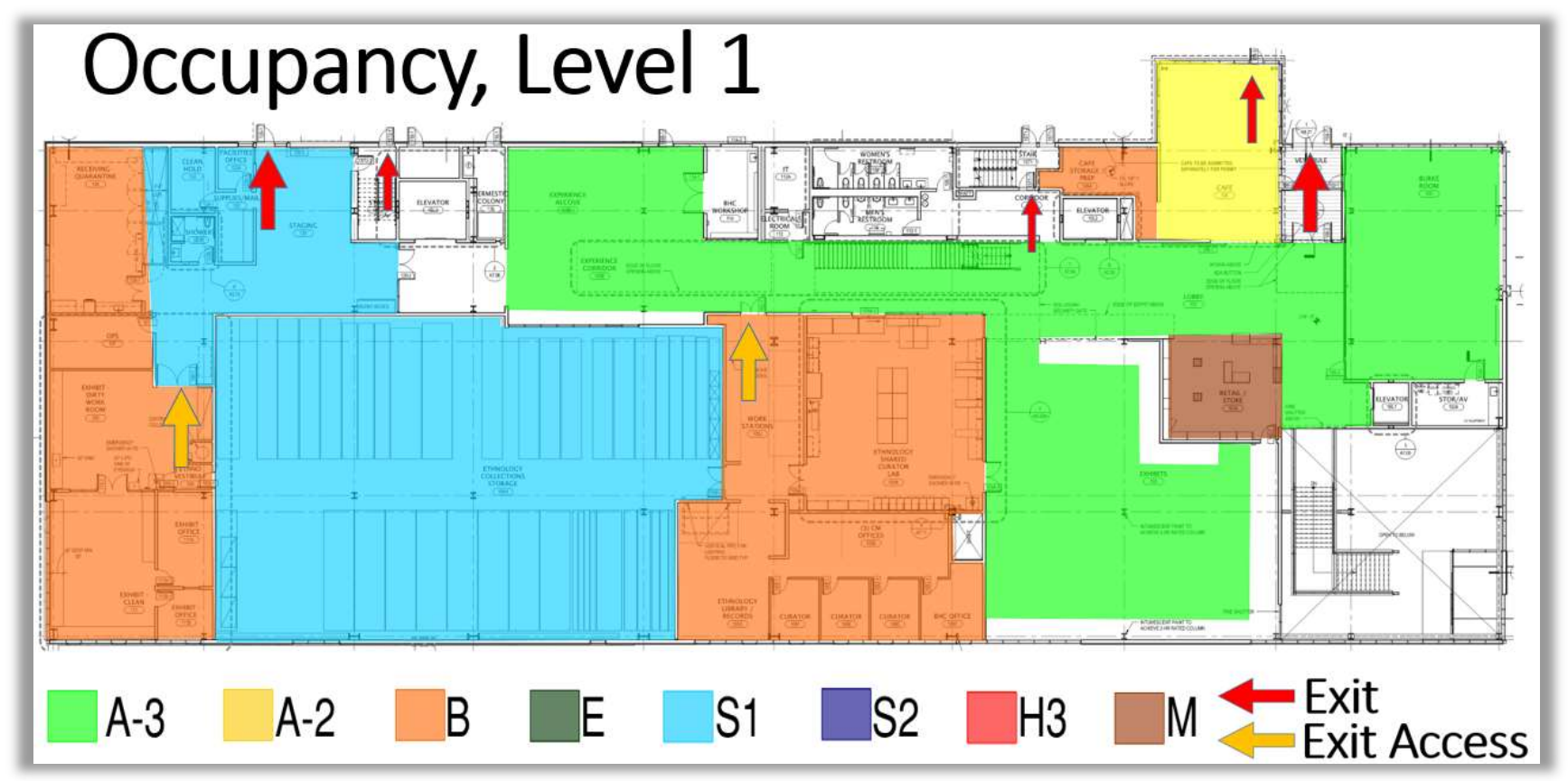

Figure 3: Level 1 Occupancy Classifications Exit Components 


\section{Occupancy, Level 2}

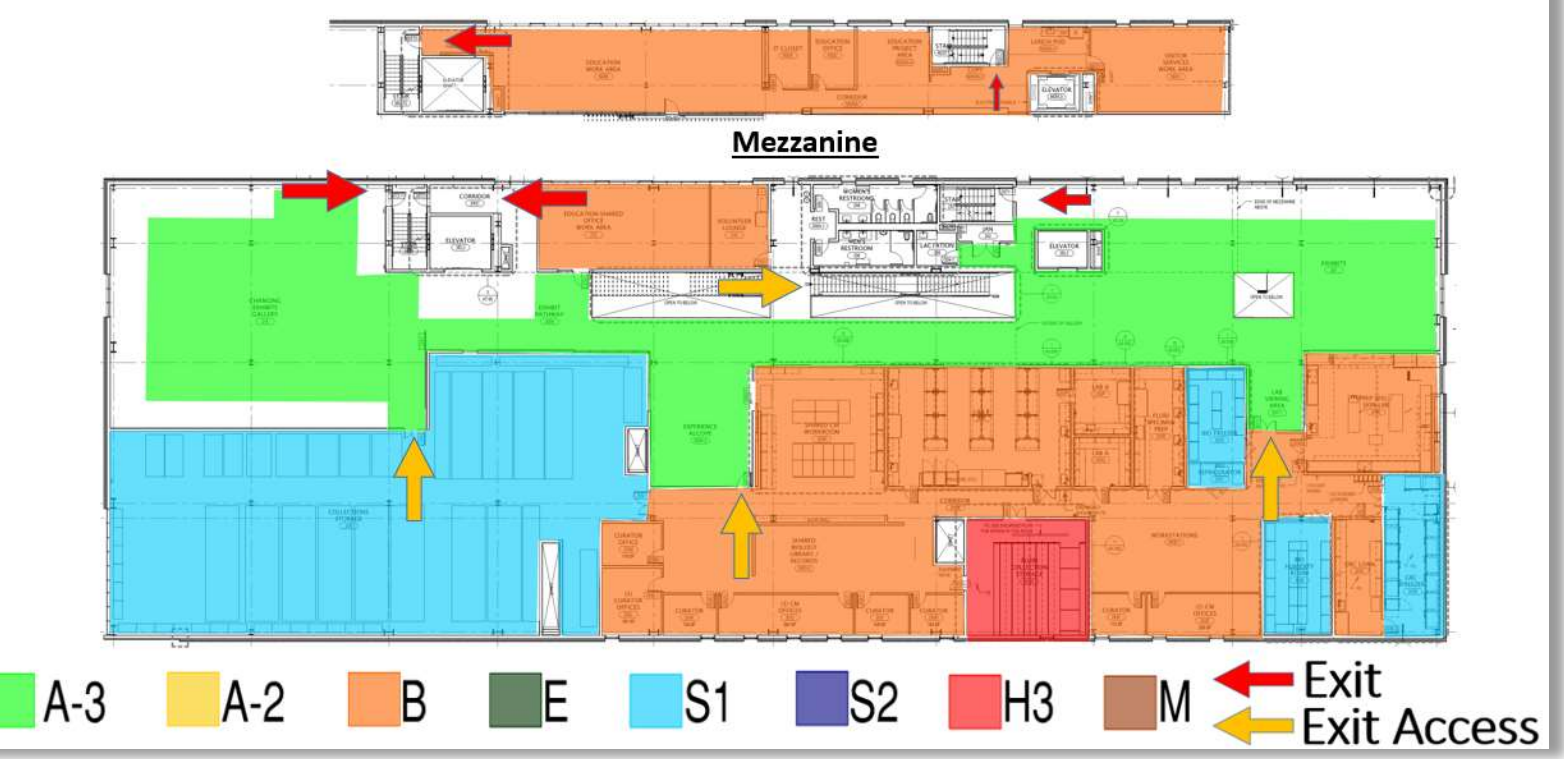

Figure 4: Level 2 Occupancy Classifications Exit Components

\section{Occupancy, Level 3}

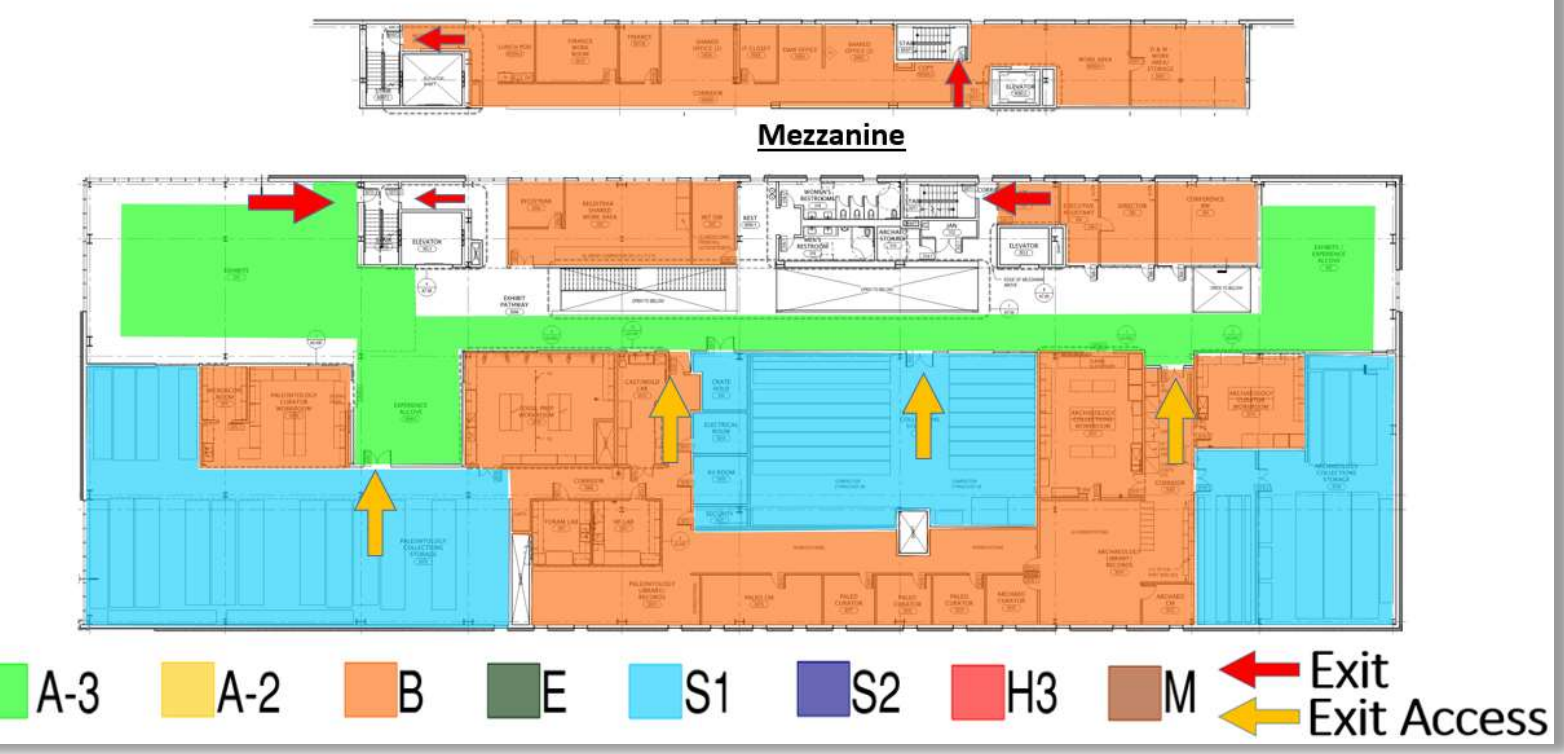

Figure 5: Level 3 Occupancy Classifications Exit Components 


\subsubsection{Occupant Load}

Occupant loads for the Burke are calculated using the occupant load factors listed in IBC Table 1004.1.2. Table 1 provides a summary of the occupant load factors for each of the occupancy types identified in the previous section and the occupant loads calculated for each level. Per Section 1004.1.1.1; where occupants egress from one room, area or space through another, the design occupant load shall be based on the cumulative occupant loads of all rooms, areas or spaces to that point along the path of egress travel. Tabel 2 provides the occupant loads of each room.

Table 1: Summary of Occupancy and Load Factors

\begin{tabular}{|l|c|c|}
\hline Function of Space & Occupancy & Occupant Load Factor \\
\hline Classrooms & E & 20 net \\
\hline Storage & S-1, S-2 \& H-3 & 300 gross \\
\hline Business Areas, Offices and Work Rooms & B & 130 gross \\
\hline Commercial Laboratories & B & 100 gross \\
\hline Mercantile on Basement and Grade Floors & M & 30 gross \\
\hline Assembly Exhibit & A-3 & 30 net \\
\hline Assembly Unconcentrated & A-3 \& A-2 & 15 net \\
\hline Exhibit Pathway (Airport Terminal Concourse) & A-3 & 100 gross \\
\hline
\end{tabular}

Table 2: Occupant loads by floor and room

\begin{tabular}{|c|c|c|c|c|c|c|}
\hline \multicolumn{7}{|c|}{ OCCUPANT LOAD CALCULATIONS } \\
\hline Name & FUNCTION & OCCUPANCY & AREA & OCCUPANT LOAD FACTOR & NET/GROSS & OCCUPANTS \\
\hline \multicolumn{7}{|l|}{ LOWER LEVEL } \\
\hline CLASSROOMS & EDUCATIONAL CLASSROOMS & E & $2,047 \mathrm{SF}$ & $20 \mathrm{SF}$ & NET & 102 \\
\hline LOBBY & ASSEMBLYYXXHIBIT & A.3 & $1,564 \mathrm{SF}$ & $30 \mathrm{SF}$ & NET & 52 \\
\hline MECHJELEC_STO. & $\begin{array}{l}\text { ACCESSORY STORAGE AREAS, MECHANICAL } \\
\text { EQUIPMENT ROOMS }\end{array}$ & S-2 & $3,601 \mathrm{SF}$ & $300 \mathrm{SF}$ & GROSS & 12 \\
\hline STORAGE & $\begin{array}{l}\text { ACCESSORY STORAGE AREAS, MECHANICAL } \\
\text { EQUIPMENT ROOMS }\end{array}$ & s-1 & $1,456 \mathrm{SF}$ & $300 \mathrm{SF}$ & GROSS & 5 \\
\hline LOWER LEVEL & & & & & & 171 \\
\hline
\end{tabular}

\begin{tabular}{|c|c|c|c|c|c|c|}
\hline \multicolumn{7}{|c|}{ OCCUPANT LOAD CALCULATIONS } \\
\hline Name & FUNCTION & OCCUPANCY & AREA & OCCUPANT LOAD FACTOR & NET/GROSS & OCCUPANTS \\
\hline \multicolumn{7}{|l|}{ MAIN LEVEL } \\
\hline LOBBY & ASSEMBLYY UNCONCENTRATED (TABLEICHAIRS) & A.3 & $1,450 \mathrm{SF}$ & $15 \mathrm{SF}$ & NET & 97 \\
\hline EXHIBTT GALLERY & ASSEMBLY EXYHBIT & A-3 & $1,391 \mathrm{SF}$ & $30 \mathrm{SF}$ & NET & 46 \\
\hline BURKE ROCM & ASSEMBLY UNCONCENTRATED (TABLEICHAIRS) & A-3 & 1,444 SF & $15 \mathrm{SF}$ & NET & 96 \\
\hline EXPERIENCE ALCOVE & ASSEMBLY EXHBIT & A-3 & $735 \mathrm{SF}$ & $30 \mathrm{SF}$ & NET & 24 \\
\hline OFFICE & BUSINESS AREAS (WITH SPRINKLERS) & $B$ & 64 SF & $130 \mathrm{SF}$ & GROSS & 0 \\
\hline COLLECTIONS STORAGE & $\begin{array}{l}\text { ACCESSORY STORAGE AREAS, MECHANICAL } \\
\text { EQUIPNENT ROOMS }\end{array}$ & S-1 & $6,281 \mathrm{SF}$ & $300 \mathrm{SF}$ & GROSS & 20 \\
\hline OFFICES, LIBRARY & BUSINESS AREAS (WITH SPRINKLERS) & B & $2,130 \mathrm{SF}$ & $130 \mathrm{SF}$ & GROSS & 16 \\
\hline OFFICES, WORK AREAS & BUSINESS AREAS (WITH SPFINKLLERS) & $B$ & $2,565 \mathrm{SF}$ & $130 \mathrm{SF}$ & GROSS & 19 \\
\hline CAFE OFFICE, PREP & BUSINESS AREAS (WITH SPRINKLERS) & $B$ & $283 \mathrm{SF}$ & $130 \mathrm{SF}$ & GROSS & 2 \\
\hline BHC WORKSHOP & EDUCATIONAL SHOPS AND VOCATIONAL ROOMS & B & $197 \mathrm{SF}$ & $50 \mathrm{SF}$ & NET & 3 \\
\hline EXHIBIT GALEERY & ASSEMBLYY EXHIBIT & A.3 & $2,029 \mathrm{SF}$ & 30 SF & NET & 70 \\
\hline LOADING DOCK & $\begin{array}{l}\text { ACCESSORY STORAGE AREAS, MECHANICAL } \\
\text { EQUIPNENT ROOMS }\end{array}$ & S-1 & $1,603 \mathrm{SF}$ & $300 \mathrm{SF}$ & GROSS & 5 \\
\hline WOFKROOM & BUSINESS AREAS (WITH SPRINIKLERS) & $B$ & $1,361 \mathrm{SF}$ & $130 \mathrm{SF}$ & GROSS & 10 \\
\hline CAFE & ASSEMBLY UNCONCENTRATED (TABLEICHAIRS) & A-2 & $526 \mathrm{SF}$ & $15 \mathrm{SF}$ & NET & 37 \\
\hline RETAIL & MERCANTILE BASEMENT AND GRADE FLOORS & M & $507 \mathrm{SF}$ & $30 \mathrm{SF}$ & GROSS & 17 \\
\hline \multicolumn{6}{|l|}{ MAIN LEVEL } & 462 \\
\hline
\end{tabular}


Table 2 Continued: Occupant loads by floor and room

\begin{tabular}{|c|c|c|c|c|c|c|}
\hline \multicolumn{7}{|c|}{ OCCUPANT LOAD CALCULATIONS } \\
\hline Name & FUNCTION & OCCUPANCY & AREA & OCCUPANT LOAD FACTOR & NET/GROSS & OCCUPANTS \\
\hline \multicolumn{7}{|l|}{ SECONDLEVEL } \\
\hline OFFICES, WORK AREAS & BUSINESS AREAS (WITH SPRINKLERS) & $B$ & $933 \mathrm{SF}$ & $130 \mathrm{SF}$ & GROSS & 7 \\
\hline EXHIBIT GALLERY & ASSEMBLY EXHIBIT & $A \cdot 3$ & $2,576 \mathrm{SF}$ & 30 SF & NET & 86 \\
\hline EXHIBIT GALLERY & ASSEMBLY EXHIBIT & A.3 & $2,433 \mathrm{SF}$ & $30 \mathrm{SF}$ & NET & 81 \\
\hline EXPEREENCE ALCOVE & ASSEMBLYY EXHIIBIT & A-3 & $663 \mathrm{SF}$ & $30 \mathrm{SF}$ & NET & 22 \\
\hline OFFICES, LIBRARY & BUSINESS AREAS (WITH SPRINKLERS) & $\mathrm{B}$ & 4,202 SF & $130 \mathrm{SF}$ & GROSS & 32 \\
\hline$\angle A B$ & COMMERCIAL LABORATORIES & B & $768 \mathrm{SF}$ & $100 \mathrm{SF}$ & GROSS & 8 \\
\hline STORAGE & $\begin{array}{l}\text { ACCESSORY STORAGE AREAS, MECHANICAL } \\
\text { EQUIPMENT ROOMS }\end{array}$ & S-1 & $368 \mathrm{SF}$ & $300 \mathrm{SF}$ & GROSS & 1 \\
\hline$\angle A B$ & COMMERCIAL LABORATORIES & B & 275 SF & $100 \mathrm{SF}$ & GROSS & 3 \\
\hline LABS & COMMERCIAL LABORATORIES & B & $2,506 \mathrm{SF}$ & $100 \mathrm{SF}$ & GROSS & 25 \\
\hline EXHIBIT PATHWAY & AIRPORT TERMINAL CONCOURSE & A.3 & $1,070 \mathrm{SF}$ & $100 \mathrm{SF}$ & GROSS & 10 \\
\hline STORAGE & $\begin{array}{l}\text { ACCESSORY STORAGE AREAS, MECHANICAL } \\
\text { EQUPMENT ROOMS }\end{array}$ & S-1 & $5,688 \mathrm{SF}$ & $300 \mathrm{SF}$ & GROSS & 18 \\
\hline STORAGE & $\begin{array}{l}\text { ACCESSORY STORAGE AREAS, MECHANICAL } \\
\text { EQUPMENT ROOMS }\end{array}$ & S-1 & $345 \mathrm{SF}$ & $300 \mathrm{SF}$ & GROSS & 1 \\
\hline ROOM & BUSINESS AREAS (WITH SPRINKLERS) & B & $60 \mathrm{SF}$ & $130 \mathrm{SF}$ & GROSS & 0 \\
\hline STORAGE & $\begin{array}{l}\text { ACCESSORY STORAGE AREAS, MECHANICAL } \\
\text { EQUPMENT ROOMS }\end{array}$ & S-1 & $442 \mathrm{SF}$ & $300 \mathrm{SF}$ & GROSS & 1 \\
\hline STORAGE & $\begin{array}{l}\text { ACCESSORY STORAGE AREAS, MECHANICAL } \\
\text { EQUIPMENT ROOMS }\end{array}$ & $\mathrm{H}-3$ & $701 \mathrm{SF}$ & $300 \mathrm{SF}$ & GROSS & 3 \\
\hline \multicolumn{6}{|l|}{ SECOND LEVEL } & 298 \\
\hline
\end{tabular}

\begin{tabular}{|c|c|c|c|c|c|c|}
\hline \multicolumn{7}{|c|}{ OCCUPANT LOAD CALCULATIONS } \\
\hline Name & FUNCTION & OCCUPANCY & AREA & OCCUPANT LOAD FACTOR & NET/GROSS & OCCUPANTS \\
\hline \multicolumn{7}{|c|}{ SECOND LEVEL - MEZZANINE } \\
\hline OFFICES, WORK AREAS & BUSINESS AREAS (WITH SPRINKLERS) & $B$ & $2,792 \mathrm{SF}$ & $130 \mathrm{SF}$ & GROSS & 21 \\
\hline SECOND LEVEL - MEZZANIN & & & & & & 21 \\
\hline
\end{tabular}

\begin{tabular}{|c|c|c|c|c|c|c|}
\hline \multicolumn{7}{|c|}{ OCCUPANT LOAD CALCULATIONS } \\
\hline Name & FUNCTION & OCCUPANCY & AREA & OCCUPANT LOAD FACTOR & NET/GROSS & OCCUPANTS \\
\hline \multicolumn{7}{|l|}{ THIRD LEVEL } \\
\hline OFFICES, WORK AREAS & BUSINESS AREAS (WITH SPRINKLERS) & B & $929 \mathrm{SF}$ & $130 \mathrm{SF}$ & GROSS & 7 \\
\hline EXHBIT GALLERY & ASSEMBLY EXHIBIT & A.3 & $780 \mathrm{SF}$ & $30 \mathrm{SF}$ & NET & 25 \\
\hline COLLCTIONS STORAGE & $\begin{array}{l}\text { ACCESSORY STORAGE AREAS, MECHANICAL } \\
\text { EQUIPMENT RCOMS }\end{array}$ & S-1 & $2,632 \mathrm{SF}$ & $300 \mathrm{SF}$ & GROSS & 8 \\
\hline EXPERIENCE ALCOVE & ASSEMBLY EXXIBIT & A.3 & $608 \mathrm{SF}$ & $30 \mathrm{SF}$ & NET & 20 \\
\hline LAB & COMMERCIAL LABORATORIES & $B$ & $271 \mathrm{SF}$ & $100 \mathrm{SF}$ & GROSS & 2 \\
\hline CONFERENCEROOM & ASSEMBLY UNCONCENTRATED (TABLEICHAIRS) & A.3 & $416 \mathrm{SF}$ & $15 \mathrm{SF}$ & NET & 30 \\
\hline COLLECTIONS STORAGE & $\begin{array}{l}\text { ACCESSORY STORAGE AREAS, MECHANICAL } \\
\text { EQUIPMENT ROOMS }\end{array}$ & S-1 & $2,180 \mathrm{SF}$ & $300 \mathrm{SF}$ & GROSS & 7 \\
\hline OFFICE & BUSINESS AREAS (WITH SPRINKLERS) & B & 517 SF & $130 \mathrm{SF}$ & GROSS & 4 \\
\hline WOFKROOM & BUSINESS AREAS (WITH SPRINKLERS) & B & $763 \mathrm{SF}$ & $130 \mathrm{SF}$ & GROSS & 5 \\
\hline LAB & COMMERCIAL LABORATORIES & $\mathrm{B}$ & $402 \mathrm{SF}$ & $100 \mathrm{SF}$ & GROSS & 4 \\
\hline STORAGE & $\begin{array}{l}\text { ACCESSORY STORAGE AREAS, MECHANICAL } \\
\text { EQUIPMENT ROOMS }\end{array}$ & S-1 & $3,843 \mathrm{SF}$ & $300 \mathrm{SF}$ & GROSS & 12 \\
\hline $\begin{array}{l}\text { OFFICES, LIBRARY, } \\
\text { WORKROCM }\end{array}$ & BUSINESS AREAS (WITH SPRINKLERS) & B & $6,082 \mathrm{SF}$ & $130 \mathrm{SF}$ & GROSS & 46 \\
\hline EXHIBIT GALLERY & ASSEMBLY EXXHIBIT & A.3 & $1,842 \mathrm{SF}$ & $30 \mathrm{SF}$ & NET & 61 \\
\hline EXHIBIT PATHWAY & AIRPORT TERMINAL CONCOURSE & A.3 & $1,558 \mathrm{SF}$ & $100 \mathrm{SF}$ & GROSS & 15 \\
\hline ARCHAEO STORAGE & $\begin{array}{l}\text { ACCESSORY STORAGE AREAS, MECHANICAL } \\
\text { EQUIPMENT ROOMS }\end{array}$ & S-1 & $69 \mathrm{SF}$ & 300 SF & GROSS & \\
\hline AUXXLIARY ROOMS & $\begin{array}{l}\text { ACCESSORY STORAGE AREAS, MECHANICAL } \\
\text { EQUIPMENT ROOMS }\end{array}$ & S-1 & $323 \mathrm{SF}$ & $300 \mathrm{SF}$ & GROSS & 1 \\
\hline THIRD LEVEL & & & & & & 247 \\
\hline
\end{tabular}

\begin{tabular}{|c|c|c|c|c|c|c|}
\hline \multicolumn{7}{|c|}{ OCCUPANT LOAD CALCULATIONS } \\
\hline Name & FUNCTION & OCCUPANCY & AREA & OCCUPANT LOAD FACTOR & NET/GROSS & OCCUPANTS \\
\hline \multicolumn{7}{|l|}{ THIRD LEVEL - MEZZANNE } \\
\hline OFFICES, WORK AREAS & BUSINESS AREAS (WITH SPRINKLERS) & $B$ & $3,057 \mathrm{SF}$ & $130 \mathrm{SF}$ & GROSS & 23 \\
\hline \multicolumn{6}{|c|}{ THIRD LEVEL - MEZZANNE } & 23 \\
\hline
\end{tabular}




\subsubsection{Exit Capacity and Configuration:}

Table 3 is a summary of the occupant loads calculated in the previous section with the number of exits per level and total exit capacity. The exit capacities are calculated per Section 1005 of the IBC which requires 0.15 " per occupant at doors and 0.2 " per occupant at stairways. Levels 2,3 and basement, utilize exit stairs that have a stair width of 44" and egress capacity of 220 occupants each. Per Section 1021.2 of the IBC, all floors require at least two exits.

Table 3: Exit Capacity per Floor

\begin{tabular}{|c|c|c|c|}
\hline Floor & Occupant Load & Number of Exits & Exit Capacity \\
\hline Basement & 171 & 2 & 860 \\
\hline Level 1 & 462 & 6 & 1,680 \\
\hline Level 2 & 298 & 2 & 440 \\
\hline Level 3 & 247 & 2 & 440 \\
\hline
\end{tabular}

The criteria for exit layout and travel distance is called out in Chapter 10 of the IBC and outlined below.

- $\quad$ Remoteness of Exit: Section 1015.2.1, exception 2, requires exit access doors to be $1 / 3$ the diagonal dimension of the area served.

- Dead Ends: Section 1018.4, limits a dead in corridor to a length of 20'.

- $\quad$ Exit Access Travel Distance: Table 1016.2 allows for a travel distance of 250'.

The following figures illustrate how each level meet these requirements. For clarity, only the most limiting layouts are shown. Figure 7 shows the layout of the basement level and highlights the remoteness of exits required in the South Lobby. The South Lobby meets the remoteness requirement as exits are located in opposite corners of the room.

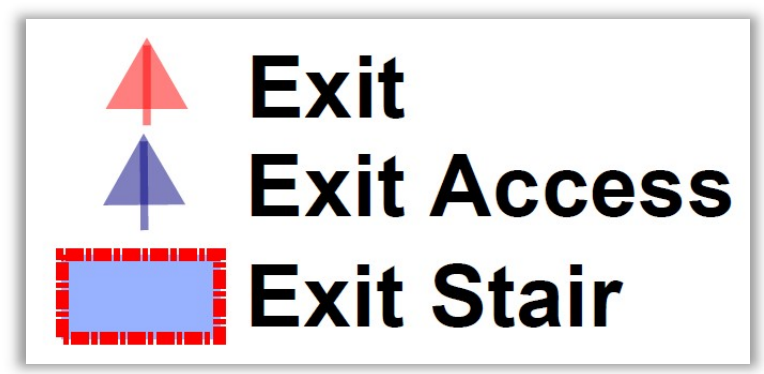

Figure 6: Egress Component Key

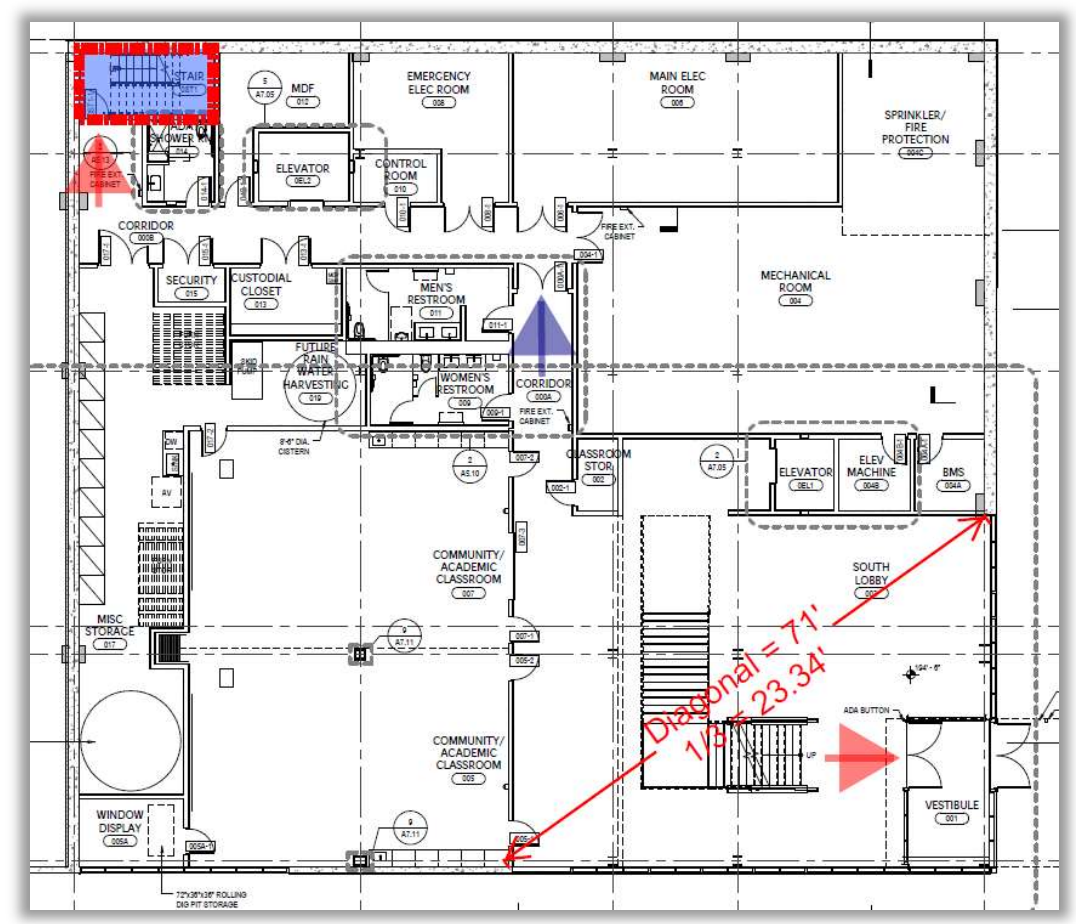

Figure 7: Basement Level Exit Configuration and Layout 
Figure 8 shows how the exits from Level 1 meet the remoteness requirements. The floors diagonal dimension is 305 feet and 1/3 of that distance is 102 feet. Level 1 meets the exit remoteness requirement by having the exits 130 feet apart. Figure 9 shows the remoteness of exits for level 2 and 3 . The exits on these floors are 127 feet 8 inches apart. Figure 9 also shows the longest travel distance from any point in the building at 206 feet 8 inches, which is less than the allowed 250 feet of travel. Figure 10 shows how the flex exhibit area meets the exit remoteness requirement and the longest deadend corridor on the project. The dead-end corridor is from the central exhibit area to the restroom and is 19 feet long which meets the 20 -foot maximum.

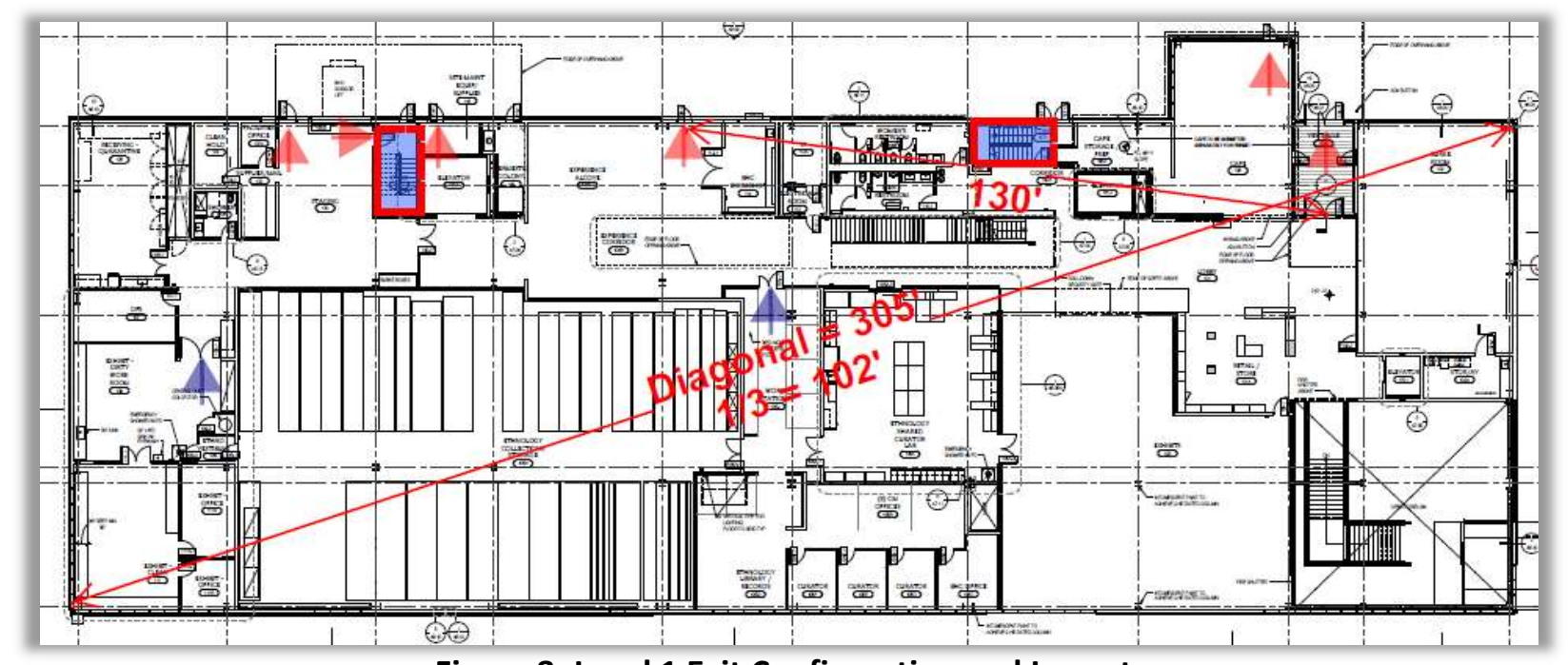

Figure 8: Level 1 Exit Configuration and Layout

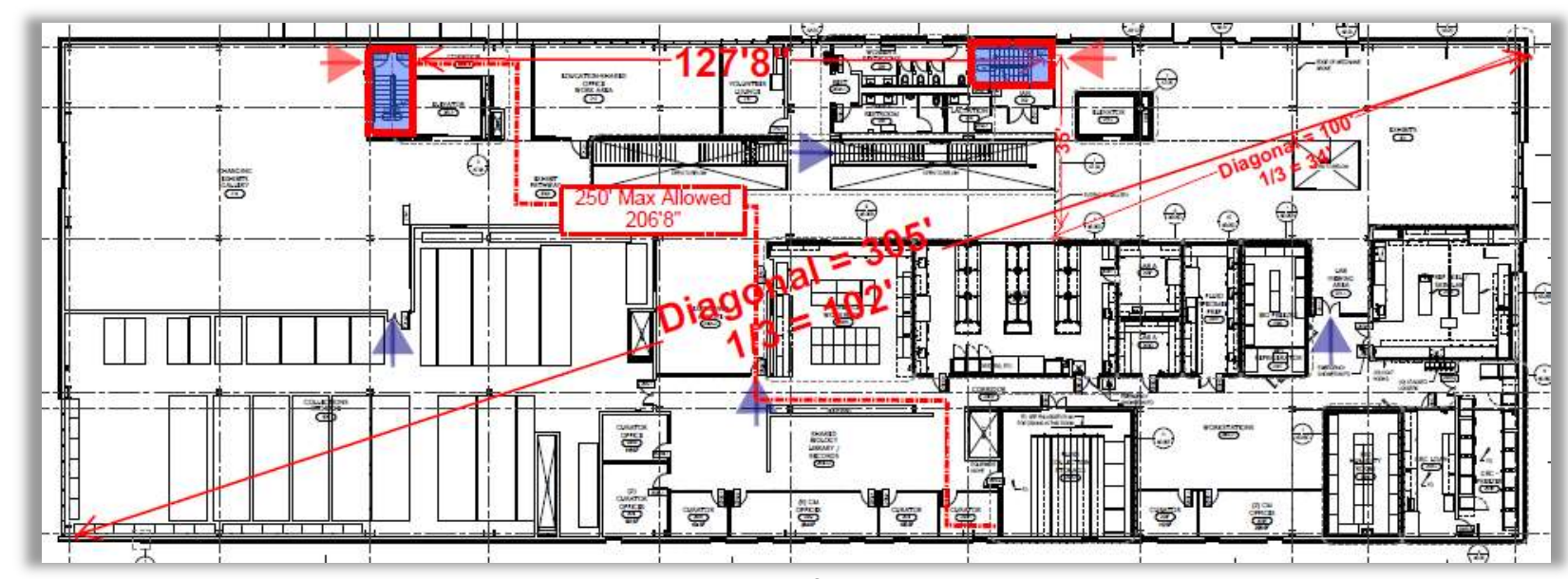

Figure 9: Level 2 Exit Configuration and Layout 


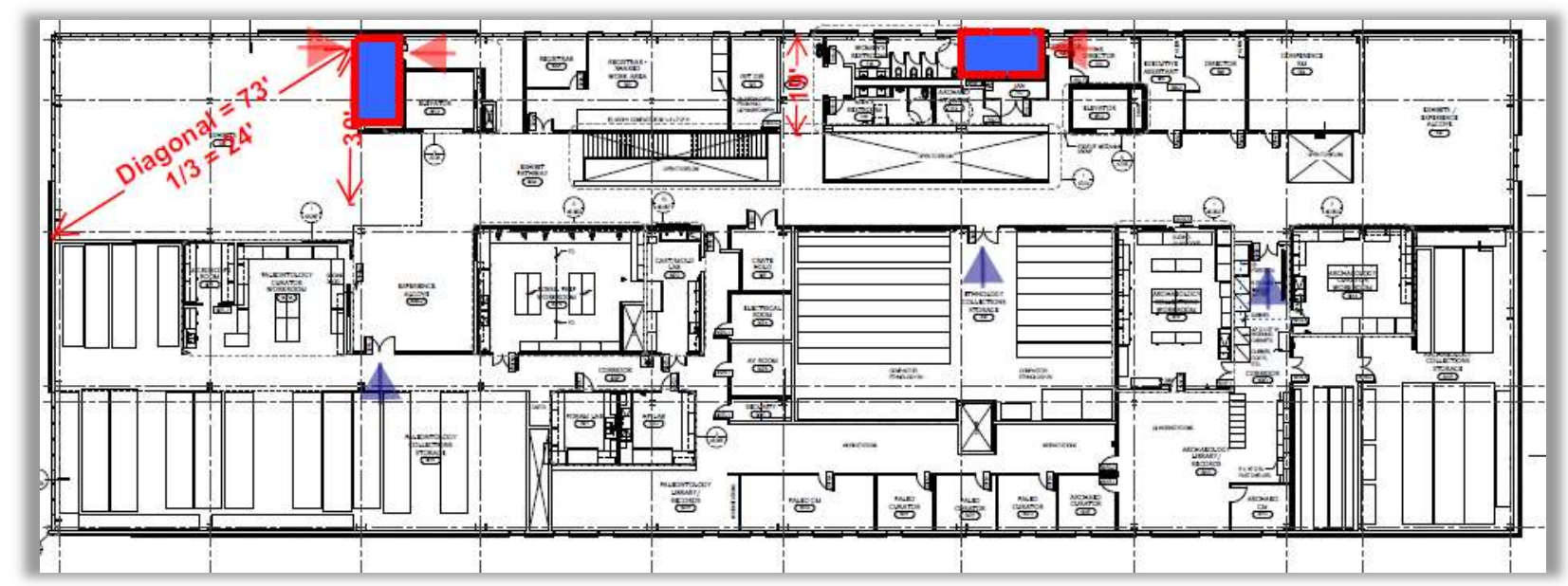

Figure 10: Level 3 Exit Configuration and Layout

The safest place to be when a building is on fire is outside the building. Chapter 10 of the IBC provides the minimum requirements to ensure that building occupants are able to exit a building in an emergency situation. The Burke meets the prescriptive egress requirements outlined in the IBC. The IBC also limits the building height and area based on the construction type of the building. 


\subsection{Building Height and Area}

\subsubsection{Construction Type:}

The Burke Museum is construction Type IIB. Type IIB is non-combustible construction. Per IBC table 601 (Table 4,) IIB construction does not require any fire resistance building elements. Though type IIB construction does not require any rated elements, other aspects of the Burke's design require rated elements. These elements will be reviewed in the Fire Resistance Rating section of this report.

Table 4: IBC Table 601

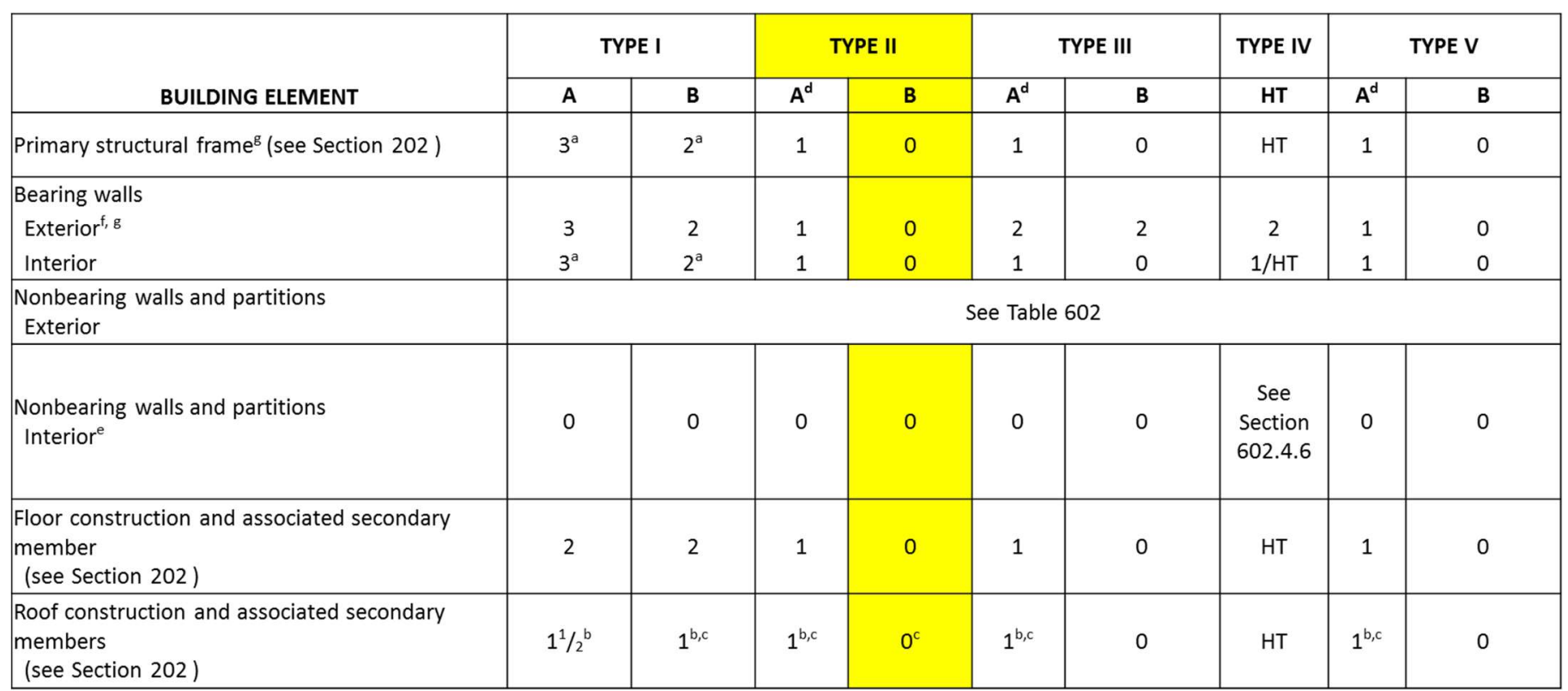

\subsubsection{Allowable Height and Area:}

Allowable building heights and areas are outlined in Chapter 5 of the IBC. The Burke has three stories above grade, is 64 feet tall and has a single level with 28,771 SF. Per Table 503 (table 5,) the base limitations for Type IIB construction and A-3 occupancy are two stories, 55' tall and 9,500 SF per floor.

Table 5: IBC Table 503

\begin{tabular}{|c|c|c|c|c|c|c|c|c|c|c|}
\hline \multirow{5}{*}{ GROUP } & & \multicolumn{9}{|c|}{ TYPE OF CONSTRUCTION } \\
\hline & & \multicolumn{2}{|c|}{ TYPE I } & \multicolumn{2}{|c|}{ TYPE II } & \multicolumn{2}{|c|}{ TYPE III } & \multirow{2}{*}{$\begin{array}{c}\text { TYPE IV } \\
\text { HT }\end{array}$} & \multicolumn{2}{|c|}{ TYPE V } \\
\hline & & $\mathbf{A}$ & B & $\mathbf{A}$ & B & $\mathbf{A}$ & B & & $\mathbf{A}$ & B \\
\hline & HEIGHT (feet) & $\mathbf{U L}$ & 160 & 65 & 55 & 65 & 55 & 65 & 50 & 40 \\
\hline & \multicolumn{10}{|c|}{$\begin{array}{c}\text { STORIES(S) } \\
\text { AREA (A) }\end{array}$} \\
\hline A-3 & $\begin{array}{l}\mathrm{S} \\
\mathrm{A}\end{array}$ & $\begin{array}{l}\mathrm{UL} \\
\mathrm{UL}\end{array}$ & $\begin{array}{l}11 \\
\mathrm{UL}\end{array}$ & $\begin{array}{c}3 \\
15,500\end{array}$ & $\begin{array}{l}2 \\
9,500\end{array}$ & $\begin{array}{c}3 \\
14,000\end{array}$ & $\begin{array}{c}2 \\
9,500\end{array}$ & $\begin{array}{c}3 \\
15,000\end{array}$ & $\begin{array}{c}2 \\
11,500\end{array}$ & $\begin{array}{c}1 \\
6,000\end{array}$ \\
\hline
\end{tabular}


IBC Sections 504 and 506 allow for additional height, stories and square footage when a building is equipped with a compliant sprinkler system and there is open area around the building.

Section 504.2 allows a height increase of 20 feet and the stories to be increase by one, when the building is equipped with sprinklers. This increases the allowable height of the Burke to 75 feet and three stories.

The allowable area can be increased using equation 5-1 $\left(A_{a}=\left\{A_{t}+\left[A_{t} \times I_{f}\right]+\left[A_{t} \times I_{s}\right]\right\}\right)$, where $I_{f}$ is found using equation $5-3$ and $I_{s}$ is listed provided in section 506.3. Below are the building area modification calculations showing a total allowable area of $35,625 \mathrm{SF}$.

\section{BUILDING AREA MODIFICATIONS, PER 506}

FRONTAGE INCREASE FACTOR (If) PER 506.2, EQUATION 5-2:

BUILDING PERIMETER THAT FRONTS ONTO A PUBLIC WAY $=860^{\prime}$

PERIMETER OF ENTIRE BUILDING $=860^{\prime}$

WIDTH OF PUBLIC WAY $=30^{\prime}$

If $=\left(860^{\prime} / 860^{\prime}-0.25\right) 30^{\prime} / 30^{\prime}$

If $=0.75$

SPRINKLER INCREASE FACTOR (IS) PER 506.3 = 2

SPRINKLER AND FRONTAGE INCREASE PER 506.1, EQUATION 5.1:

$A a=$ ALLOWABLE BUILDING AREA/ STORY

TABULAR BUILDING AREA PER STORY IN ACCORDANCE WITH TABLE $503=9,500$

$\mathrm{Aa}=\{9500+[9500 \times 0.75]+[9500 \times 2]\}=16,625+19,000=35,625 \mathrm{SF}$

Figure 11: Building Area Modifications 


\subsubsection{Fire Resistance Ratings:}

The Burke is construction Type IIB and per IBC Table 601, its structure is not required to have a fire resistance rating. However, there are multiple parts of the design that do require building elements to be fire rated.

The Burke Museum has three, 3-story shaft enclosures (one stair and two elevator shafts) and one 4story shaft enclosure (stair.) The 3-story shaft enclosures are constructed of 1-hour fire barriers and the 4-story shaft is constructed of 2-hour fire barriers.

As previously mentioned, the Burke contains a room that is an $\mathrm{H}-3$ occupancy. That room is required to be separated from the rest of the building with 2-hour construction (per IBC Table 508.4.) Per section 508.4.4.1, this separation shall be constructed of fire barriers and horizontal assembly's. The room is also on the second level so all structure supporting the rated assemblies have to be rated as well. Most of the structure supporting this room consists of columns and beams wrapped in Type X GWB per UL designs. For aesthetic reasons, one column was left exposed and painted with intumescent paint. Figure 12 shows how the columns and beams supporting this room are wrapped in Type X GWB to provide a 2-hour fire rating.
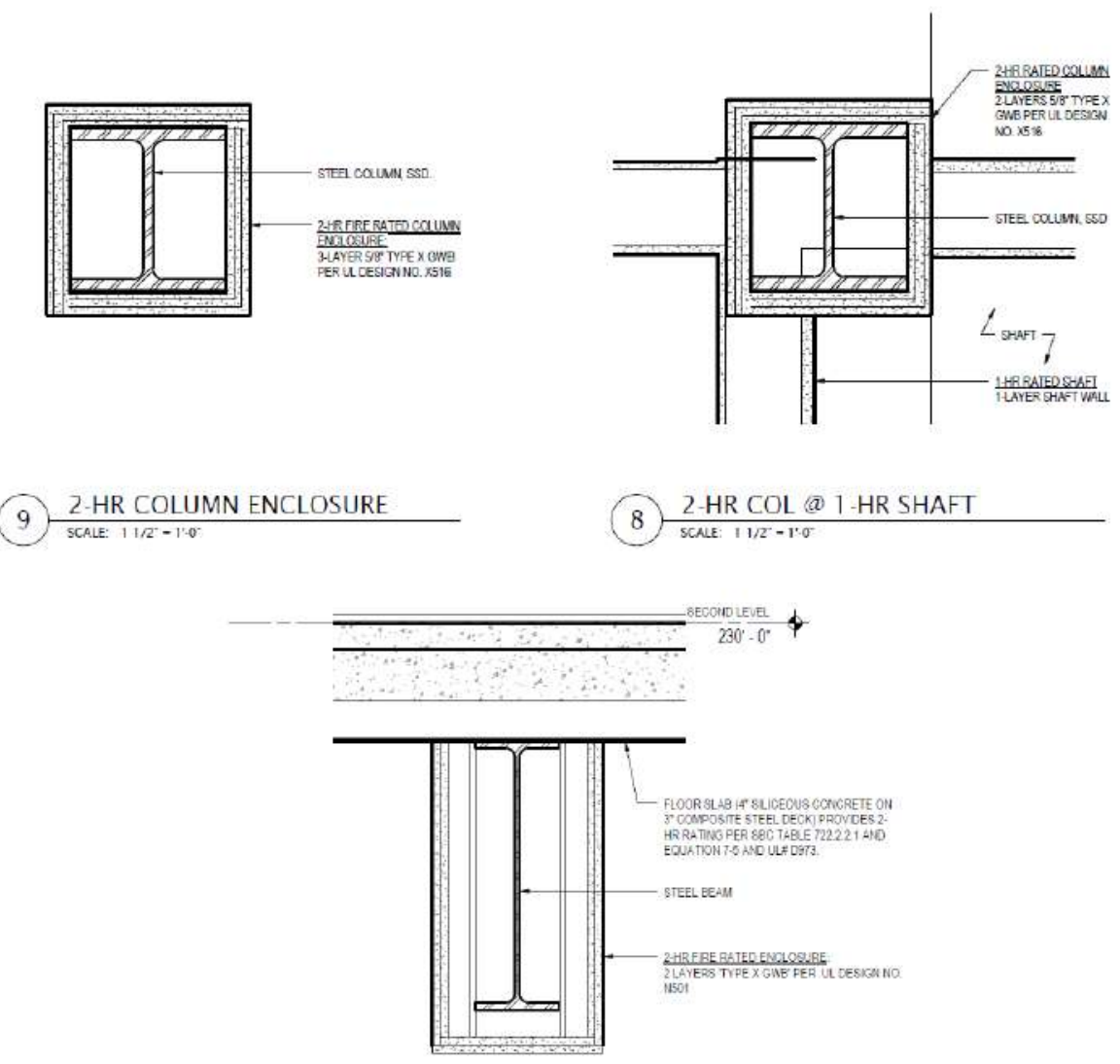

7 2-HR RATED ENCLOSURE AT BEAMS

Figure 12: Details for Fire Rating the Structural Elements 
The Burke is designed to meet the height and area limitations defined in IBC Chapter 6 . The Building is construction Type IIB. Type IIB is non-combustible and non-rated construction. 4-story shafts and separated occupancies in the Burke require different fire rated elements that are designed into the building. The Burke meets all fire rating requirements.

The structural fire rated elements in the Burke are part of its passive fire protection. The fire rated elements are passive because they do not have to be activated or do anything to provide protection. Conversely, active fire protection systems such as fire alarms, fire sprinklers and smoke control, activate to provide fire protection.

\subsection{Fire Protection Systems}

At the time of this report, the final fire protection system for the Burke was not designed. The Burke will be equipped throughout with fire sprinklers and fire alarm detection but the exact components and characteristics of these systems are unknown. This section will include a summary of these fire protection system requirements and possible components. The standard atrium Smoke Control Requirements in IBC Section 404 along with activation scenarios will be explored as part of the atrium design comparison.

\subsubsection{Fire Alarm Detection and Notification System:}

The fire alarm system will be designed per the 2012 IBC and 2013 NFPA 72 (National Fire Alarm and Signaling Code for New Construction.) The University of Washington uses Simplex fire alarm systems. Requiring Simplex systems allows in house service and continuity throughout the campus. Buildings on campus are monitored by the University's TruSite system. Connection of the Burke to this system is through fiber optic cables in utility tunnels.

The design incorporates automatic and manual fire detection components. The detection devices are smoke detectors, sprinklers, manual pull stations and VESDA. The notification devices consist of horns, strobes and Voice for notifications. The alarm system will also interface with exhibit AV systems. The Fire Alarm Control Panel is located in the basement in the main electrical room and a remote enunciator is located at the main entrance vestibule.

The following is a list of detection devices and their general layouts based on the University's Fire Alarm System Design Guide.

Water Flow Switch: Sprinkler water flow switches are an integral part of the building's detection system. This device is located in the mechanical room but provides heat detection for most of the building through the sprinkler system.

Manual Pull Stations: Manual pull stations are located at all building exits in the direct path of egress and at each floor within 5 feet of exit stair doors. Additional pull stations are not provided at stair and corridors because they become a maintenance burden. This is compliant with NFPA 72 section 17.14.8.4. 
Photoelectric Smoke Sensors: Smoke detectors are located in public areas and in the office area, 35 40 feet on center. Smoke detectors are not provided at stairways, or labs to reduce the chance of false activation.

VESDA Aspirating Smoke Detector: VESDA detectors are provided the Collections Areas. VESDA aspirating smoke detectors consists of a plastic pipe laid in a grid pattern at the ceiling connected to a single air sampling station. The plastic pipes have small holes drilled at a set distance along their length. The air sampling station continuously draws air through the pipes to sample the air at each of the inlet points. VESDA systems provide early detection of fire and are less likely to activate from dust in the air. The VESDA systems are being used at the Collections Areas to reduce false alarms and to provide early warning if a fire does start.

Notification appliance are laid out per NFPA 72. Below is a summary of the Audio and Visual appliance layouts.

Audio Appliances: All audio appliances will have appropriate location spacing and placement. Below is a summary of these requirements.

\section{NFPA 72 References and Calculations:}

- Per Table A18.4.3, the average ambient sound level for an Education Occupancy is 45 dBA.

- Per 18.4.3.1, the alarm shall be $15 \mathrm{~dB}$ over average ambient sound level

- $45+15=60 \mathrm{dBA}$ necessary for horn.

- Per A18.4.3, loss of 6dBA per doubling of distance

- $20^{\prime}(-6 \mathrm{~dB})+40^{\prime}(-6 \mathrm{~dB})+80^{\prime}(-6 \mathrm{~dB})+160^{\prime}(-6 \mathrm{~dB})=-24 \mathrm{~dB}$ total drop at $160^{\prime}$ and the furthest spacing is $60^{\prime}$

$\circ$ Required $\mathrm{dBA}=84$ and NAs are providing 90dBA.

O Section 18.4.8.1, Wall mounted appliances must be mounted more than 90 in. (2.29 m) and below the finished ceilings at distances of not less than 6 in. $(150 \mathrm{~mm})$.

Visual Appliances: All visual appliances will have appropriate location spacing and placement. Below is a summary of these requirements.

\section{NFPA 72 References and Calculations}

O Per Table 18.5.5.4(a)

- $15 \mathrm{~cd}: 20^{\prime} \times 20^{\prime}$

- 30cd: $28^{\prime} \times 28^{\prime}$

- $75 \mathrm{~cd}: 45^{\prime} \times 45^{\prime}$

- 110cd: $54^{\prime} \times 54^{\prime}$

- Per 18.5.5.5.5, visible notification appliances shall be located not more than $15 \mathrm{ft}(4.57$ $\mathrm{m})$ from the end of the corridor with a separation not greater than $100 \mathrm{ft}(30.5 \mathrm{~m})$ between appliances.

- Per 18.5.5.5.3, in a corridor application, visible appliances shall be rated not less than 15 $\mathrm{cd}$ 
○ Per 18.5.5.1 Wall-mounted appliances shall be mounted such that the entire lens is not less than 80 in. $(2.03 \mathrm{~m})$ and not greater than $96 \mathrm{in}$. $(2.44 \mathrm{~m})$ above the finished floor

\subsubsection{Fire Alarm Secondary Power Supply:}

Section 10.6.7.2.1 of NFPA 72 requires a secondary power supply be provided with sufficient capacity to operate the system under quiescent load (system operating in a nonalarm condition) for a minimum of 24 hours. At the end of that period, the backup power supply shall be capable of operating all alarm notification appliances used for evacuation or to direct aid to the location of an emergency for 5 minutes, with a 20 percent safety margin. Table 6 is an example of the calculations required to size a battery being used for a secondary power supply.

Table 6: Example of secondary power battery size calculations

\begin{tabular}{|c|c|c|c|c|c|}
\hline \multirow{3}{*}{ Equipment } & \multirow{3}{*}{ Quantity } & \multicolumn{2}{|c|}{ Standby } & \multicolumn{2}{|c|}{ Alarm } \\
\hline & & \multicolumn{2}{|c|}{ Max Current (AMPS) } & \multicolumn{2}{|c|}{ Max Current (AMPS) } \\
\hline & & Per Unit & Total & Per Unit & Total \\
\hline Control Panel (Include Detction Devices) & 1 & 0.595 & \begin{tabular}{|l|}
0.595 \\
\end{tabular} & 1.185 & 1.185 \\
\hline Weatherproof Horn Strobe $(75 \mathrm{~cd})$ & 3 & 0.0008 & 0.0024 & 0.238 & 0.714 \\
\hline Horn Strobe (110cd) & 24 & 0.0008 & 0.0192 & 0.139 & 3.336 \\
\hline Horn Strobe (15cd) & 16 & 0.0008 & 0.0128 & 0.059 & 0.944 \\
\hline Horn Strobe (30cd) & 6 & 0.0008 & 0.0048 & 0.067 & 0.402 \\
\hline Horn Strobe ( $75 c d)$ & 13 & 0.0008 & 0.0104 & 0.107 & 1.391 \\
\hline Strobe $(110 \mathrm{~cd})$ & 1 & 0.0008 & 0.0008 & 0.132 & 0.132 \\
\hline Strobe $(15 \mathrm{~cd})$ & 41 & 0.0008 & 0.0328 & 0.047 & 1.927 \\
\hline Strobe $(30 \mathrm{~cd})$ & 5 & 0.0008 & 0.004 & 0.057 & 0.285 \\
\hline \multirow[t]{6}{*}{ Strobe $(75 \mathrm{~cd})$} & 9 & 0.0008 & 0.0072 & 0.1 & 0.9 \\
\hline & & Totals & 0.6894 & & 11.216 \\
\hline & & $20 \%$ safety margin & 0.13788 & & 2.2432 \\
\hline & & PanelTotal & 0.82728 & & 13.4592 \\
\hline & & 24 Hours of STB & 19.85472 & $5 \mathrm{~min}$ Alarm & 1.1216 \\
\hline & & \multicolumn{3}{|c|}{ Total Amp-Hours Require for Battery } & 20.97632 \\
\hline
\end{tabular}

\subsubsection{Fire Alarm Testing and Maintenance:}

To ensure the fire alarm system is operational, the Burke will require commissioning testing and periodic testing through the life of the building. NFPA 72 outlines the testing requirements for the fire alarm system. Section 14.4.1.1 requires all new systems to be inspected and tested in accordance with the requirements of Chapter 14. This requires a full system test at initiation of the system. Additionally, the $\mathrm{AHJ}$ will have to be notified and is often required to witness this initial testing

Periodic testing requirements are outlined in NFPA 72 Table 14.4.3.2. Table 14.4.3.2 states which systems must be tested, annually, semiannually, monthly and daily. Most of the systems will require annual testing. Systems like battery backups require semiannual testing. The supervisory system will require monthly testing. No systems on this project require daily testing. Records of all testing should be kept and made available to the AHJ upon request. 
NFPA 72 does not have specific maintenance requirements but refers to manufacturer and product requirements. Different products manufactured by different companies can have drastically different maintenance requirements. These maintenance requirements are typically outlined in the Installation and maintenance guidelines and should be provided by the contractor at the close of the project. Most manufacturers recommend annual maintenance is performed at the time of testing. Ideally any maintenance issues will be caught and fixed at this time. It is important to keep all records of maintenance as well.

The Burke's fire alarm system will be designed to meet the requirements of NFPA 72. At completion of the project, a commissioning test will be performed to verify the system is working correctly. Through the life of the building, the system will be tested and maintained to ensure continued operation. The second part of the Burke's active fire protection system will be its fire sprinkler system.

\subsubsection{Fire Sprinkler System:}

IBC and UW Facility Standards require the Burke to be fully protected with a sprinkler system designed per NFPA 13. The building is protected throughout with a wet pipe system. There are also dry sprinkler heads at a walk in freezer. Standpipes are provided at the two egress stairs with $2 \frac{1}{2}$ inch hose outlets on each landing. As part of an alternate means and method appeal, windows are also protected with closely spaced sprinklers.

Sprinkler heads shall be quick response, glass bulb, ordinary temperature and standard coverage. Figure 13 shows examples of sprinkler heads that could be used in the Burke.

\section{Standard Spray Upright, Pendent and Recessed Pendent Standard and Quick Response}

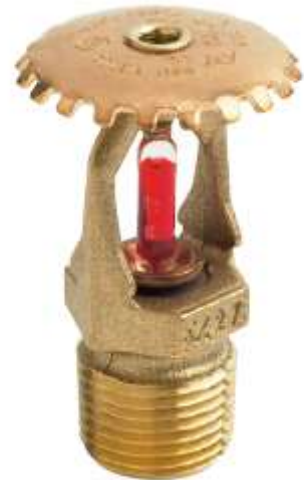

V2703/V2704 Upright

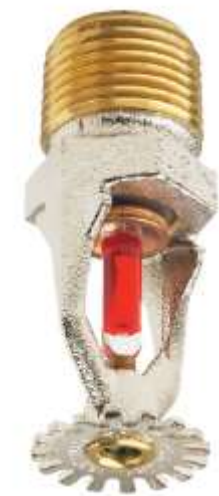

V2707/V2708

Pendent

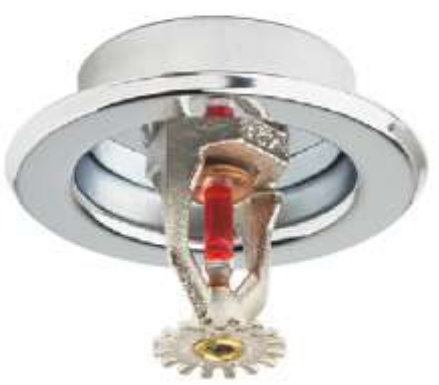

V2707/V2708

Recessed Pendent

Figure 13: Example of Sprinkler Heads Allowed in The New Burke Museum 


\subsubsection{Building Occupancy Classification:}

The Burke Museum has several different occupancy classifications. The exhibit areas, and work rooms are Ordinary Hazard Group 1. The storage areas and labs are Ordinary Hazard Group 2. The Fluid Collection Storage Room (H3 occupancy) is Extra Hazard Group 2. The area and density of coverage for each occupancy is shown in NFPA 13 Figure 11.2.3.1.1 (Figure 14.) Table 7 summarizes the requirements for the different occupancy in the Burke and Figure 15 shows their locations.

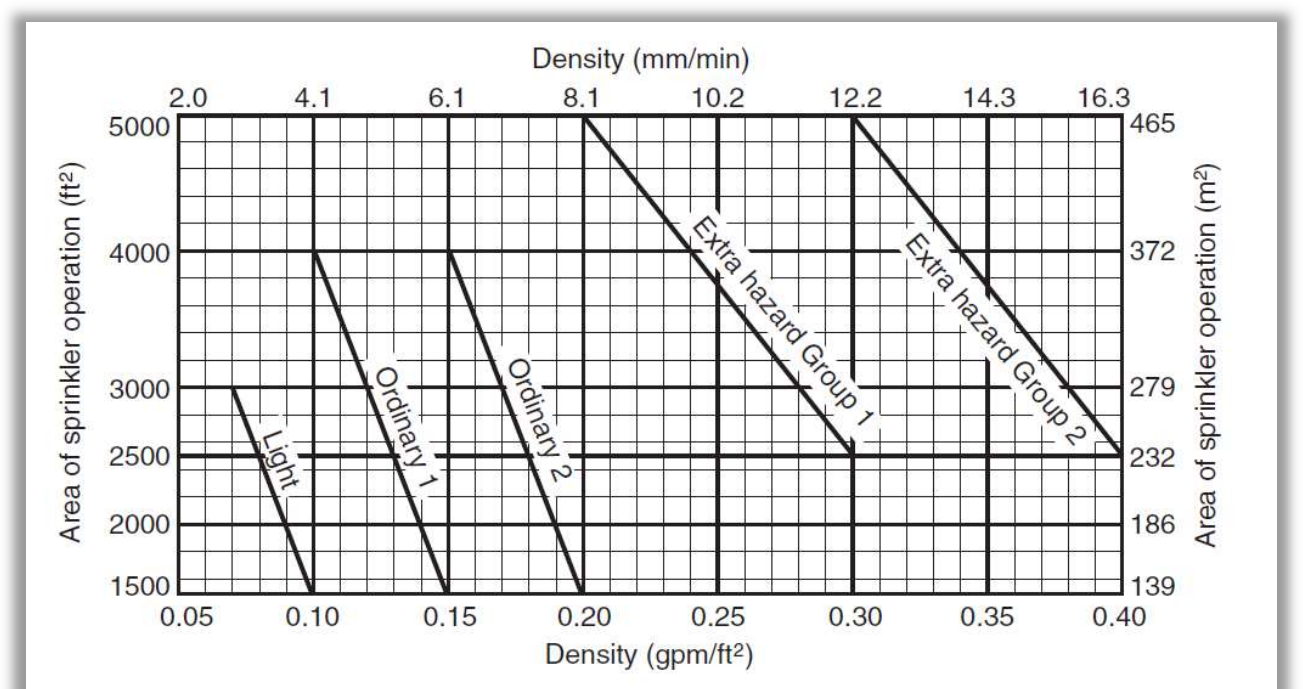

FIGURE 11.2.3.1.1 Density/Area Curves.

Figure 14: NFPA 13, Figure 11.2.3.1.1

Table 7: Summary of Occupancies

\begin{tabular}{|l|c|c|c|}
\hline Room Description & Occupancy & Area (ft^2) & Density (gpm/ft^2) \\
\hline Exhibit Area & Ordinary 1 & 1,500 & 0.15 \\
\hline Lab and Storage Area & Ordinary 2 & 1,500 & 0.20 \\
\hline Fluid Collection Storage & Extra Hazard 2 & 2,500 & 0.40 \\
\hline
\end{tabular}

Fire Suppression (Second Floor)

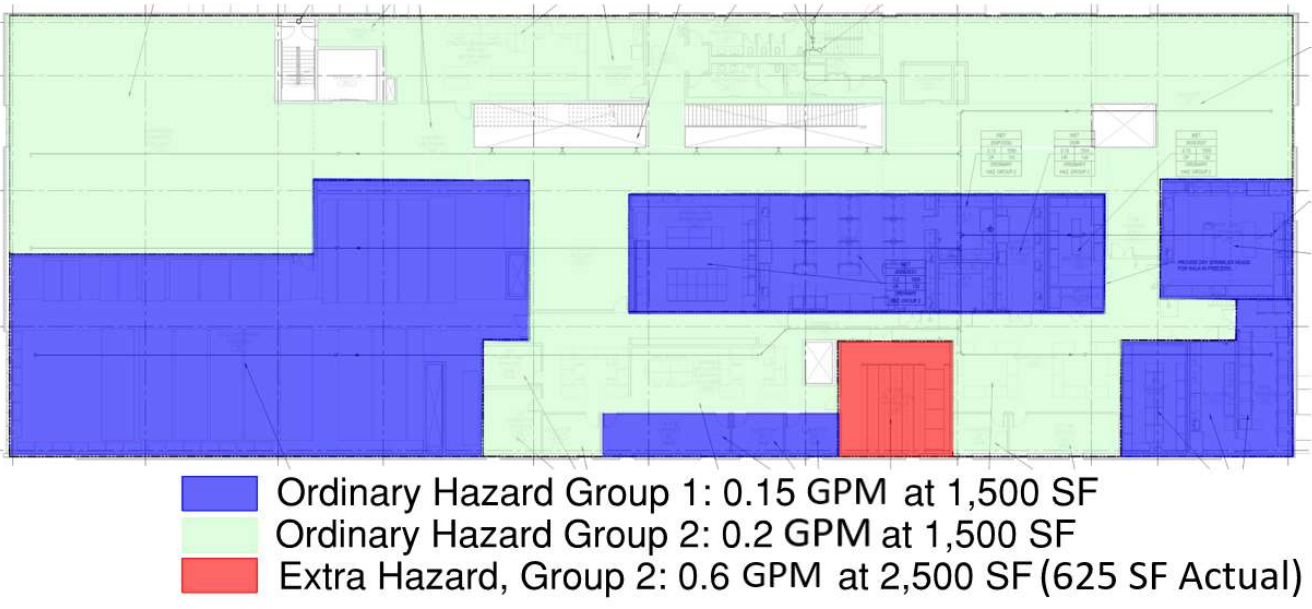

Figure 15: Level 2 Floor Plan Showing the Location of Different Sprinkler Coverages 


\subsubsection{Sprinklers at Windows:}

As part of an approved alternate means and method, all exterior windows are protected with closely spaced sprinklers designed to completely wet the glass. Figure 16 shows the location of the sprinklers in relation to the glazing. The code alternate is to allow for combustible wood siding to be installed up to 79' above grade plane. The basis of approval is to provide a 1-hour rated wall behind the wood siding to reduce the chance of the wood siding catching on fire from a fire originating inside the building. Sprinklers are used at the windows to provide the 1-hour fire rating.

This is similar to the IBC exception to Section 404.6 that allows sprinkled glass in lieu of a 1-hour rated fire barrier wall to separate the atrium from the rest of the building. These sprinklers are to be spaced no more than 6 FT O.C. and within 4 inches to 12 inches of the window.

Using sprinkled glass to replace a 1-hour fire rated wall is a commonly approved appeal in the Pacific Northwest. Approval of these appeals are typically based on ESR-2397. ESR-2397 is an ICC research report for Tyco's wall sprinklers and allows the WS sprinklers to be used as part of an alternate means and methods per IBC Section 104.11.

Justification for using sprinkled glazing as a fire rated barrier originates from Richardson, J.K. and Oleskievicz, I. Fire Tests on Window Assemblies Protected by Automatic Sprinklers. The IRC (Institute for Research in Construction) has also published a Construction Technology Update in 1997 presenting research on the use of dedicated sprinkler systems to protect glazing in fires. When these two documents from the National Research Council of Canada are compared to the requirements in ESR-2397 and NFPA 13, there is a distinct difference. The National Research Council of Canada documents state that the window sprinklers should be on a dedicated line and the American documents do not. Logically it makes sense that the window sprinklers should be on a

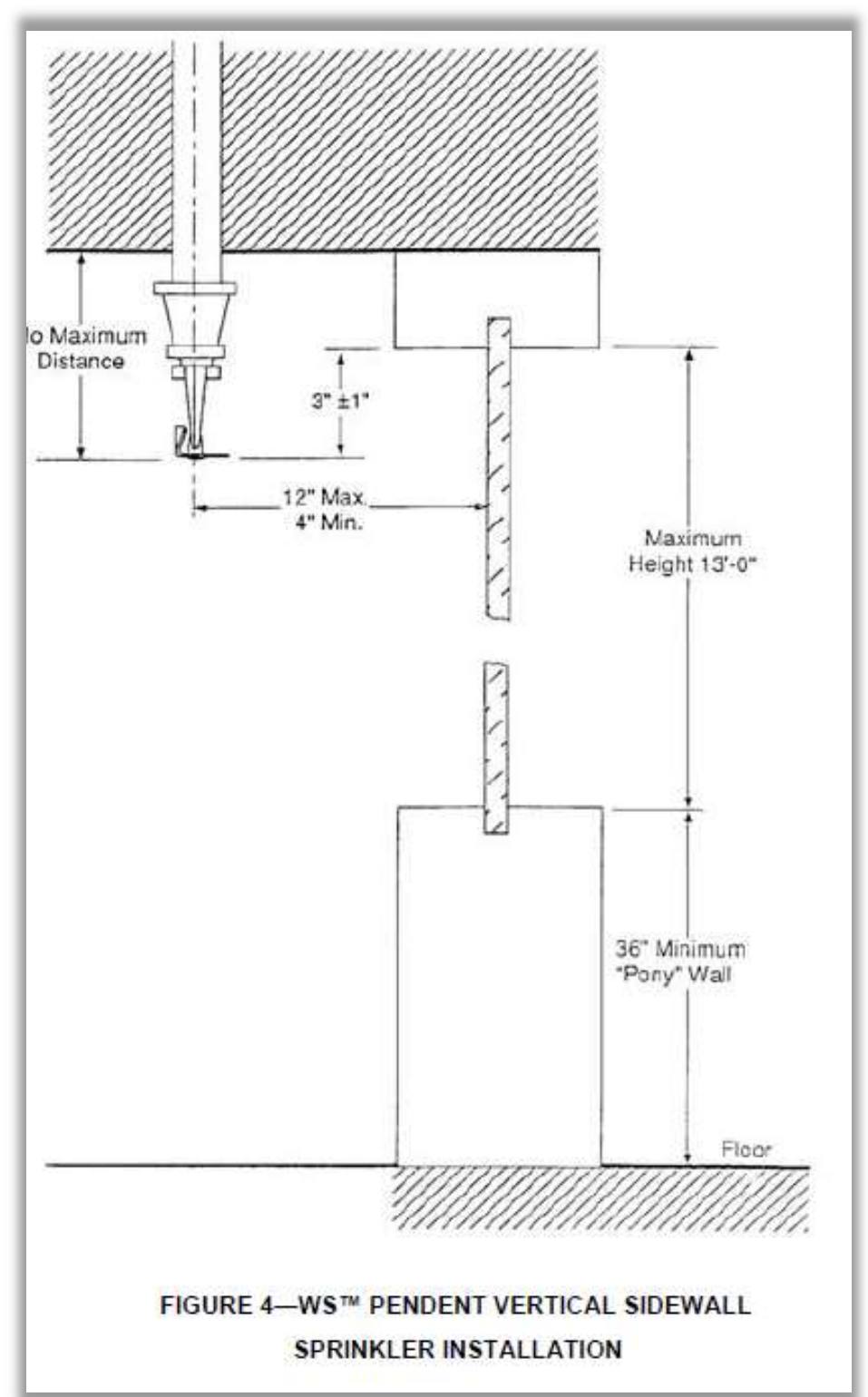

Figure 16: Installation Diagram for Window Sprinklers ICC ESR-2397 from Tyco WS Sprinklers dedicated sprinkler line. Sprinklers protecting the glazing do so to create a passive fire wall which is required to provide protection regardless of whether the building's sprinklers work or not. It should be expected that sprinkled glazing will still provide protection even if the building's sprinkler system has 
failed. This redundancy can only be accomplished if the window sprinklers are on a dedicated line not effected by the building's sprinkler activation or failure.

\subsubsection{Sprinkler System Design Calculations:}

Hydraulic calculations will be required to validate the Burke's final sprinkler design. These calculations will show that the water supply can adequately supply the fire sprinkler system. The hydraulic calculation will be performed by taking the most remote area and calculating the required flow rate based on the Density/Area Curves. Hydraulic calculations are then performed to ensure the water supply has enough pressure to push the water to the remote area.

The calculated water demand is then compared to the tested water supply. This comparison is accomplished using hydraulic graph paper. Figure 17 is an example of a sprinkler demand curve graphed against a water supply curve.

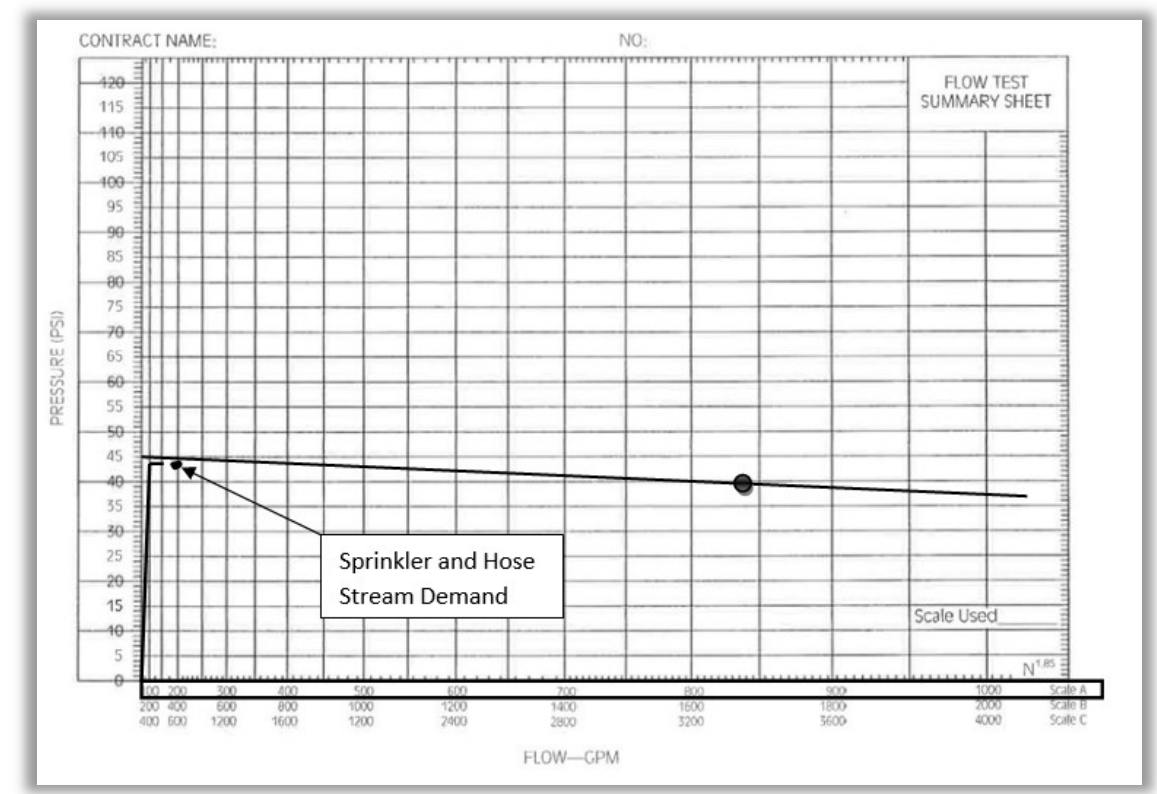

Figure 17: Example of sprinkler demand curve graphed with water supply curve.

\subsubsection{Sprinkler System Inspection, Testing and Maintenance:}

Inspections, testing and maintenance should be completed periodically to ensure the Burke's system remains functional. The different components of the sprinkler system will be inspected; monthly, quarterly, annually and long term. Testing requirements are outlined in NFPA 25 and include visual and functional inspections. All inspection and testing should be performed by a properly trained and competent person. Below is an inspection checklist organized by required frequency.

Monthly Inspection:

- Valves:
- In their normal open or closed position
- Properly sealed, locked or supervised
- Accessible 
- Free from damage or leaks

- Appropriately labeled

- Gauges:

- Ensure they are in working condition and normal water supply pressure is maintained.

Quarterly:

- Water Flow and alarm and supervisory alarm devices are free of physical damage.

- Test the water flow alarm

- Ensure fire department connection are visible and undamaged and that gasket and valves are not leaking or damaged.

Annually:

- Visible Sprinkler Inspection:

○ No damage or leaks

- Free of corrosion, foreign material or paint

- Installed in proper orientation

- Fluid in glass blubs

- Spare sprinklers are available

- Hangers and seismic bracing is not damaged or loose.

- Visible Pipes and Fittings.

- No leaks or mechanical damage and in good condition

- Correct alignment with no external loads

- Interior inspection of dry pipe valves.

- Trip test of dry pipe valve (shall be tested during warm weather condition)

- Each Control Valve shall be operated through its full range and returned to its normal condition.

Long Term:

- Gauges shall be replaced every 5 years or tested in comparison with a calibrated gauge

- Piping shall be inspected infernally every 10 year

- A sampling of the sprinkler heads shall be tested at 20 years then every 10 years thereafter.

Parts of the Burke's fire and life safety design have not been completed so were not able to be analyzed for compliance. All completed aspects of the Burke meet the prescriptive IBC requirements. The egress plan, building height and area and structural fire rating meet the requirements listed in Chapters 5, 6, 7 and 10 of the IBC. The Burke's fire alarm and fire sprinkler systems are still being designed but will meet the requirements of NFPA 72 and NFPA 13.

Chapter 4 of the IBC provides special detailed requirements based on use and occupancy. Atrium design requirements are listed in Section 404. The Burke's final design utilizes rated separations to avoid triggering the requirements of Section 404. 


\section{Atrium Design Comparison and Performance Based Analysis}

The IBC defines an atrium as an opening connecting two or more stories other than enclosed stairways, elevators, hoistways, escalators, plumbing, electrical, air-conditioning or other equipment, which is closed at the top and not defined as a mall. The Burke Museum has four levels of exhibit area connected by several vertical openings. Figure 18 is a plan and Figure 19 is a schematic section showing these horizontal openings. Per the IBC definition, the entire connected space is considered an atrium and subject to the atrium requirements of IBC Section 404. The design team chose to pursue an alternate means and methods design approach per IBC section 104.11 to avoid the Section 404 requirements. The following is a comparative analysis of that alternate design method and a more traditional design. The Burke is being built using the alternate design method being analyzed.

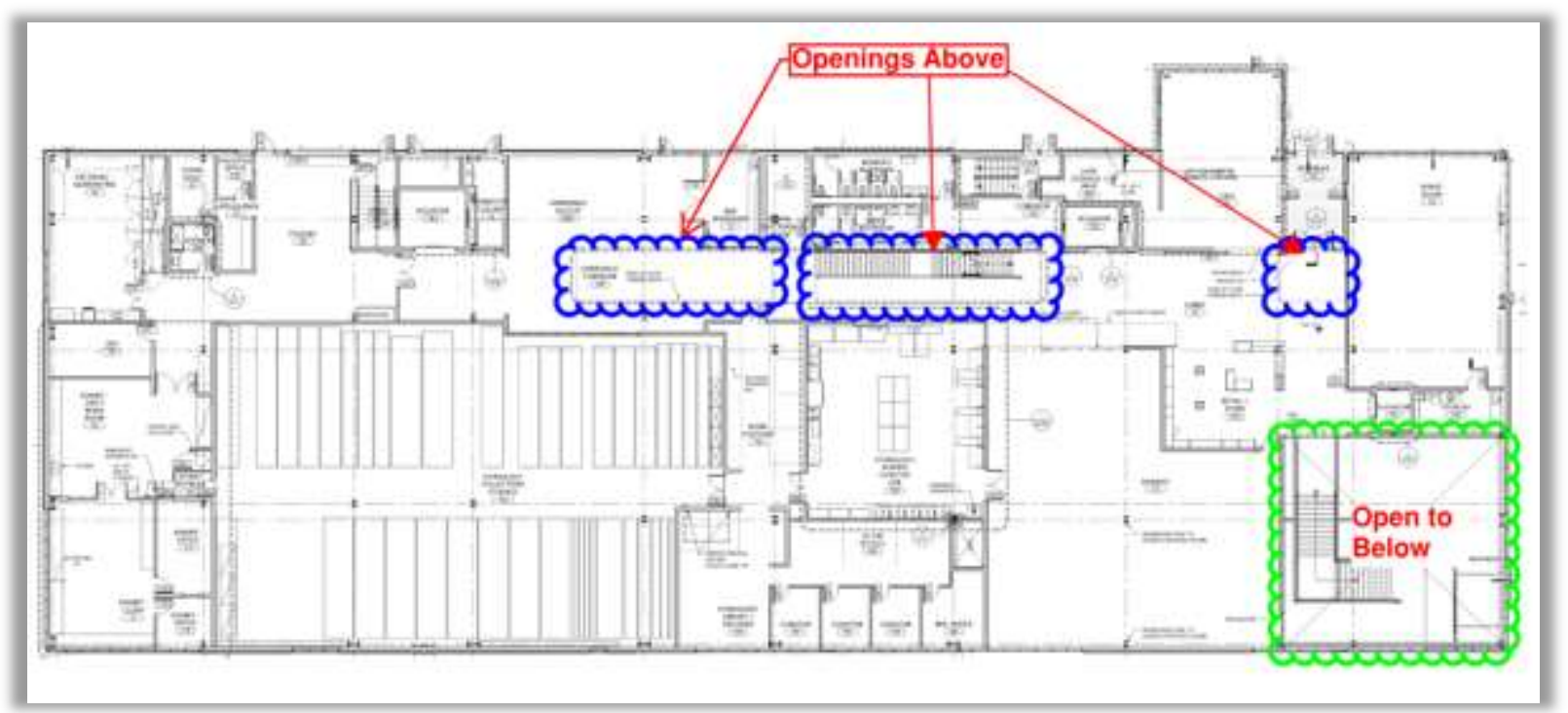

Figure 18: Level 1 Floor Plan Showing Atrium Layout

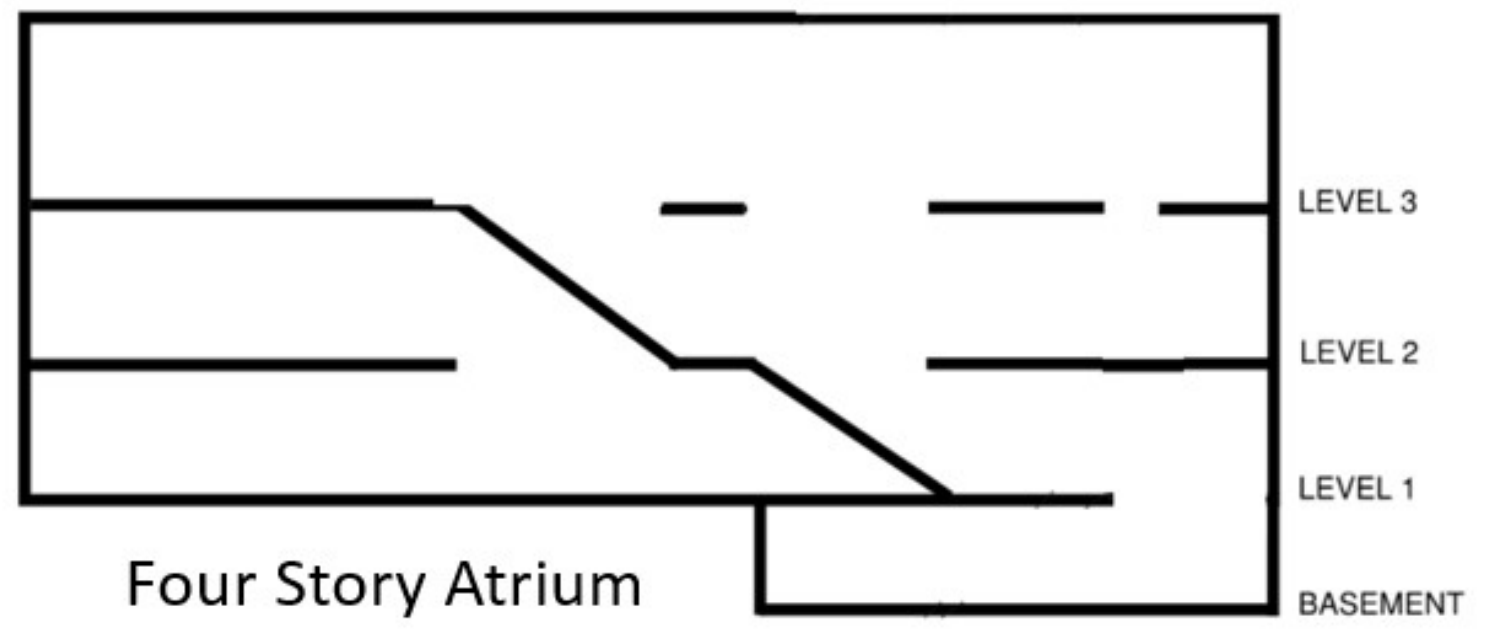

Figure 19: Section Showing Atrium Layout 


\subsection{IBC Section 404 Atrium Design}

The Burke is designed using an alternate design that eliminates the need to meet the 404 atrium requirements. This section creates a theoretical design for the atrium space so it can be compared to the actual design used in the building. The design and analysis will focus on reduced travel distance, required separation and smoke control. The building is already equipped throughout with a sprinkler and fire alarm system and it is assumed that the AHJ would approve the use of the atrium as exhibit space. The Section 404.8 provision that limits finishes to Class B would also restrict the designer's options for finishing the space.

\subsubsection{Summary of Atrium Requirements:}

The purposes of the life safety requirements of the IBC are to protect building occupants and surrounding properties. Building occupants are protected by active fire protections systems and passive fire protection features to allow them to use a means of egress out of the building. Active systems, such as sprinklers and smoke control, react to a fire event and actively work to suppress the fire or remove smoke from the building. Passive fire protection features consist of fire rated (and non-rated) walls, floors and structural elements. These features are meant to impede the travel of fire and smoke through a building independent of the active systems.

Openings in floors interfere with the continuity of passive protection features and can decrease the effectiveness of active systems. Floors are typically the largest passive features in a building and resist the vertical spread of smoke and fire. Both, rated and non-rated floors, resist the vertical spread of smoke and fire. Openings in floors allow for rapid vertical movement of smoke and fire. Consecutive floor openings can also put the nearest sprinkler head well above a potential fire source. Sprinkler systems become less effective and less likely to activate the further they are from the fire source. For practical purposes, sprinklers become ineffective at a height of 55 feet. To compensate for the effects of putting large unprotected openings in floors, the IBC has the atrium requirements outlined in section 404.

404.2: The Floor of the atrium shall not be used for other than low fire hazard uses and only approved materials and decorations in accordance with the International Fire Code shall be used in the atrium space. This requirement is meant to decrease the potential fire size by reducing the fuel load. It necessary to reduce possible fuel loads in an atrium because smoke and fire can travel through the space unimpeded. This requirement would be particularly difficult for the Burke Museum to meet as the floors of the atrium are being used as exhibit space. There is an exception to this section that lets the space be used for any approved use when the space is provided with an automatic sprinkler system. This gives the $\mathrm{AHJ}$ the ability to approve more hazardous uses if the atrium space will be protected by sprinklers. The IBC is unclear whether this acceptation applies to atriums that have ceilings of 55 feet or higher.

404.3: An approved automatic sprinkler system shall be installed throughout the entire building. Sprinklers greatly increase the fire safety of a building. In order to have an atrium in the building, the code requires the building be equipped with a sprinkler system. There are two exceptions to this provision. If a portion of the building is separated from the atrium by a 2-hour fire barrier, that portion 
does not have to be protected with sprinklers. The second exception allows the floor of the atrium to be unprotected when the ceiling is more than 55 feet above. Sprinklers are not required at this height because they would not be effective. This provision is not an issue for the Burke as there are several other factors that already mandated the use of sprinklers.

404.4: A fire alarm system shall be provided in accordance with Section 907.2.14. This provision ensures that building occupants are quickly notified of a fire so they can quickly exit the building. The Burke is already equipped with a fire alarm system so this provision would not add any requirements.

404.5: A smoke control system shall be installed in accordance with Section 909. An issue with vertical openings in a building is that they allow smoke to quickly travel vertically through a building. Instead of stopping the smoke from spreading like a solid floor, smoke control removes the smoke from a building to provide a tenable environment for occupants to exit the building. A properly designed and maintained smoke control system greatly improves the safety of any space. A smoke control system can also be very difficult to fit into a design and very costly to install and maintain. Seemingly small changes to the atrium space can greatly diminish the effectiveness of a smoke control system. The requirement of smoke control is the primary reason the Burke used an alternate means and method approach for its atrium. There is an exception to this requirement that does not require smoke control for atriums that connect only two stories.

404.6: Atrium spaces shall be separated from adjacent spaces by a 1-hour fire barrier constructed in accordance with Section 707 or a horizontal assembly constructed in accordance with Section 711, or both. This provision is in place to ensure a fire event in the atrium does not affect occupants in other parts of the building. The 1-hour fire barrier also creates a boundary around the atrium that stops the atrium requirements. The 1-hour fire barrier separation is similar to the separation of occupancies and fire areas with rated walls and floors. One of the exceptions allows any three floors to be left open to adjoining spaces as long as those spaces are accounted for in the smoke control system. However, the code is not clear on what is defined as adjoining spaces. If an entire 5-story building was designed as an atrium there would be no adjoining spaces required to be separated. There are two other exceptions to this provision that allow sprinkled glass or glass blocks to be installed in lieu of a 1-hour fire barrier. It was a goal of the Burke Designers to create an open museum experience and the requirement of 1-hour fire barrier separation would have been difficult to accommodate.

404.7: Equipment required to provide smoke control shall be connected to a standby power system in accordance with Section 909.11. Like any active life safety system, it must work with or without building power. Standby Power ensures smoke control will work when the power is out. This requirement would have increased the cost and size of the generator at the Burke.

404.8: The interior finish of walls and ceilings of the atrium shall be not less than Class B with no reduction in class for sprinkler protection. Similar Section 404.2, this provision is aimed at reducing the potential fire size and fuel load. This requirement would have forced some design changes for the Burke.

404.9: In other than the lowest level of the atrium, where the required means of egress is through the atrium space, the portion of exit access travel distance within the atrium space shall be not greater than 200 feet $(60960 \mathrm{~mm})$. The travel distance requirements for areas of buildings open to the atrium and where access to the exits is not through the atrium, shall comply with the requirements of Section 1016. 
This requirement reduces the amount of time occupants will be in the atrium while exiting the building. All areas of the Burke exit through the atrium so this provision would likely require some redesign.

\subsubsection{Travel Distance:}

Per Section 404.9, when egress is through the atrium, travel distance is limited to 200 feet. The Burke is laid out so that all egress paths exit through the atrium at all levels of the building. Figure 20 shows how the level 2 floor plan creates a travel distance of 209 feet through the atrium. Figure 2 shows a possible solution to this problem. If the experience alcove and the lab switch places, an occupant in this location would have a straighter path to an exit stair.

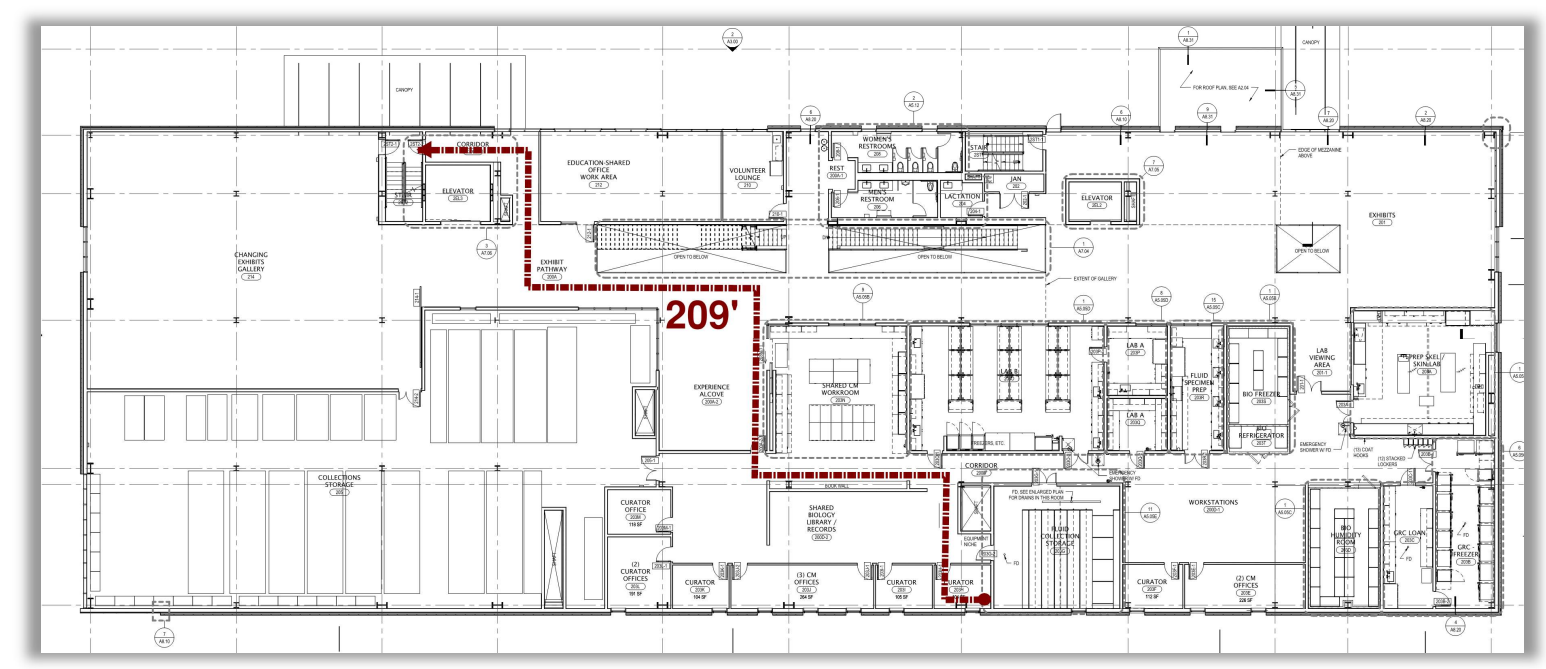

Figure 20: Level 2 Showing Travel Distance

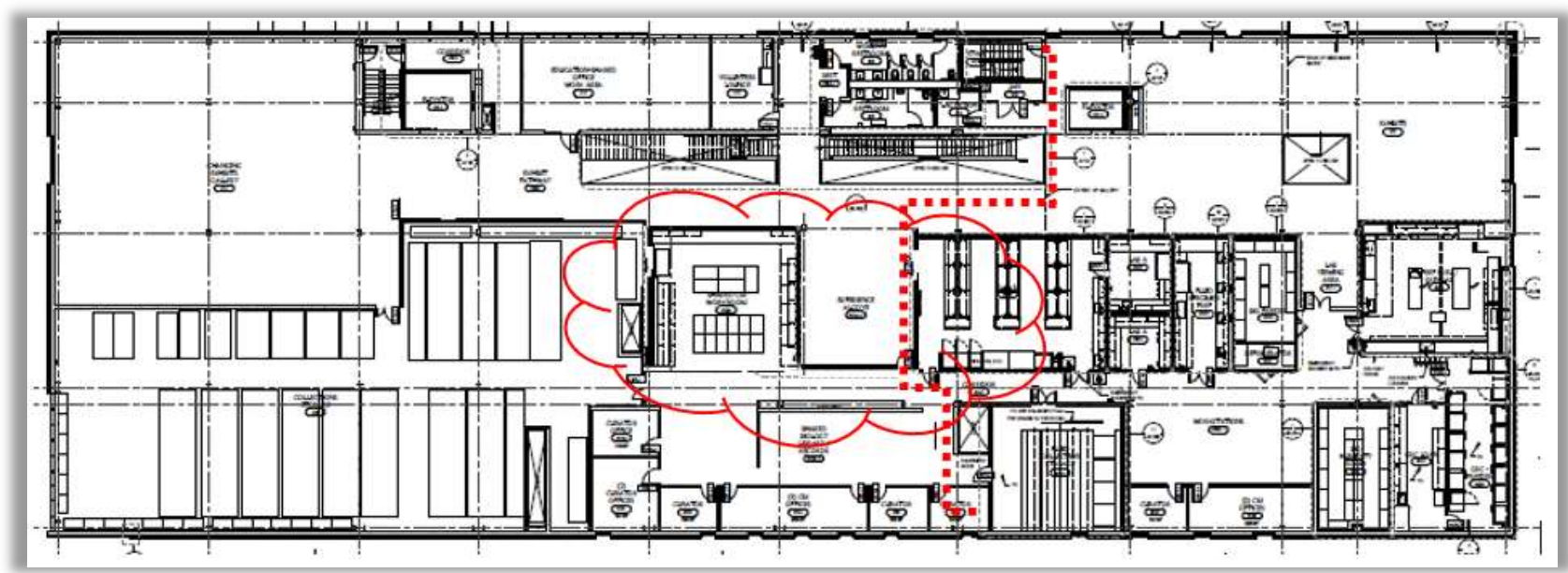

Figure 21: Level 2 Showing Plan Revisions in Order to Meet Travel Distance Requirement

\subsubsection{Enclosure of Atrium:}

The Section 404.6 provision requiring atrium spaces be separated with a 1-hour fire barrier from adjoining spaces can be difficult to design. The 1-hour fire barrier seperation is also an important tool in setting up an atrium design. There is an exception to 404.6 that allows any 3 floors to be left open as 
long as those adjoining spaces are accounted for in the smoke control system. The caveat of having to consider non-separated adjoining spaces in the smoke control system would drive the use of 1-hour fire barrier separation on all floors in the Burke.

The Burke's layout provides logical location to separate the main atrium area from adjoining space. The Level 1 floor plan also provides an opportunity to completely separate the basement level from the upper three levels. As shown in the Figures 22 and 23, this separation reduces the size of the atrium from four floors to three and eliminates the entire basement area from being considered in the smoke control plan.

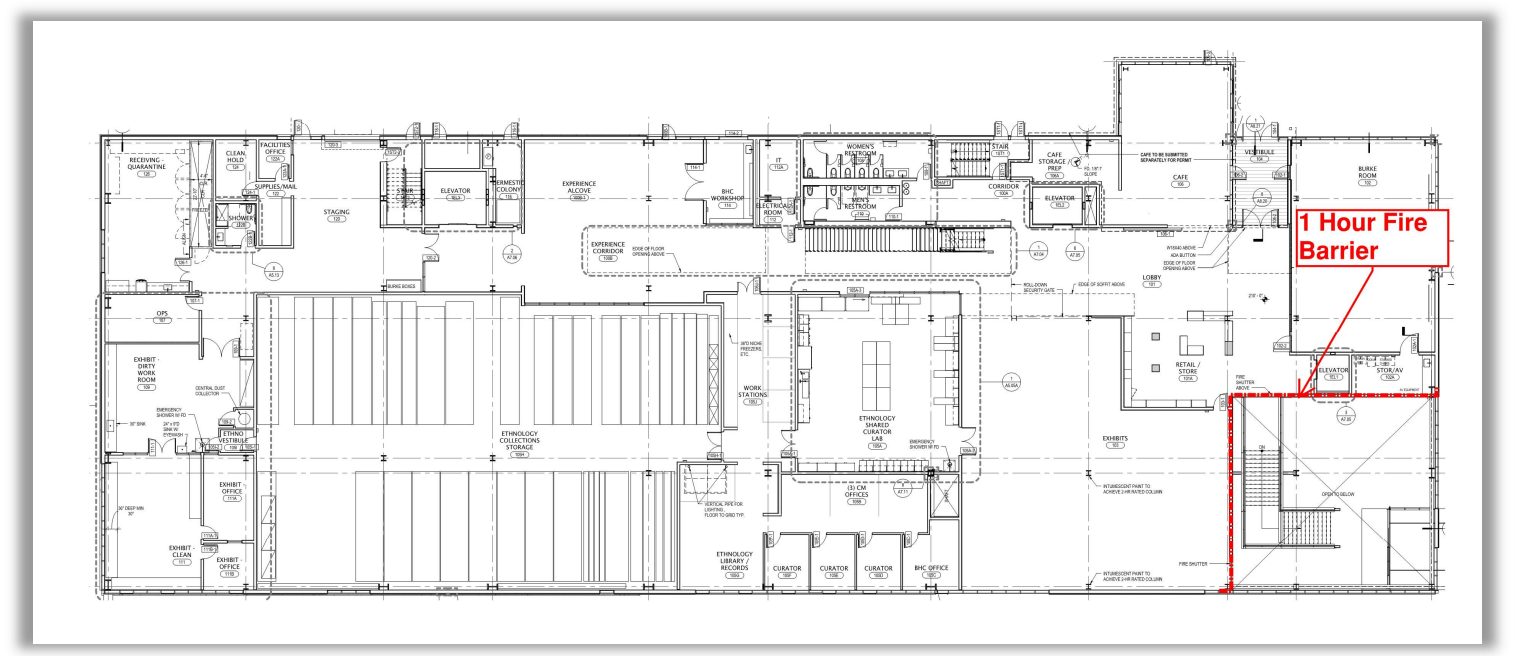

Figure 22: Level 1 Showing Fire Barrier Separation to Reduce Number of Connected Floors

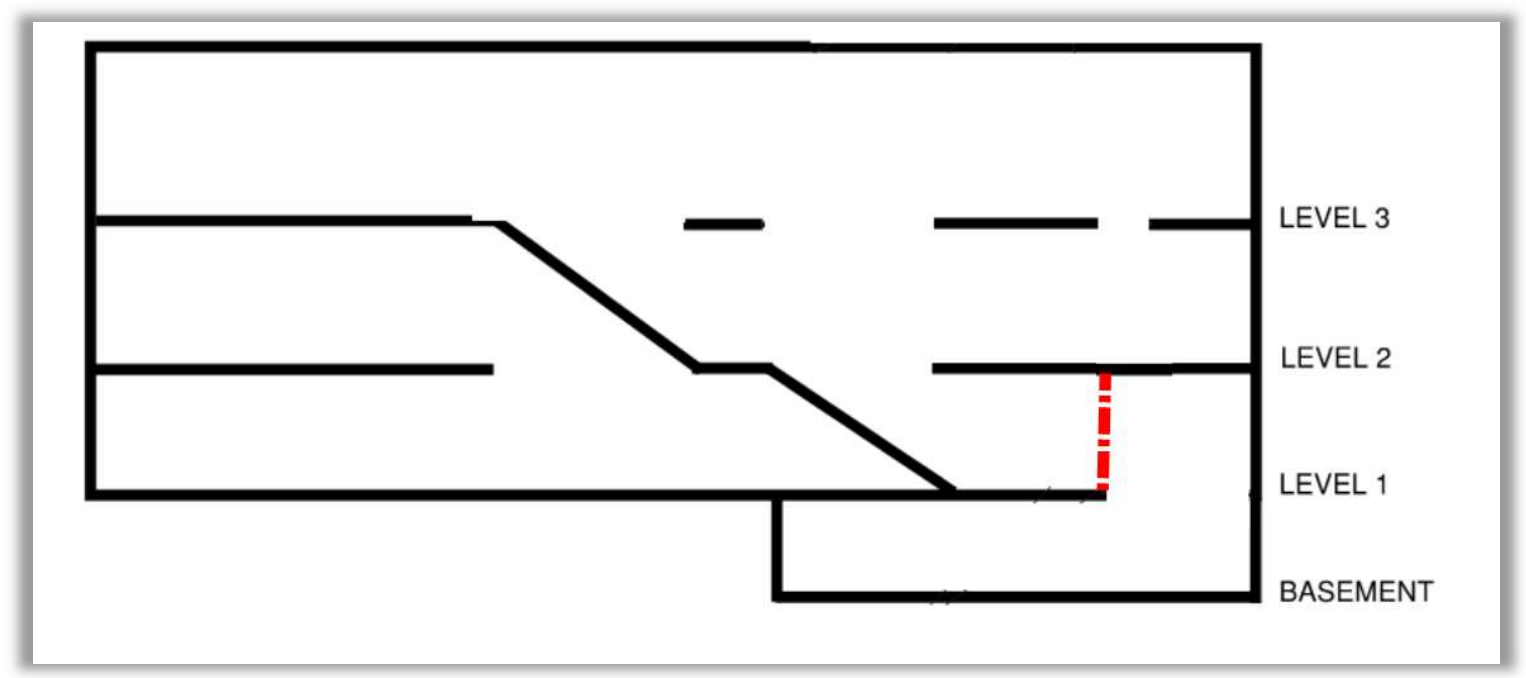

Figure 23: Section Showing Fire Barrier Separation to Reduce Number of Connected Floors

The next logical area to separate from the atrium spaces are the labs, office and storage spaces on each floor. These adjoining spaces have the potential for large fires due the large fuel loads and tall ceilings. The spaces are already separated with a wall for security purposes so the biggest impact would be the cost of upgrading the wall to a 1-hour fire barrier. This rated separation would be a combination of 
gypsum wall, glazing with sprinklers and fire doors. This design would require the operable glazing turn into fixed glazing. Sprinklers have to be able to wet the entire glass surface so some of the glazing heights would also have to be reduced. Figure 24 shows the location of the 1-hour fire barrier separation at each level. These fire barriers provide the boundary for the required smoke control system.

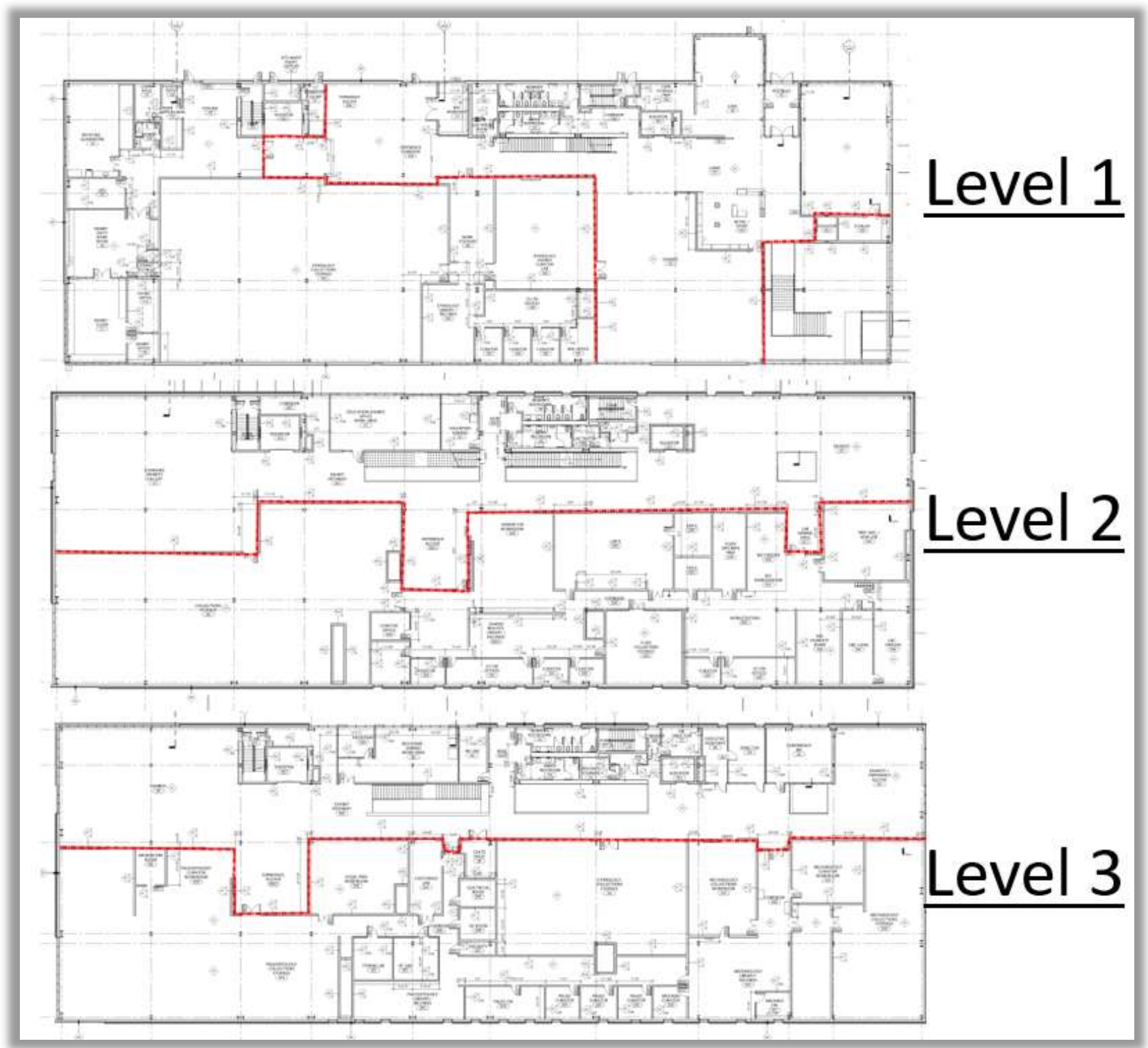

Figure 24: Levels 1 thru 3 Showing Fire Barrier Locations to Separate Adjoining Areas from Atrium 


\subsubsection{Smoke Control:}

IBC Section 404.5 requires smoke control system be installed in accordance with Section 909. Section 909 provides design, construction, and testing requirements for several different kinds of smoke control. Below is a summary of the pertinent requirements for this design and comparative analysis.

Section 909.4.6: All portions of active or passive smoke control systems shall be capable of continued operation after detection of the fire event for a period of not less than either 20 minutes or 1.5 times the calculated egress time, whichever is less. The 2015 IBC code amends this section to be whichever is greater. ICC documents stated that it was an error that the code had stated whichever is less in previous versions. A duration of 1.5 times the calculated egress time provides a safety factor to the calculated time. When this calculated duration is less than 20 minutes, requiring a 20-minute minimum allows time for the fire service to arrive and provide assistance to any occupants that were slower to exit than calculated.

Section 909.8: When approved by the fire code official, mechanical smoke control for large enclosed volumes, such as in atriums or malls, shall be permitted to utilize the exhaust method. Smoke control systems using the exhaust method shall be designed in accordance with NFPA 92B. This section of the IBC refers the designer to NFPA 92B for instructions on designing a smoke exhaust system. The referencing of NFPA 92B can be an issue because parts of NFPA 92B are in direct contradiction to section 909 of the IBC. The largest contradiction is the design objective. NFPA 92B allows the design objective to be; to maintain a tenable environment in necessary areas to allow occupants to reach an exit or area of refuge. Section 909 requires the height of the smoke layer interface to be maintained at least 6 feet above any walking surface that forms a portion of the required egress system for either 20 minutes or 1.5 times the calculated egress time, whichever is less (whichever is more in the 2015 IBC.) As most tenability criteria allow for some degree of smoke and the duration in NFPA 92B does not specify the $50 \%$ safety factor or a 20 -minute minimum, the IBC 909 requirements are much more stringent.

Section 909.9: The design fire shall be based on a rational analysis performed by the registered design professional and approved by the fire code official. The design fire shall be based on the analysis in accordance with Section 909.4 and this section. The size and composition of the design fire is one of the biggest factors in the smoke control design. The design fire must consider all fuel loads and positions within the atrium that can be reasonably expected. This includes all furnishings and transient fuels. Transient fuels are temporary fuel loads that can be moved into and around the atrium. The classic example of a transient fuel is a Christmas Tree. Per Section 909.9.1, when a documented engineering analysis is provided, the design fire growth can be halted at the time of sprinkler activation. The design fire should be approved by the AHJ prior to designing the exhaust system. 


\subsubsection{Design Objective:}

The smoke control design of the Burke will use a combination of the IBC 909 and NFPA 92B requirements. The required duration of the system will be based on the 2015 IBC section 909.4.6. (1.5 times the calculated egress or $\mathbf{2 0}$ minutes, whichever is greater.) Given the purpose of the IBC duration is to provide enough time for all occupants to exit the building (with safety factor) and provide time for the fire service to respond, there is no justification to use the less stringent NFPA 92B requirement.

The required safe egress time (RSET) is calculated per the ASHRAE Handbook of Smoke Design. The Required Safe Egress Time, or RSET, is the total time it takes from ignition of a fire to evacuation. This includes the time to detection, validation, pre-movement and movement. Figure 25 graphically shows the sequence of occupant response to a fire.

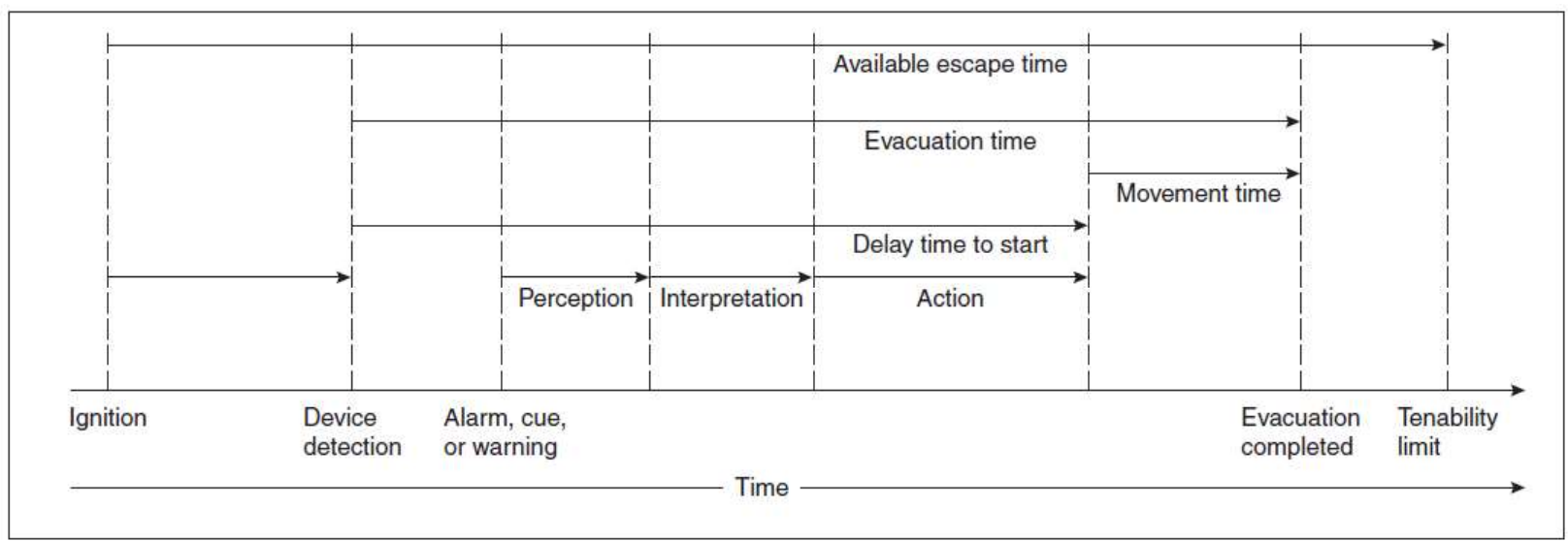

Figure 25: Sequence of Occupant Response to Fire, SFPE Handbook

The first step in analyzing the RSET is identifying the occupant characteristics. The Burke will have a sizable staff (roughly $10 \%$ to $20 \%$ of occupants) who will be trained and drilled on what to do in the event of a fire. The rest of the occupants will be the general public ranging all ages, sizes and physical capabilities. These occupants will not be familiar with the building or exit pathways. These are all factors that will increase the pre-movement time. One factor that will greatly improve the RSET is the Burke's open floor plan. The open floor plan will allow occupants to quickly validate the alarm by visually seeing smoke or fire. The openness will also help building occupants quickly find the exits.

Summary of Calculated Egress:

- Time to Notification: 30 seconds

- Pre-Movement: 90 seconds

- Hydraulic Flow Rate of 296 Occupants Out of Stair 2: 502 seconds

- Time to controlling element: $190^{\prime} / 275 \mathrm{ft} / \mathrm{min}+160^{\prime} / 106 \mathrm{ft} / \mathrm{min}=132 \mathrm{~seconds}$

- Time through controlling element: $296 / 48=370$ seconds

- Safety Factor: $622 \times 0.5=311$ seconds

1.5 times the calculated egress time is only 933 seconds so 20 minutes (1,200 seconds) will be used for the required duration. 
The design objective will be to maintain tenability in the atrium for 20 minutes per NFPA 92B.

Maintaining tenability is less demanding than the IBC requirement of maintaining the smoke layer 6 feet above the highest walking surface. To justify using tenability as the objective, the final smoke control design will be validated with Computational Fluid Dynamics (CFD) fire modeling. Figure 26 shows the different hazards created by a fire (the space is large enough and fire is small enough that radiant heat is not considered in the tenability criteria.) A CFD fire model will calculate the level of heat exposure, toxic gas exposure and reduced visibility at 6 feet above any walking surface to determine if tenability is maintained.

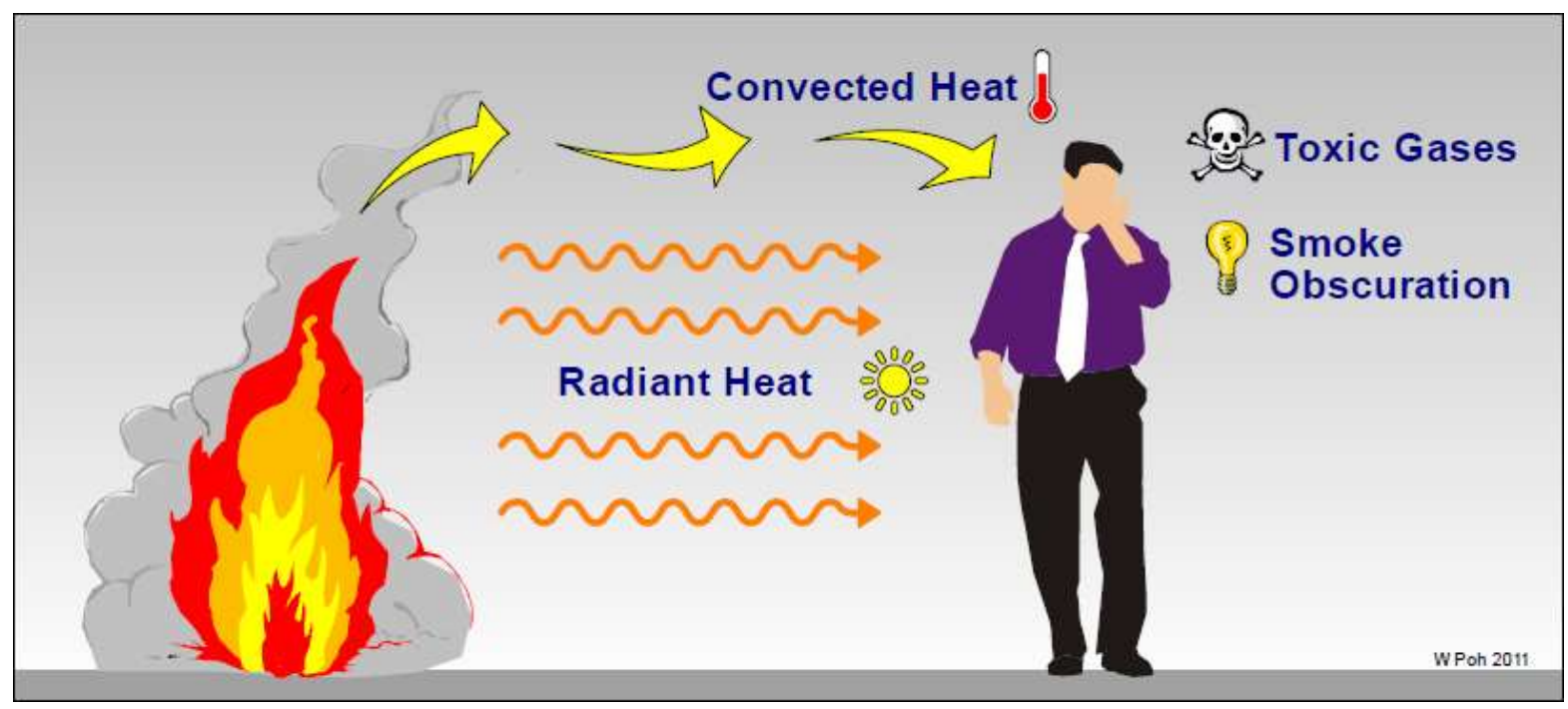

Figure 26: Hazards of Building Fire, Practice Note for Tenability Criteria in Building Fires

Tenability is defined as the conditions that will allow occupants to safely egress a building so the criteria for tenability is set well below survivability limits. Per Figure 27 , at $100^{\circ} \mathrm{C}$ heat exposure starts to cause issues for building occupants for durations of 10 to 20 minutes. $100^{\circ} \mathrm{C}$ is the maximum acceptable heat at 6 feet above any walking surface. Figure 28 shows that at extended exposure (20 to 30 minutes) of $1000 \mathrm{ppm}$ of CO incapacitation can occur. 1,000 ppm of CO is the maximum acceptable CO level at 6 feet above any walking surface

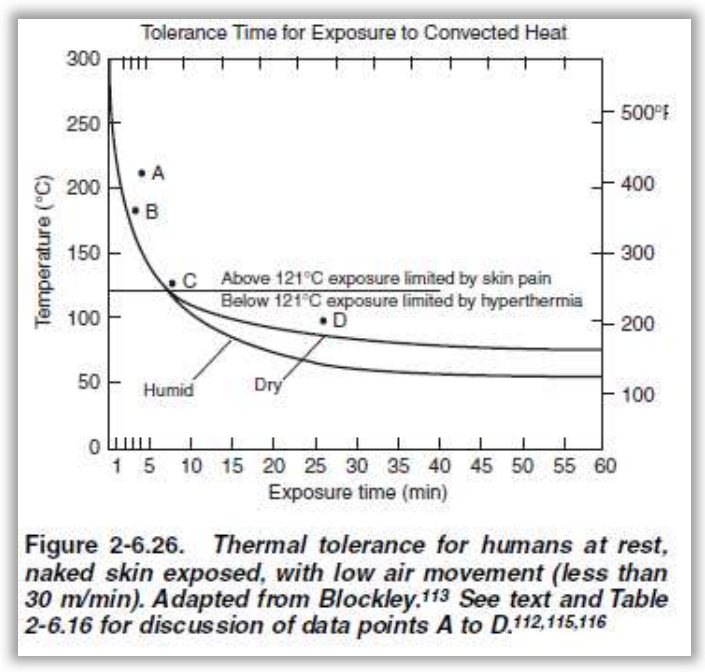

Figure 27: Thermal Tolerance, SFPE Handbook

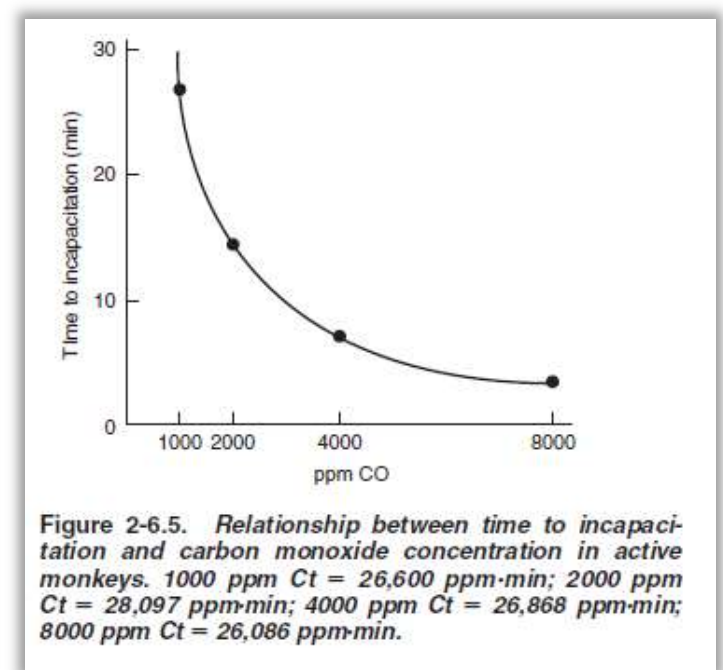

Figure 28: Rate of Incapacitation from CO, SFPE Handbook 30 
When dense smoke obscures visibility occupants will slow their progress towards an exit and could become completely disoriented all together. Many of the building occupants will have no familiarity with the building and disorientation from smoke obscuration is a major risk. 10 meters will be the minimum visibility at 6 feet above all walking surfaces.

\subsubsection{Design Fire Fuel Sources:}

The size and characteristics of the design fire is based on the available fuel sources in the space. When considering potential fuel loads it's important to be realistic and avoid wishful thinking. The most demanding fuel source considered for the Burke are the exhibits. Figure 29 shows photos of actual exhibits in the old Burke Museum building.

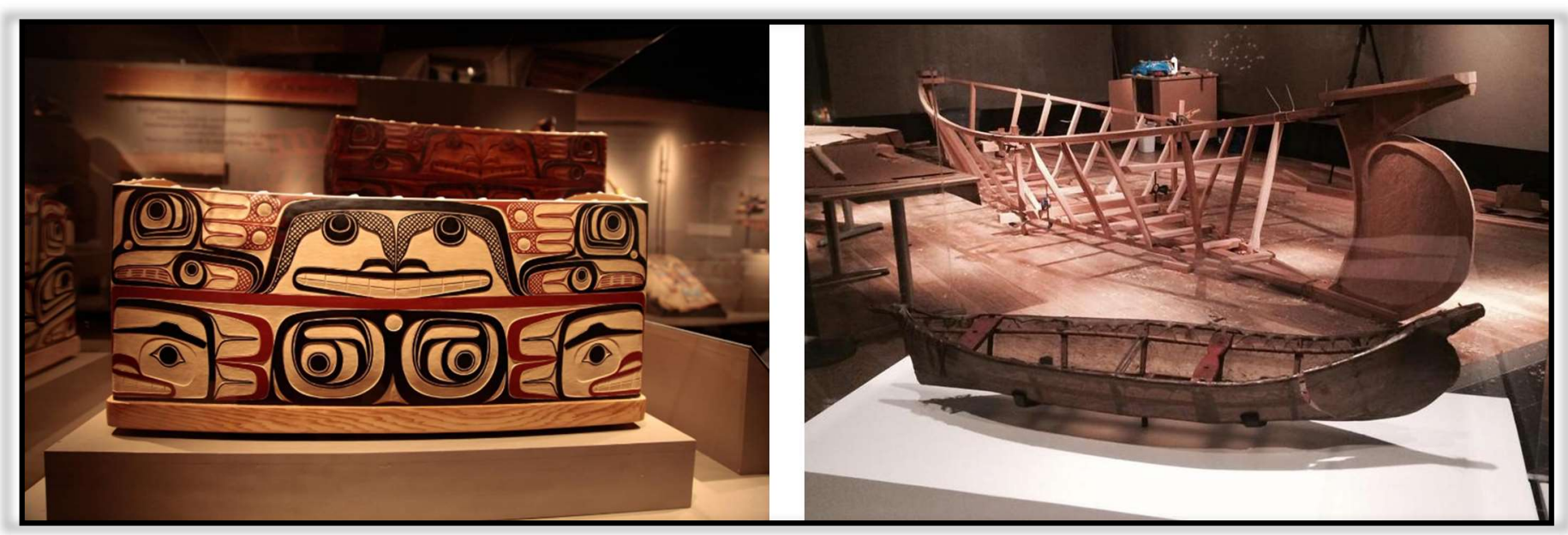

Figure 29: Photos of Exhibits in the Old Burke Museum

Not shown in the pictures are the crates and potential foam packaging that the different exhibits might arrive in or be staged with. Setting up new exhibits could involve electrical work for specialty lighting which could be a potential ignition source. The Burke also has a biology fluid collection storage area that is classified as an $\mathrm{H} 3$ occupancies. These specimens will be shown with different exhibits adding combustible liquids to a potential fuel source. These combustible liquids could act as an accelerant to any potential fire. Similar to how buildings are most at risk to fire during their construction, the exhibit areas are most at risk to fire while they are being set up. Fortunately, the amount of museum visitors should also be reduced during this time as visitors are not allowed in exhibit areas while they are being set up. The potential fuel source of the exhibits will be used to determine the design fire characteristics. 


\subsubsection{Design Fire:}

Peak heat release rate, fire growth rate, soot yield and $\mathrm{CO}$ yield are calculated based on the potential fuel source. When possible full scale test results should be used to specify these characteristics. This is especially true for peak heat release rates and fire growth rates as scaling of these characteristics can be problematic (particularly when material combinations are used.) Bench scale testing of different materials will be used to provide the soot and $\mathrm{CO}$ yield rates

It would not be possible to do full scale testing on the many different possibilities for exhibits so the fire characteristics are generalized and extrapolated from available testing data. The specified maximum heat release rate is extrapolated from wood pallet fire tests. The exhibit area is estimate at 6 square meters so the peak heat release rate is $1,420 \mathrm{~kW} / \mathrm{m} 2 \times 6 \mathrm{~m} 2=8,520 \mathrm{~kW}$. (per Figure 30)

\section{Table B.5.2(a) Unit Heat Release Rate for Commodities}

\begin{tabular}{ccc}
\hline \hline Commodity & $\begin{array}{c}\text { Btu/sec } \cdot \mathrm{ft}^{2} \text { of } \\
\text { Floor Area }\end{array}$ & $\begin{array}{c}\mathrm{kW} / \mathrm{m}^{2} \text { of } \\
\text { Floor Area }\end{array}$ \\
\hline $\begin{array}{c}\text { Wood pallets, stacked } 1 \frac{1}{2} \mathrm{ft} \text { high } \\
(6-12 \% \text { moisture })\end{array}$ & 125 & 1,420
\end{tabular}

Figure 30: Excerpt from SFPE Handbook, Unit Heat Release Rate for Wood Pallets,

Per Figure 31, the wood pallet fire that was used to calculate the peak heat release rate of the exhibit has a growth rate between fast and ultra-fast. However, with the potential of foam packing material, plywood crates and combustible liquids being present, an ultra-fast growth rate is used for the exhibit fire.

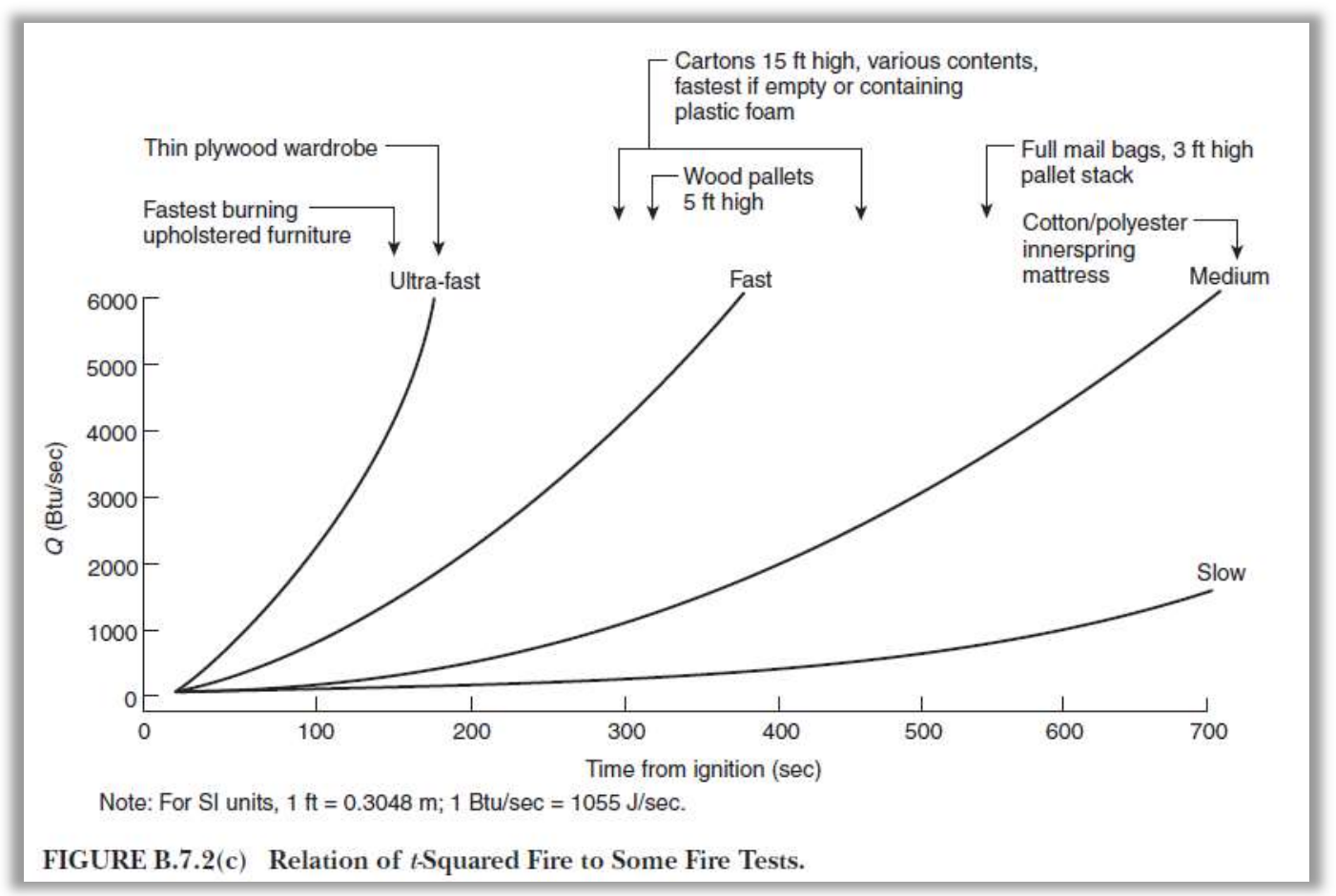

Figure 31: Fire Growth Rates, SFPE Handbook 
The Soot and $\mathrm{CO}$ yields for the exhibit fire is derived from information provided in Table A.39 from the fifth addition of the SFPE handbook. The fuel load is simplified as a combination of wood and polyurethane foam. The $\mathrm{CO}$ yield for wood and polyurethane foams are estimated at 0.005 and 0.04 . The Soot yield for wood and polyurethane foams are estimated at 0.015 and 0.2 . The composition of the exhibit is $90 \%$ wood and $10 \%$ polyurethane foam. Tables 8 and 9 summarize the design fire characterstics.

Table 8: Composite Design Fire Characteristics

\begin{tabular}{|l|c|c|c|c|c|}
\hline Fuel Source & Wood (\%) & $\begin{array}{c}\text { Polyurethane } \\
\text { Foam (\%) }\end{array}$ & $\begin{array}{c}\text { Wood CO } \\
\text { Yield (g/g) }\end{array}$ & $\begin{array}{c}\text { Polyurethane } \\
\text { CO Yield (g/g) }\end{array}$ & $\begin{array}{c}\text { Composite CO } \\
\text { Yield (g/g) }\end{array}$ \\
\hline Exhibit & 90 & 10 & 0.005 & 0.04 & 0.0085 \\
\hline & & & & & \\
\hline Fuel Source & Wood (\%) & $\begin{array}{c}\text { Polyurethane } \\
\text { Foam (\%) }\end{array}$ & $\begin{array}{c}\text { Wood Soot } \\
\text { Yield (g/g) }\end{array}$ & $\begin{array}{c}\text { Polyurethane } \\
\text { Soot Yield (g/g) }\end{array}$ & $\begin{array}{c}\text { Composite Soot } \\
\text { Yield (g/g) }\end{array}$ \\
\hline Exhibit & 90 & 10 & 0.015 & 0.2 & 0.0335 \\
\hline
\end{tabular}

Table 9: Summary of Design Fire Characteristics

\begin{tabular}{|l|c|l|c|c|}
\hline Fire Source & $\begin{array}{c}\text { Peak Heat } \\
\text { Release Rate } \\
(\mathrm{kW})\end{array}$ & $\begin{array}{c}\text { Growth } \\
\text { Rate }\end{array}$ & $\begin{array}{c}\text { Soot } \\
\text { Yield } \\
(\mathrm{g} / \mathrm{g})\end{array}$ & $\begin{array}{c}\text { CO Yield } \\
(\mathrm{g} / \mathrm{g})\end{array}$ \\
\hline \hline Exhibit & 8,520 & Ultra-Fast & 0.0355 & 0.0085 \\
\hline
\end{tabular}

All potential fire locations are located in areas that will be protected with sprinklers and ceiling heights of 20 feet. The design takes sprinkler activation into consideration of the design fire's HRR and stops the growth at time of activation. The DETACT model is used to estimate sprinkler activations time at approximately 100 seconds, which caps the HRR at 1,880 kW. As further justification, these results will be verified in the CFD model. Table 10 contains the DETACT input parameter and Figure 32 show the DETACT results.

Table 10: DETACT Input Parameters

\begin{tabular}{|r|c|l|}
\hline \multicolumn{1}{|l|}{ INPUT PARAMETERS } \\
\hline Calculation reset & 1 & 0 or 1 \\
\hline Ceiling height $(\mathrm{H})$ & 6 & $\mathrm{~m}$ \\
\hline Room width $(\mathrm{W})$ & 20 & $\mathrm{~m}$ \\
\hline Radial distance $(\mathrm{R})$ & 2.1 & $\mathrm{~m}$ \\
\hline Ambient temperature (To) & 20 & $\mathrm{C}$ \\
\hline Actuation temperature (Ta) & 68 & $\mathrm{C}$ \\
\hline Rate of rise rating (ROR) & 8.3 & $\mathrm{C} / \mathrm{min}$ \\
\hline Response time index (RTI) & 50 & $(\mathrm{~m}-\mathrm{s}) 1 / 2$ \\
\hline Fire growth power $(\mathrm{n})$ & 2 & - \\
\hline Fire growth coefficient $(\mathrm{k})$ & 0.188 & $\mathrm{~kW} / \mathrm{s}^{\wedge} \mathrm{n}$ \\
\hline Fire location factor $(\mathrm{kLF})$ & 1 & - \\
\hline
\end{tabular}

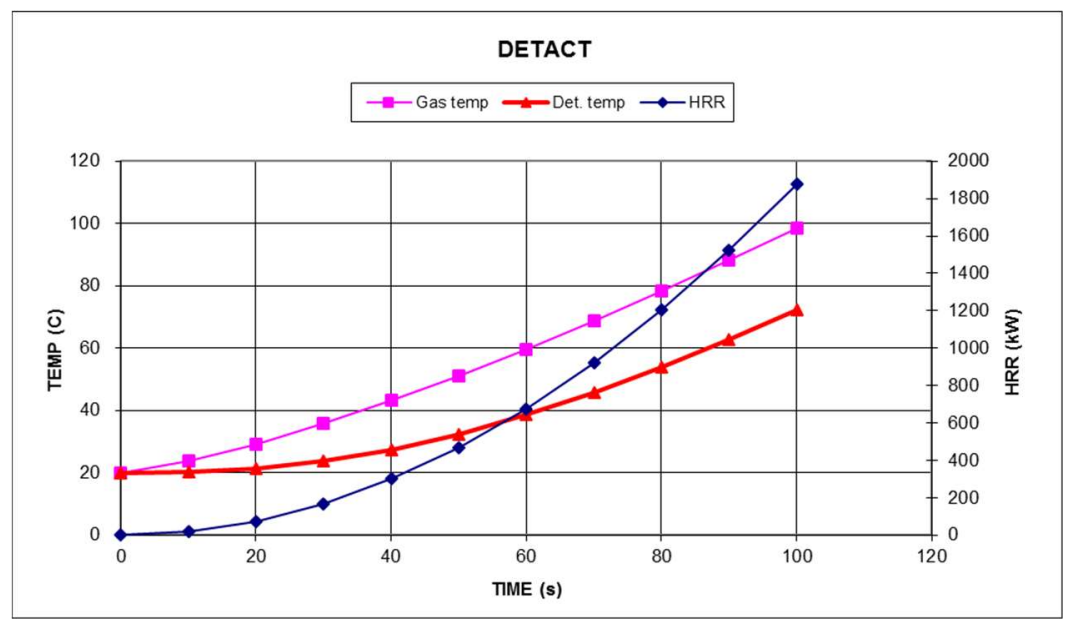

Figure 32: DETACT Results 


\subsubsection{Design Fire Location:}

A unique and challenging feature of the Burke, are the amount of areas that a sizable design fire could be expected. The entire atrium space is flexible exhibiting area so the specified design fire can occur at any location and at any floor of the space. 20-foot-high ceilings at each floor reduces the effectiveness of sprinklers and allows fires to grow larger than would typically be required in adjoining spaces. Figure 33 shows the three locations for the design fires. These locations were chosen to ensure the exhaust system is designed to handle a fire on each floor of the atrium. These locations were also chosen due to their remoteness from each other and from the exhaust vents or floor openings. The fire locations are designate as Level 1, Level 2 and Level 3.

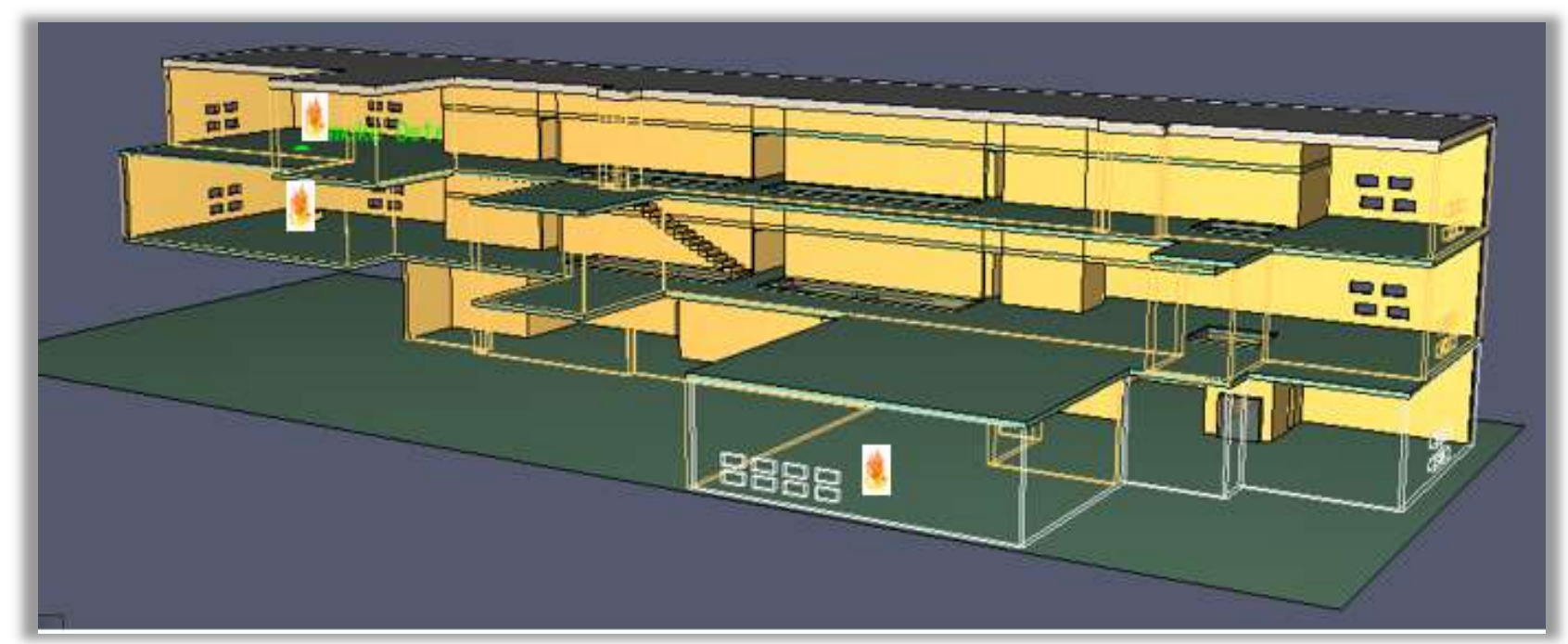

Figure 33: PyroSim Rendering of Burke Model Showing Fire Locations

\subsubsection{NFPA 92B Mechanical Exhaust Calculations:}

The smoke control system will ultimately be designed using FDS but as a starting point and for validation, the NFPA 92B calculations are performed. Unfortunately, the NFPA 92B calculations are set up for a traditional atrium and the Burke Museum does not have a traditional Atrium layout. The smoke exhaust calculations are designed around a large fire located in a large volume space. Figure 35 shows the idealized atrium that the NFPA 92B calculations are based on. The smoke gathers at the top of the large volume space and is expelled by an exhaust fan.

Conversely, the Burke Museum has several large volume space that are connected by relatively small openings. Figure 34 shows how the Burke design requires that smoke is exhausted from each floor through the floor openings before it can be exhausted at the top of the building. Figure 34 still shows an ideal situation with smoke gathering at the top each floor to be exhausted above. The CFD model will show that the smoke does not exhaust in this ideal manner. 


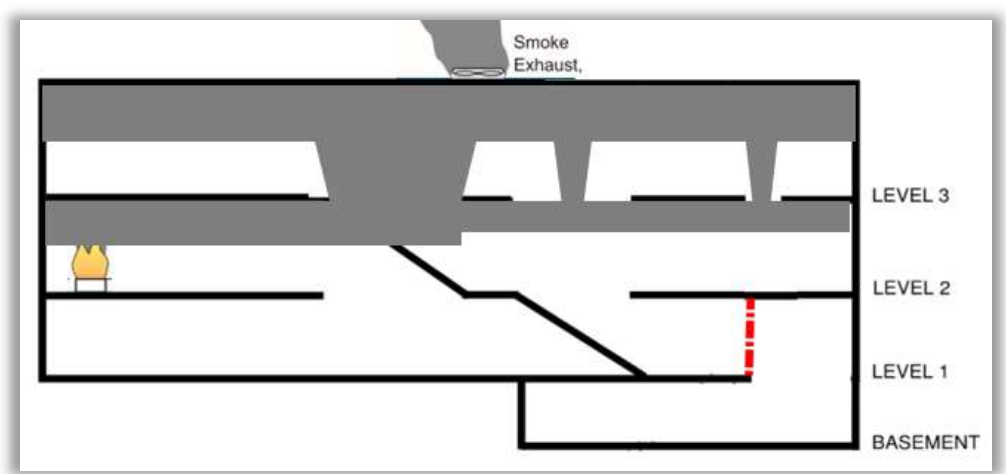

Figure 34: Section of Burke Showing Ideal Smoke Movement

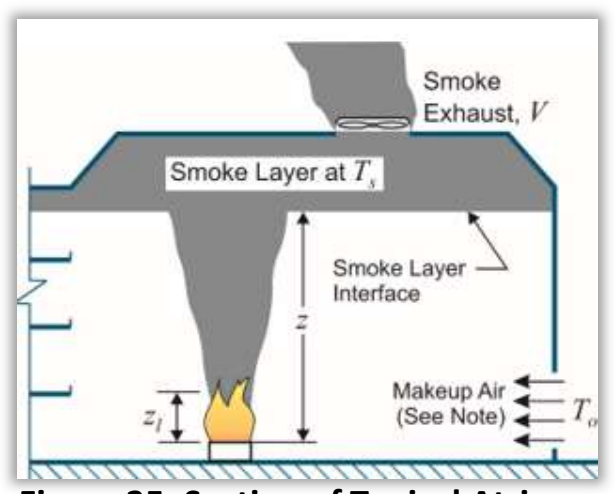

Figure 35: Section of Typical Atrium, ASHRAE'S AtriumCalc

The production of smoke caused by smoke traveling along the ceiling before moving to the level above is similar to what can be calculated using the Balcony Spill Plume Orientation in NFPA92B. However, the floor openings are too small and the fire is too far away from them for the smoke to naturally move through vertical openings to the highest level. A combination of the NFPA 92B calculations can be used to provide a starting point for the CFD model but cannot be reliably used to design the system. ASHRAE's AtriumCalc spread sheet is used to run the various NFPA 92B calculations. Table 11 provides a summary of the calculations for each fire location (full calculations are provided in the Appendix.)

The NFPA 92B calculations also predict plugholing issues between levels. The second and third-floor slabs have consecutive openings. Each floor has three opening; approximately $10^{\prime} \times 40^{\prime}$, $10^{\prime} \times 38^{\prime}$ and $10^{\prime} \times 14^{\prime}$. The openings are not sized correctly for exhaust vents and will each exceed the maximum allowable airflow to resist plugholing.

\subsubsection{CFD Smoke Control Design:}

Table 11: Summary of NFPA 92B Calculations

Per NFPA 92B Section 5.1.3, a smoke control system can be designed using CFD models. It is common practice to use a CFD model to justify reducing the size of the exhaust system or required makeup air calculated with the NFPA 92B algebraic equations. As concluded in the previous section, the only way to accurately design the Burke's smoke control system is with CFD modeling. This design uses the Fire Dynamics Simulator (FDS) developed by NIST. Pyrosym is used to develop the FDS model and Smokeview is used to interpret the results. This section will provide the process used to complete the smoke control design using FDS and summarize the results.

The sole purpose of this FDS model is to design the smoke control system and many of the computational features of FDS are not necessary. All obstructions are modeled as inert surfaces and the fire is modeled per the design fire criteria previously defined. Due to computing limitations and the amount of modeling required, the design is using a 2' $\times 2$ ' mesh. The is a coarser than preferred mesh so a sensitivity analysis was performed using a $1^{\prime} \times 1^{\prime}$ mesh that will be summarized at the end of this section. 
Based on the NFPA 92B calculations, the initial model was ran with 200,000 CFM of exhaust from the top of the atrium space. The Burke design is utilizing sprinklers to protect exterior glazing which does not allow for windows to operate. For this reason, the initial model does not have any automatic opening windows to provide makeup air. Figure 36 shows that, without makeup air on each floor, eddies are created in each of the wings and the smoke does not leave the wing of the building where it originates. To get the smoke to move beyond the wing of origin, makeup air is required on each level. Because the system must work no matter where the smoke originates it is necessary to provide equal exhaust and make up air around the atrium and at each level.

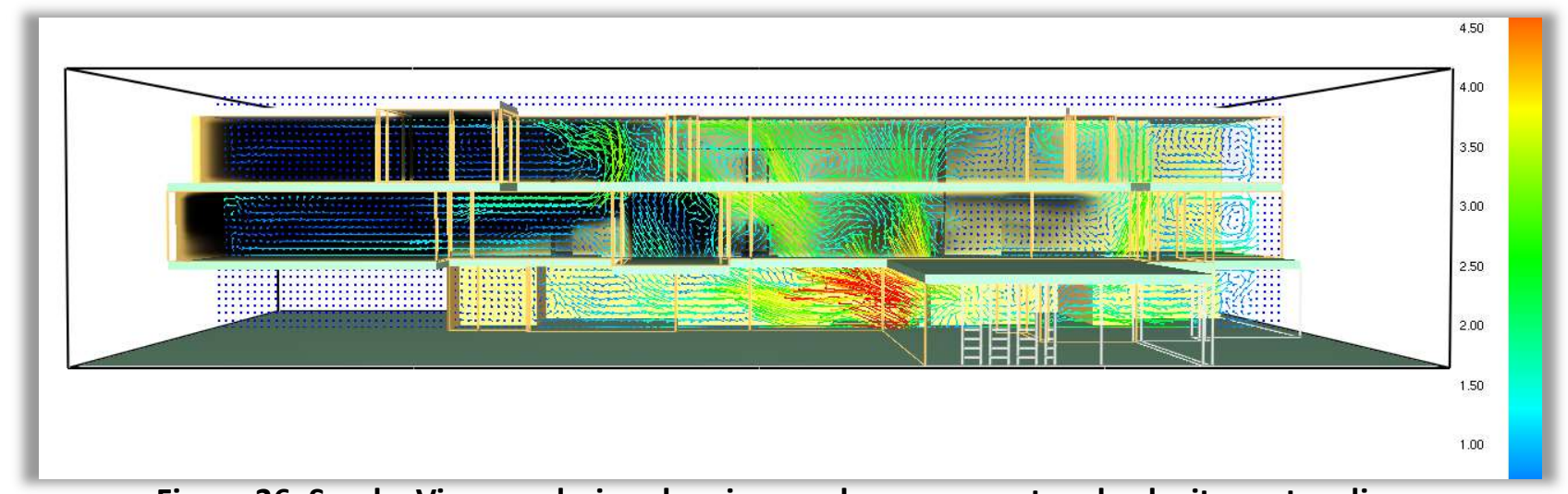

Figure 36: Smoke View rendering showing smoke movement and velocity vector slice.

Figure 36 also shows that plugholing and short circuiting is unavoidable due to the layout of the atrium and floor openings. The plugholing shown in figure 36 validates NFPA 92B calculations that predicted similar results. Further design attempts showed that the different fire scenarios required very different exhaust systems. A fire at level one requires significantly more exhaust than a fire at level 3 . Early design attempts using FDS showed that exhaust systems large enough for a fire at level 1 are too large for a fire at level 3 . The biggest challenge was to get the smoke control to work for all fire scenarios.

The final smoke control design required extensive changes to the building design. Figure 37 shows the location of design changes required for the smoke control design. Figure 38 provides a detailed list of specific architectural design changes required by the smoke control system.

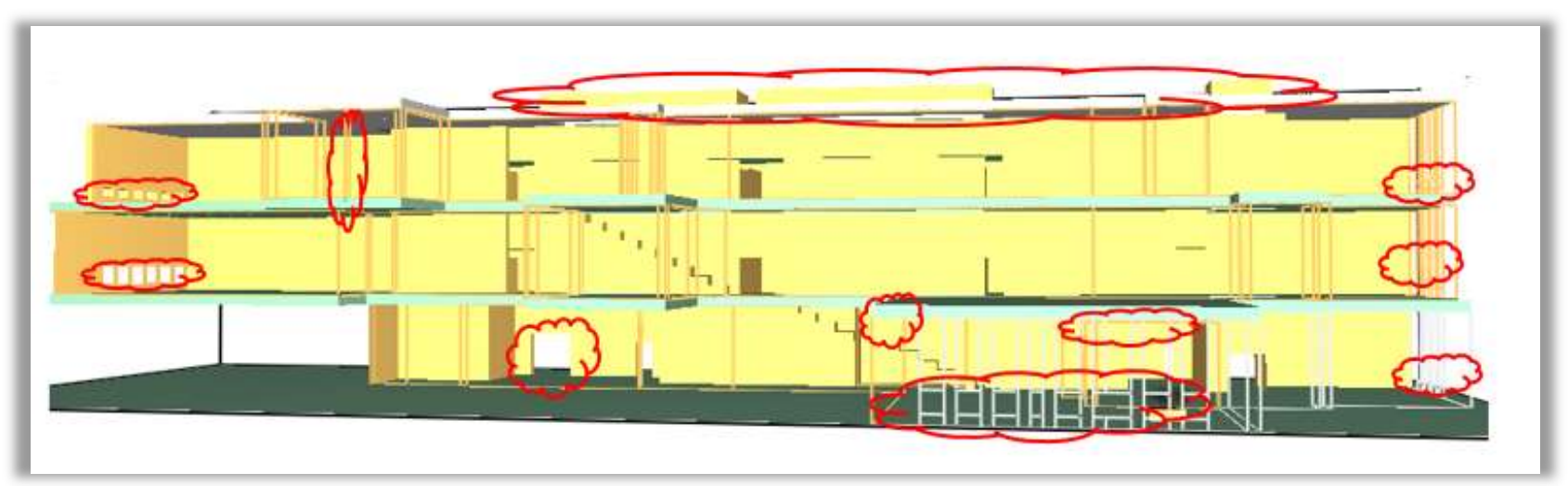

Figure 37: Rendering with all required changes clouded 


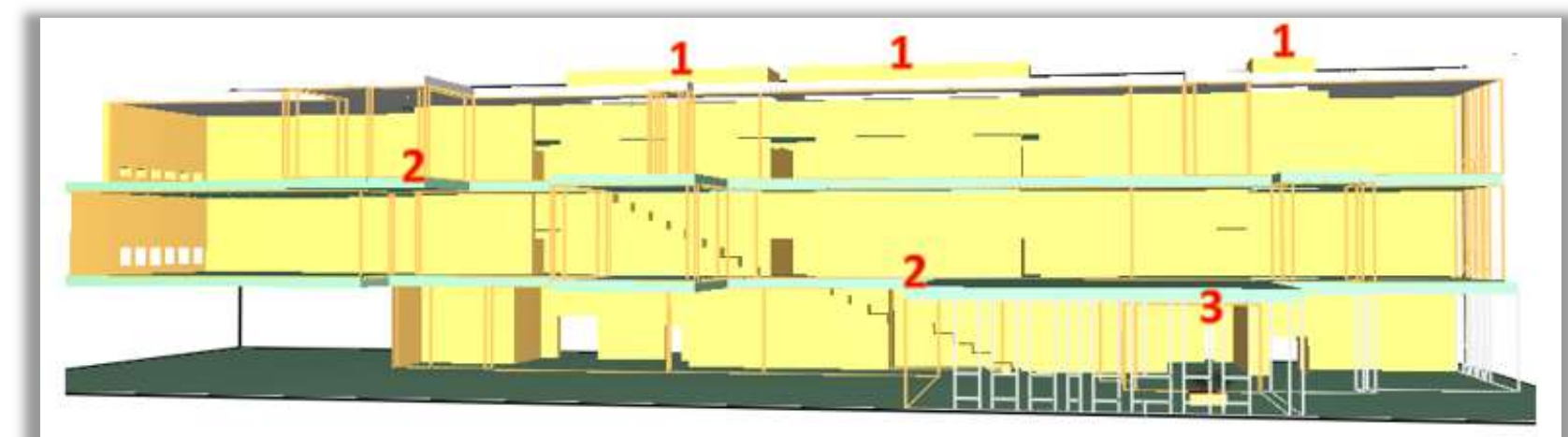

Figure 38: Rendering of the atrium with specific changes numbered: 1: Four-foot-tall doghouses were added at the top of the atrium at each skylight to provide a location for the main exhaust vents and to provide a smoke reservoir. 2: Fire rated vent shafts required of exhaust vents not located at roof. 3: Wall required to be partial height to allow smoke to exhaust from first floor exhibit area (held 2' from ceiling)

A series of exhaust vents laid out at the top of the atrium did not work with this design. The size and orientation of the atrium required different sized exhaust vents located throughout the atrium space. Figure 39 shows the location of each exhaust vent and Table 12 provides their size, orientation and capacity. The exhaust vents are triggered by the buildings smoke detection system. They ramp up to full force within 20 seconds of activation. For the different fire scenarios, activation is typically at 35 to 40 seconds.

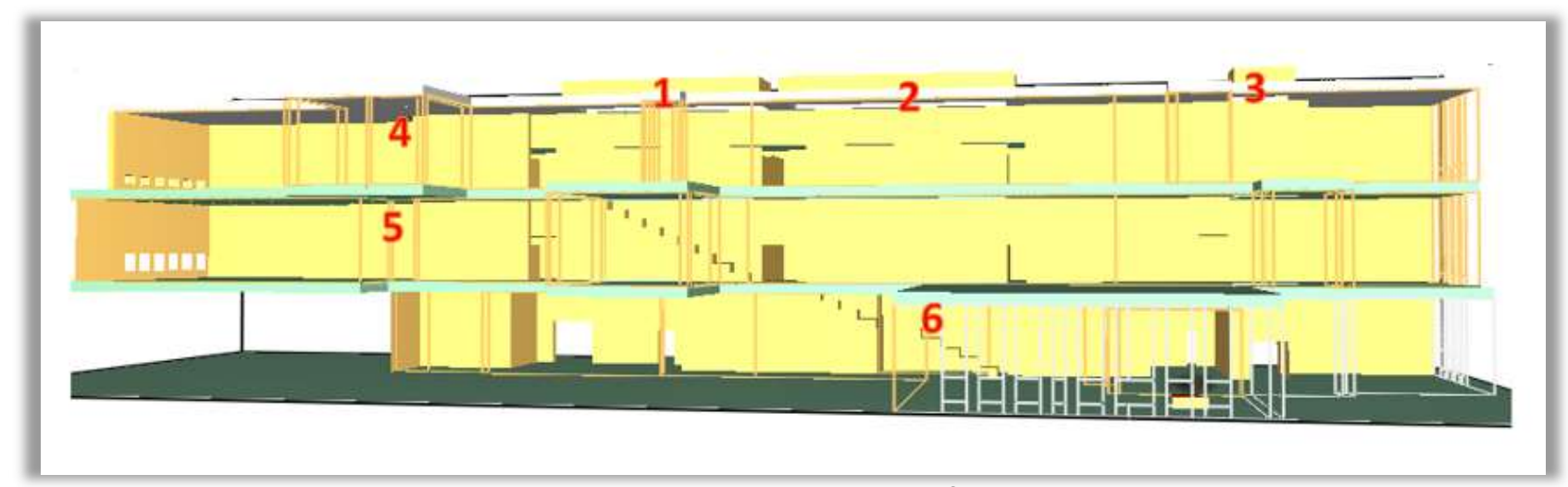

Figure 39: Rendering showing location of exhaust vents

Table 12: Exhaust vent summary

\begin{tabular}{|c|c|c|c|}
\hline Vent & Orientation & Size & Volume Flow Rate \\
\hline 1 & Vertical & $4^{\prime} \times 40^{\prime}$ & 75,000 CFM \\
\hline 2 & Vertical & $4^{\prime} \times 40^{\prime}$ & 75,000 CFM \\
\hline 3 & Vertical & $4^{\prime} \times 10^{\prime}$ & 35,000 CFM \\
\hline 4 & Vertical & $2^{\prime} \times 8^{\prime}$ & 30,000 CFM \\
\hline 5 & Horizontal & $2^{\prime} \times 8^{\prime}$ & 30,000 CFM \\
\hline 6 & Horizontal & $2^{\prime} \times 8^{\prime}$ & 30,000 CFM \\
\hline \multicolumn{2}{r|r|}{} & Total: & 275,000 CFM \\
\cline { 3 - 4 } & &
\end{tabular}

The layout of the atrium and exhaust vents made it necessary to provide many different points of makeup air around the atrium. All makeup air sources are passively provided with operable windows, 
doors and louvers. Table 13 provides a summary of the makeup air provided and figure 40 provides their general locations. The components are activated by the building's smoke detector and are fully opened within 5 seconds of activation.

Table 13: Makeup air summary

\begin{tabular}{|c|l|c|c|}
\hline $\begin{array}{c}\text { Area } \\
\text { Designation }\end{array}$ & $\begin{array}{c}\text { Number of } \\
\text { Openings }\end{array}$ & $\begin{array}{c}\text { Open } \\
\text { Area (sf) }\end{array}$ \\
\hline 1 & Operable Windows & 6 & 48 \\
\hline 2 & Operable Windows & 4 & 32 \\
\hline 3 & Operable Windows & 6 & 96 \\
\hline 4 & Operable Windows & 4 & 64 \\
\hline 5 & Operable Doors or Louvers & 1 & 100 \\
\hline 6 & Operable Windows & 4 & 64 \\
\hline 7 & Operable Windows & 8 & 128 \\
\hline 8 & Operable Door & 1 & 24 \\
\hline 9 & Operable Door & 1 & 24 \\
\hline 10 & Operable Door & 2 & 64 \\
\hline & & 37 & 644 \\
\hline
\end{tabular}

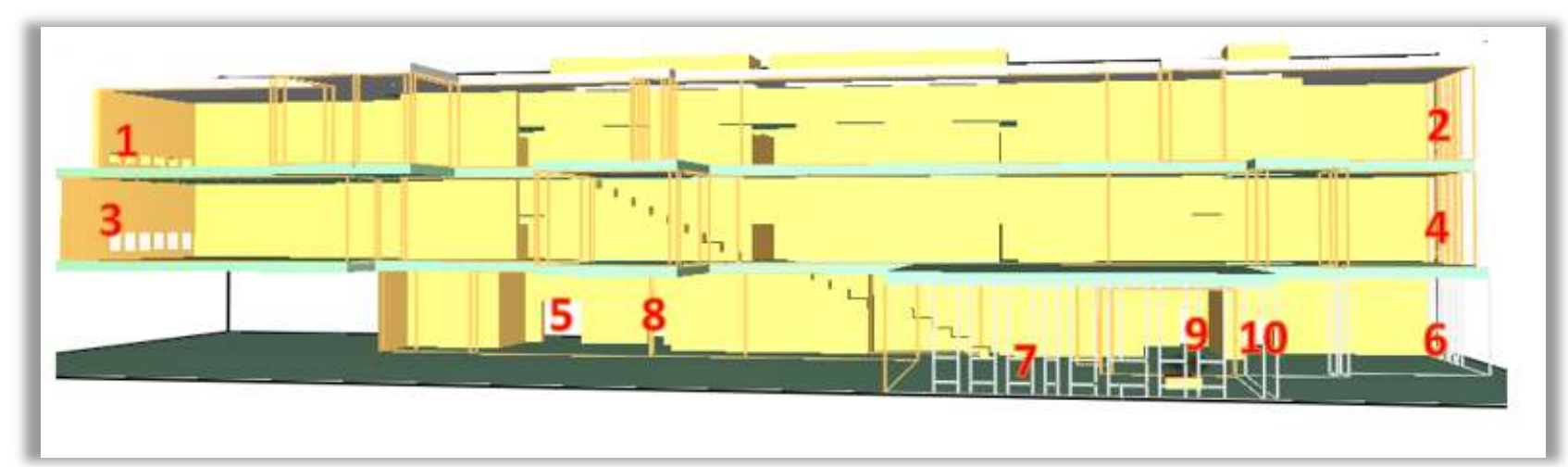

Figure 40: Rendering showing locations of makeup air

\subsubsection{CFD Smoke Control Results:}

To monitor tenability conditions slice files for Temperature, CO Concentration and Visibility are placed 6 feet above each floor. Summaries of results for each of the three fire scenarios are presented in this section. 
Level 1 Fire Scenario: Tenability Maintained

The smoke control system maintains tenability through the level 1 fire scenario. Table 14 shows conditions $6^{\prime}$ above each floor. Figure 41 is a rendering showing the visibility 6 feet above the fire floor. Figure 42 is a rendering showing the visibility 6 feet above the highest walking surface exposed to the atrium.

Table 14: Level 1 Fire Scenario Tenability Summary

\begin{tabular}{|l|c|c|c|c|}
\hline Level 1 Fire Scenario & \multicolumn{3}{|l|}{$\begin{array}{l}\text { Minimum Tenability } \\
\text { Conditions at 6' above floor }\end{array}$} & \multicolumn{3}{|c|}{ Conditions 6' Above Floor } \\
& & Level 1 & Level 2 & Level 3 \\
\hline Fire Scenario & 100 & 25 & 22 & 27 \\
\hline Temperature (c) & 1,000 & 9 & 3 & 8 \\
\hline CO Concentration (ppm) & 10 & 14 & N/A & 12 \\
\hline Visibility (m) & \multicolumn{4}{|l}{} \\
\hline
\end{tabular}

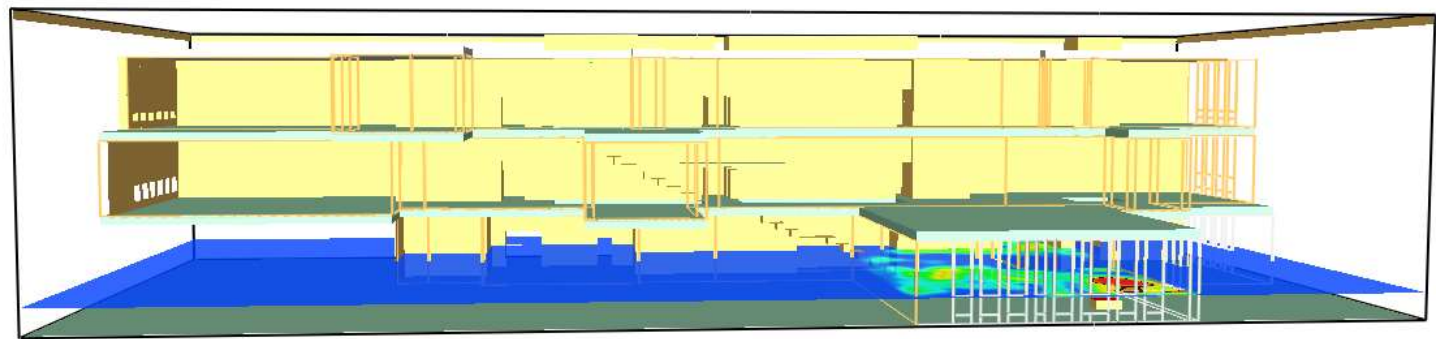

Figure 41: Rendering showing visibility slice $\mathbf{6}^{\prime}$ above floor of fire origin (level 1)

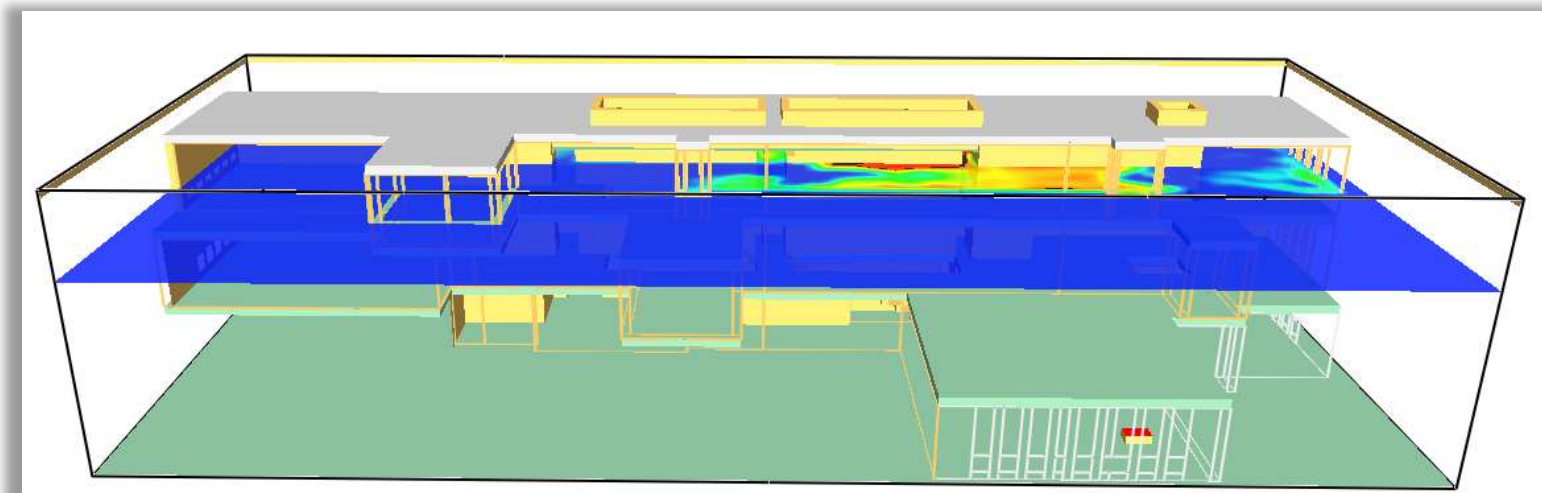

Figure 42: Rendering showing visibility slice 6' above highest walking surface (level 3) 
Level 2 Fire Scenario: Tenability Maintained*

The smoke control system maintains tenability through the level 2 fire scenario. Table 15 shows conditions $6^{\prime}$ above each floor. Figure 42 is a rendering showing the visibility 6 feet above the fire floor. Figure 44 is a rendering showing the visibility 6 feet above the highest walking surface exposed to the atrium.

As shown in figure 44 , there is a small area adjacent to an atrium opening where visibility is reduced to 7.5 meters. This area is less than 2 meters wide and is located between two egress stairs. An occupant in this area would be able to travel a short distance in any direction and be traveling toward an exit and quickly reach an area with tenable visibility. This area of decreased visibility does not keep the system from meeting tenability requirements.

Table 15: Level 2 Fire Scenario Tenability Summary

\begin{tabular}{|l|c|c|c|c|}
\hline Level 2 Fire Scenario & \multicolumn{3}{|l|}{$\begin{array}{l}\text { Minimum Tenability } \\
\text { Conditions at 6' above floor }\end{array}$} & \multicolumn{3}{|c|}{ Conditions 6' Above Floor } \\
& & Level 1 & Level 2 & Level 3 \\
\hline Fire Scenario & 100 & N/A & 30 & 25 \\
\hline Temperature (c) & 1,000 & N/A & 8 & 8 \\
\hline CO Concentration (ppm) & 10 & N/A & 11 & $12^{*}$ \\
\hline Visibility (m) & &
\end{tabular}

*a small area adjacent to atrium opening has decreased visibility of to 7.5 meters

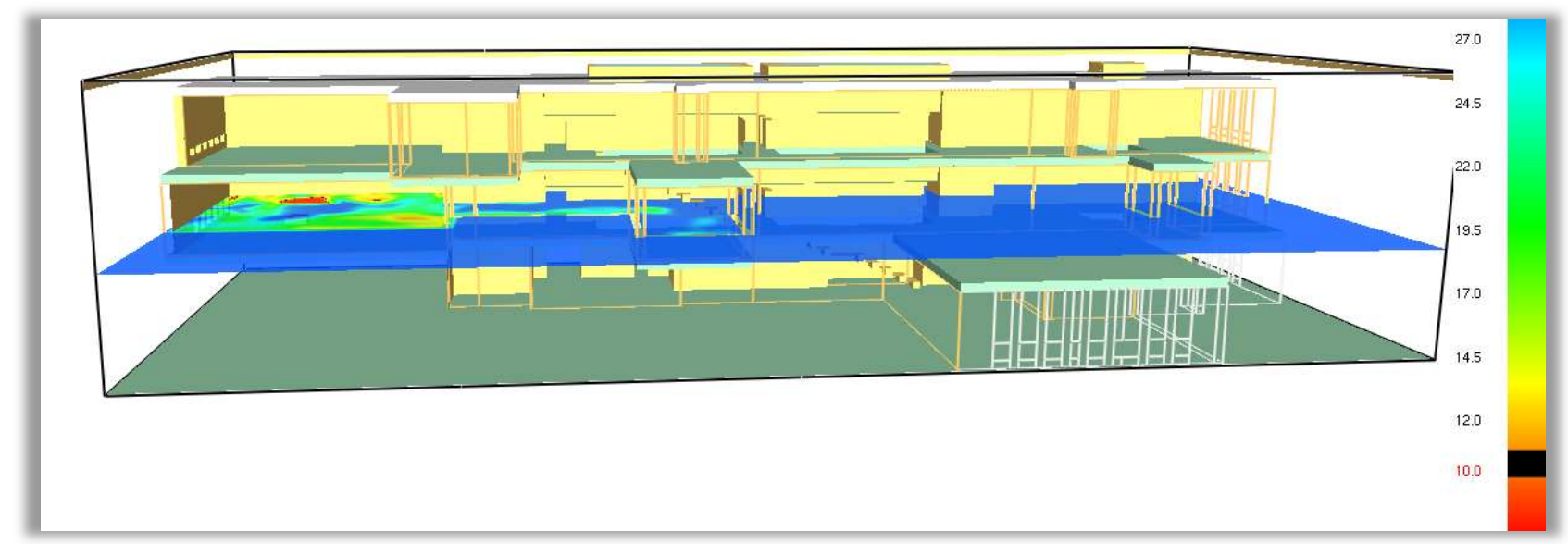

Figure 43: Rendering showing visibility slice 6' above floor of fire origin (level 2) 


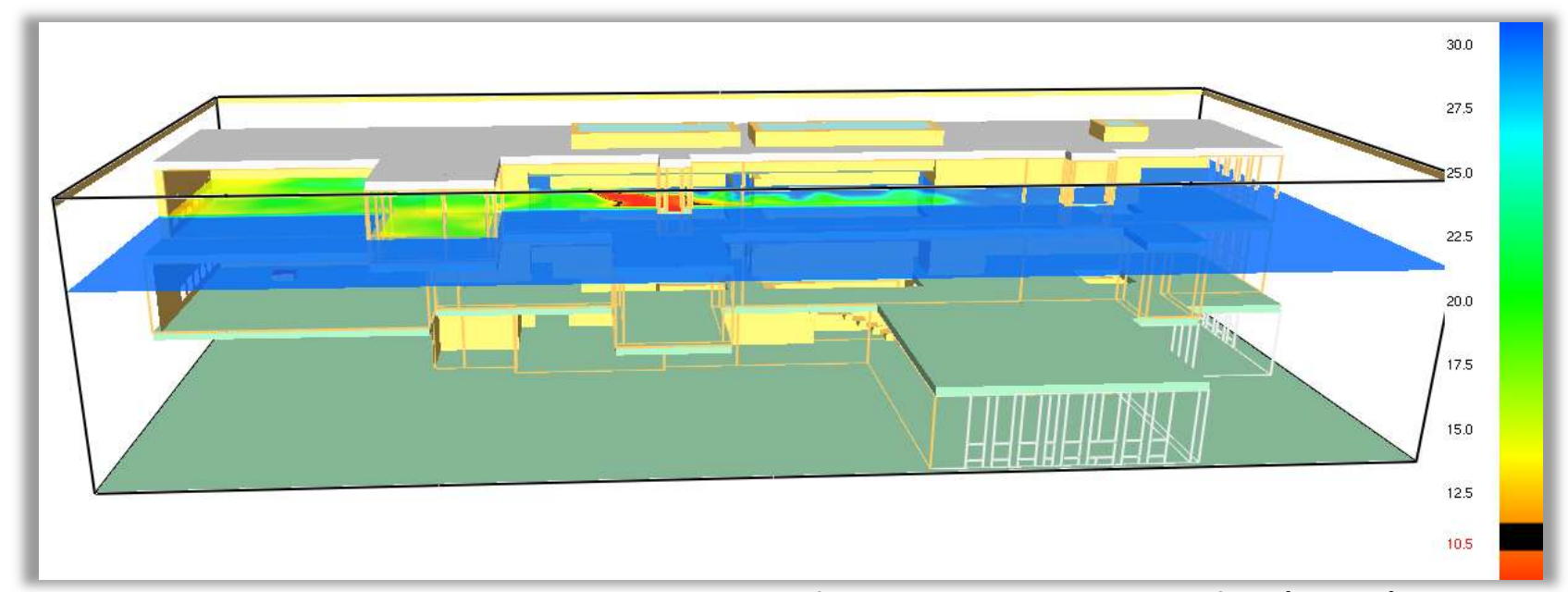

Figure 44: Rendering showing visibility slice 6' above highest walking surface (level 3)

Level 3 Fire Scenario: Tenability Maintained

The smoke control system maintains tenability through the level 3 fire scenario. Table 16 shows conditions 6 ' above each floor. Figure 45 is a rendering showing the visibility 6 feet above the fire floor and the highest walking surface open to the atrium.

Table 16: Level 3 Fire Scenario Tenability Summary

\begin{tabular}{|l|c|c|c|c|}
\hline Level 3 Fire Scenario & \multicolumn{3}{|l|}{$\begin{array}{l}\text { Minimum Tenability } \\
\text { Conditions at 6' above floor }\end{array}$} & \multicolumn{3}{|c|}{$\begin{array}{l}\text { Conditions 6' Above Floor } \\
\text { Walking Surface at 1,200 (s) }\end{array}$} \\
\hline Fire Scenario & & Level 1 & Level 2 & Level 3 \\
\hline Temperature (c) & 100 & N/A & N/A & 30 \\
\hline CO Concentration (ppm) & 1,000 & N/A & N/A & 8 \\
\hline Visibility (m) & 10 & N/A & N/A & 10 \\
\hline
\end{tabular}

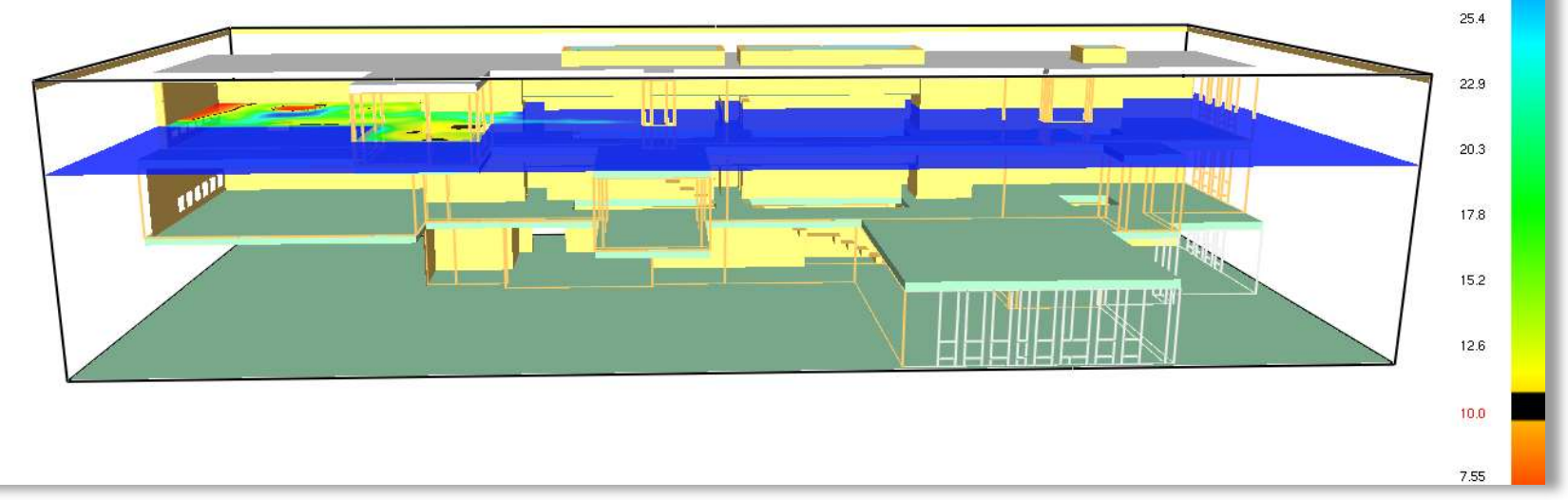

Figure 45: Rendering showing visibility slice 6' above floor of fire origin and highest walking surface (level 3) 


\subsubsection{CFD Uncertainty:}

The CFD models were set up to provide a high level understanding of what would be required to provide a working smoke control system in the Burke. The models were not sufficiently detailed to be used for an actual smoke control design. The two major limitations were mesh size and failure to consider weather conditions.

Due to computing limitations, the mesh size used was 24 inches. This is a very coarse mesh for this size of building. A sensitivity analysis was ran using a 12 -inch mesh and the smoke control system had performed noticeably better however it had taken over 8 days to run one simulation. The amount of times this model had to be run made it unrealistic to use the finer mesh and because the system ran better with the finer mesh it was assumed that the coarser mesh would provide a more conservative design.

Weather conditions were not considered to simplify the design. This can be acceptable when makeup vents are located on a single side of the building but the final layout and of natural makeup air vents on the Burke would necessitate an analysis on the affects of wind and temperature to the system. With the vents located on all sides of the building and at different elevations, winds blowing from different directions would change the effectiveness of the makeup air vents.

The uncertainty involved with any smoke control system and the excessive design changes that would have been required to meet section 404 drove the Burke design team to pursue an alternate design that would eliminate these requirements. 


\subsection{Alternate Atrium Design:}

An alternate design is used on the Burke to eliminate the atrium provisions of section 404 . The alternate design uses horizontal and vertical fire rated assemblies to create separation so that the exhibit areas are no longer required to be designed as atriums. This is achieved with a fire barrier and rated vertical shutters at level 1 and horizontal fire shutters at level three. This separation transforms a 4-story atrium into a two-story opening allowed per section 712.1.8. Figure 46 is a schematic section showing the locations of these separations and Figure 47 shows a picture of the horizontal shutter used at level 3

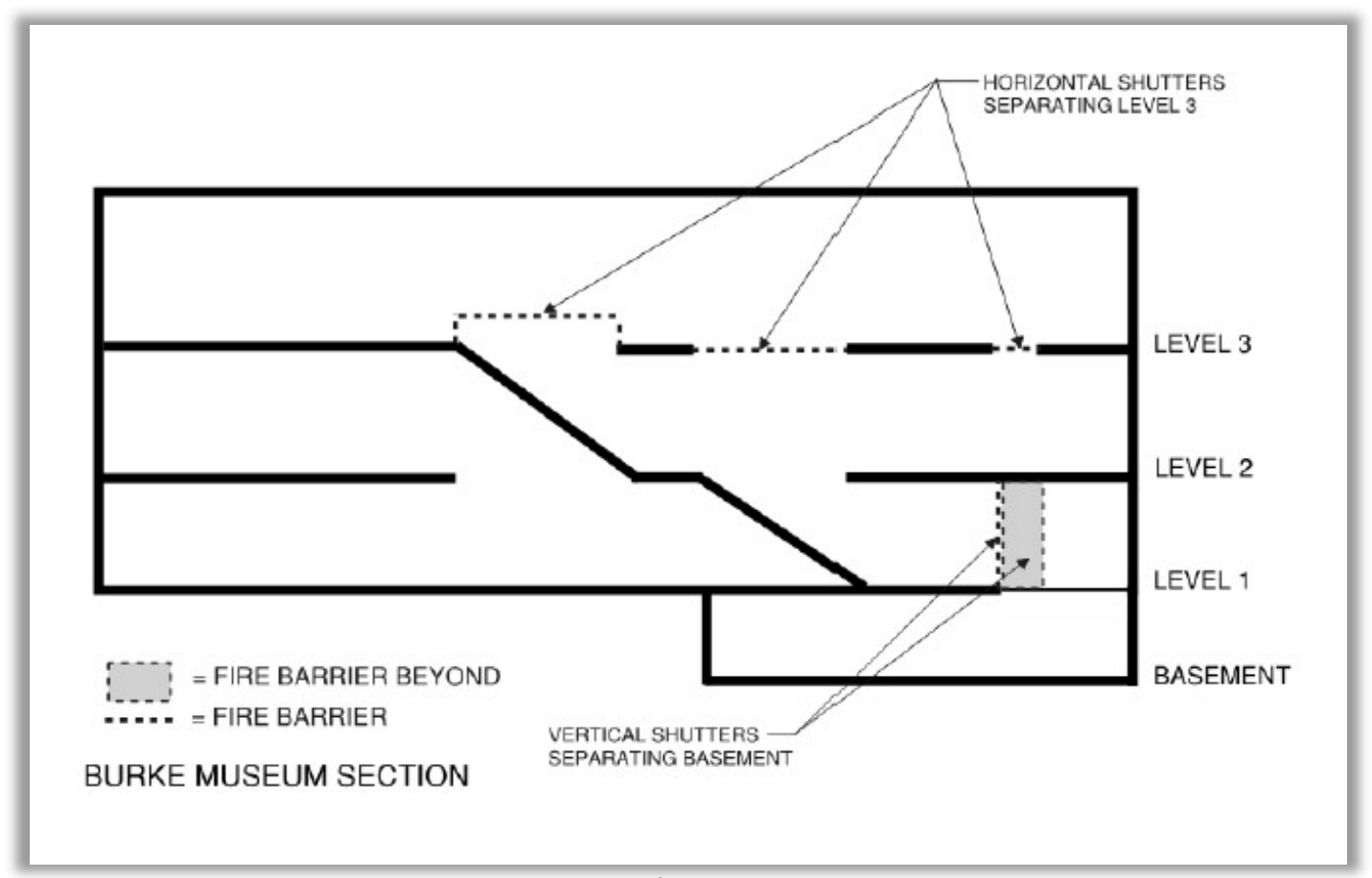

Figure 46: Schematic section of Burke showing rated separations.

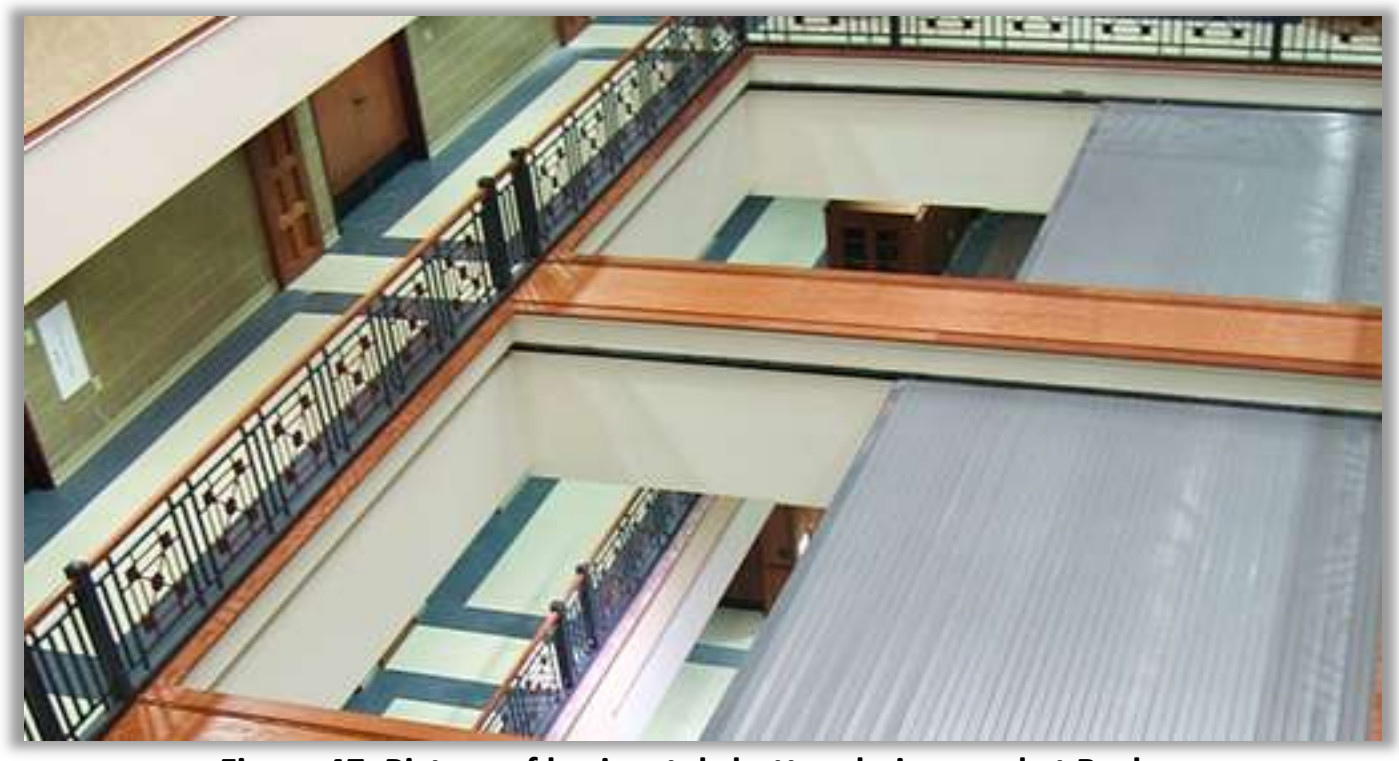

Figure 47: Picture of horizontal shutters being used at Burke 


\subsubsection{IBC Justification:}

Section 712.1.8 (Figure 48) allows for two story openings that are separated from any other openings by construction conforming to required shaft enclosures.

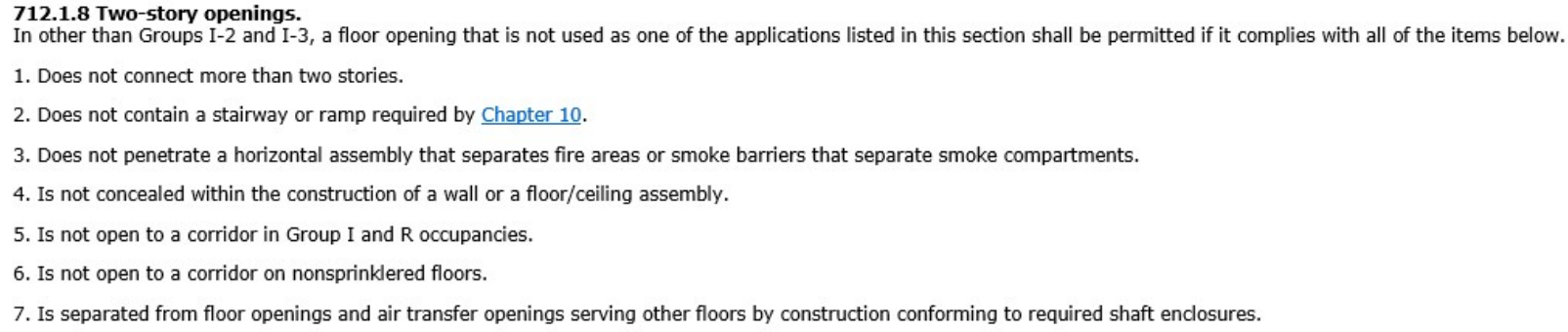

Figure 48: Excerpt from the 2012 International Building Code

Section 713.2 requires that shaft enclosures be constructed as fire barriers in accordance with Section 707 or horizontal assemblies in accordance with Section 711 . Section 713.4 requires shaft enclosures to have a fire-resistance rating of not less than 1 hour where connecting less than four stories. Section 711.3 requires the fire-resistance rating of the floor assemblies to be not less than that required by the building type. The Burke is building type IIB which does not require floors to be rated. However, because the purpose of this design is to create 1-hour separation, the floor assemblies are rated for 1hour. The Burke uses 1-hour rated fire barriers and horizontal assemblies to separate the basement level from level 1 and level 3 from level 2 . This results in a single, two-story space that is compliant with section 712.1 .8 and is not bound by the atrium requirements of section 404 .

The separation between the basement and level 1 is shown in figure 49 and is accomplished with a 1hour fire barrier and two 1-hour rated vertical coiling fire doors. This separation is in complete compliance with section 707. The floor separating the basement from level one and the basement from level 2 have fire resistance ratings of 1-hour.

The separation between level 2 and level 3 is shown in Figure 50 and is accomplished with a 1-hour rated floor and 2-hour rated horizontal fire shutters.

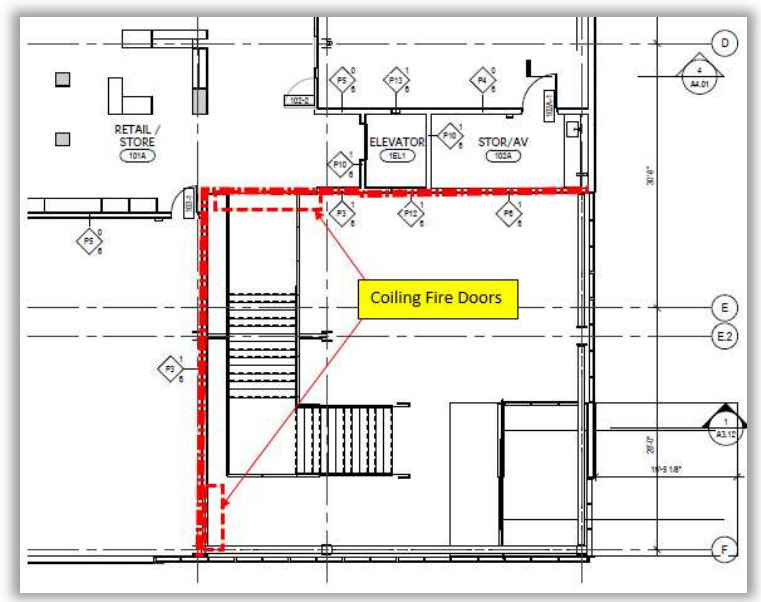

Figure 49: Level 1 plan showing separation

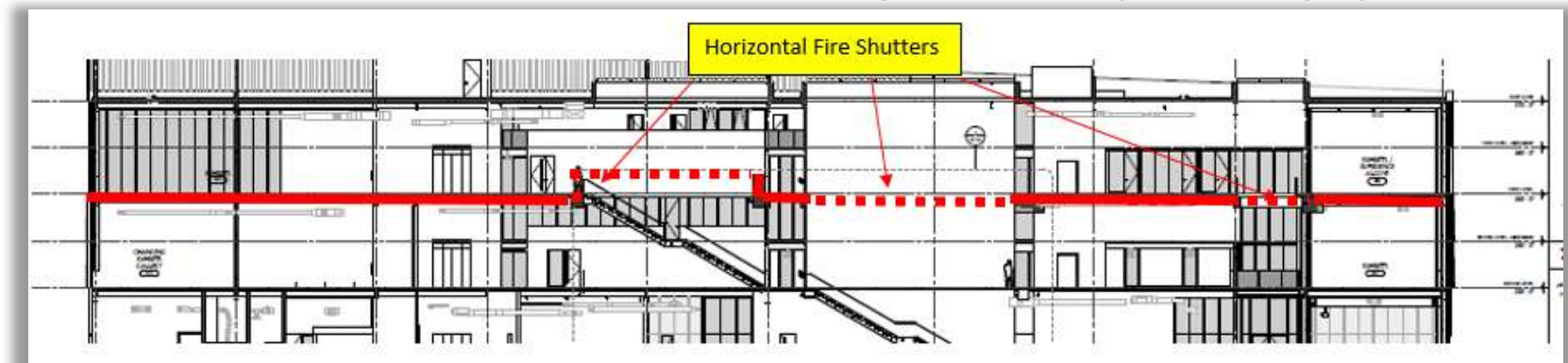

Figure 50: Section showing rated separation between levels 2 and 3 
Section 711.8 states that floor fire door assemblies shall be tested in accordance with NFPA 288. NFPA 288 is a test for a small structural floor fire door assembly designed to accommodate heavy loads such as equipment and people in order to maintain the integrity of a structural assembly. The horizontal fire shutter is not meant to act as part of the floor assembly. Instead, the horizontal shutter acts as a fire and smoke rated protective designed to stop the passage of smoke and fire through the vertical opening. As such, the horizontal shutter is tested as an opening protective with NFPA 252/UL 10B per section 716.5.2. Below is a summary of the pertinent difference between NFPA 288 and NFPA 252/UL $10 \mathrm{~B}$.

Section 6.3 of NFPA 288 calls for a superimposed load to be applied to the specimen throughout the duration of the test to simulate the maximum load condition. Section 6.3.1 defines this load to be the maximum load allowed by the limiting condition of the design. Section 6.3.2 tempers this requirement by allowing a specific load condition other than the maximum permitted load condition to be tested. Considering there is no load requirement on the proposed installation, NFPA 288 would not actually require the door be tested under a load.

Section 8.1.3 of NFPA 288 requires that the transmission of heat through the specimen during the classification period shall not raise the average temperature on its unexposed surface more than 250 degrees $\mathrm{F}$ above its initial temperature. The temperature rise requirement is part of this standard to ensure that a fuel load placed on the unexposed side of the fire door will not be ignited from a fire on the lower floor. The horizontal shutter in this building will remain open under normal conditions and will only activate and close when a fire is detected. This design will prohibit the placement of a fuel load on the unexposed side of the fire door eliminating the need to limit transmission of heat through the door. NFPA 252 does limit flaming on the unexposed side of the specimen which is the purpose of an opening protective.

Section 6.2 of NFPA 288 requires floor fire doors be tested under combustion pressures of $0.01 \mathrm{in}$. wg. NFPA 252 does not have this requirement but the horizontal configuration of the fire door during testing created a condition where the door was exposed to combustion pressures. During the testing of the horizontal shutters, combustion pressures of over 0.02 in.wg. were measured, exceeding NFPA 288 requirements

NFPA 252 has the added requirement of a hose stream test, which is not part of NFPA 288. Per section 6.2.1. Within the 2 minutes immediately following the fire test, the fire-exposed side of the door assembly shall be subjected to the impact, erosion and cooling effects of a standard hose stream. Annex Section B-13 adds further commentary on the importance of the hose stream test.

The horizontal shutter is UL and ITS tested as a 2-hour fire and smoke rated assembly to UL10B (Standard for Fire Tests of Door Assemblies) and UL1784 (Standard for Air Leakage Tests of Door Assemblies). These ratings exceed the minimum requirements as indicated in Sections 713.4 and Table 7.16.5.

The horizontal assembly self-closes mechanically by pre-charged, forced torsion spring which is held in the open position by an electro-magnetic brake. When activated by a smoke detector, fire alarm and/or loss of power the brake is released and the assembly automatically self closes as it is forced to the closed position by the pre-charged torsion spring at a consistent and safe governed rate of closure of 6"12 " per second, NFPA 80 requires a self-closing rate of no less than 6 " and no greater than 24 " per 
second. Should the building lose power, the electro-magnetic brake releases due to the absence of power to hold it open and the shutter automatically self closes.

In summary, a horizontal shutter tested per NFPA 252/UL 10B in the horizontal positions installed in this application provides equivalent protection as a floor fire door tested to NFPA 288 installed in manor that will allow fuel and weight load on top of it.

\subsubsection{Performance Based Analysist:}

The alternate design of the Burke is based on the horizontal fire shutter tested to NFPA 252 being equivalent to a floor fire door tested to NFPA 288 (a code appeal for this design is provided in the appendix.) Performance of the fire life safety system was not considered in the alternate design so a performance based analyst was not required or provided. This section summarizes a performance based analyst for the Burke's final design and with show whether or not it would meet a performance based criteria. The analysist will be based on the same design fire and tenability criteria used for the Smoke Control Design. Figure 51 shows the location of the design fire used for this analysts. The fire location is the $2^{\text {nd }}$ floor fire scenario used in the Smoke Control Design performance based analysist.

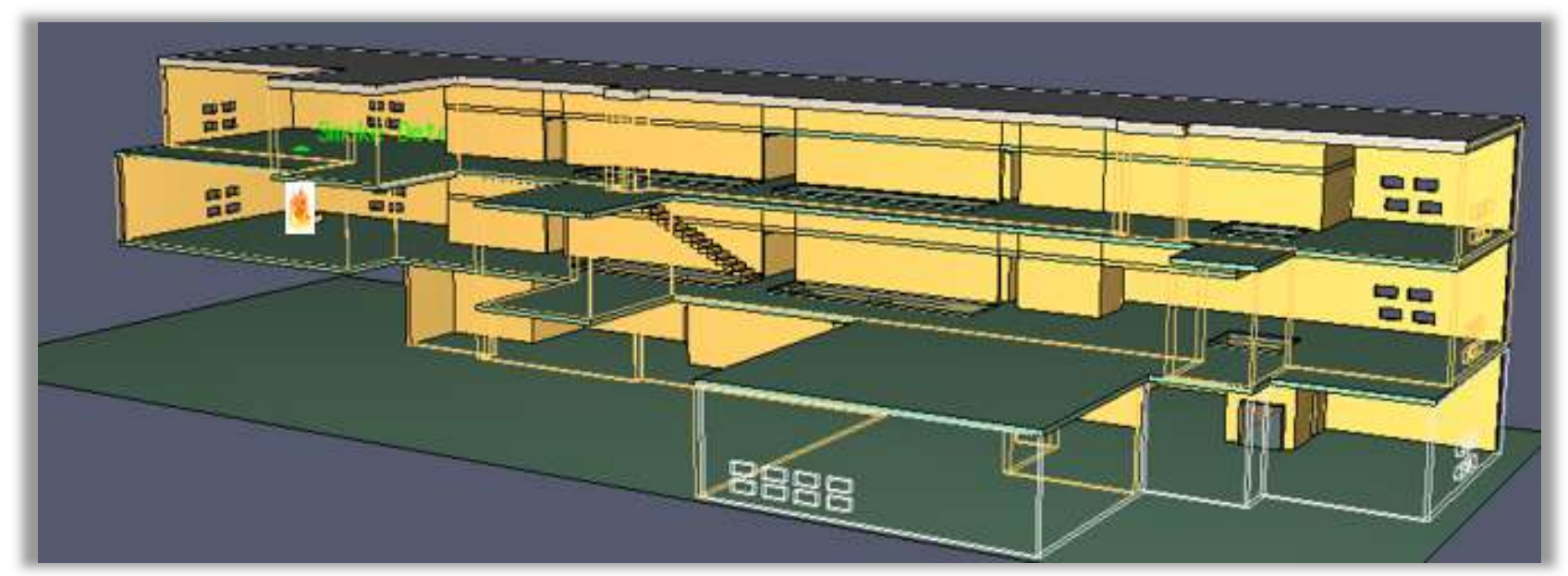

Figure 51: Rendering showing location of fire for life safety analysis

\subsubsection{Required Safe Egress Time}

The required safe egress time (RSET) is calculated for this specific fire scenario. The fire shutters will confine the smoke to the floor of fire origin so the RSET is based on the amount of time it takes occupants to exit the floor and not the entire building.

Level 2 is shown in Figure 52 and has an egress capacity of 296 occupants. The fire room of origin in this scenario is connected to an egress stair. The direct access to the stair from the fire room of origin will allow occupants to very quickly recognize that there is a fire and exit the floor. Unfortunately, the location of the fire will also cause the stair to become unusable in a short period of time. This room has an occupant load of 81 and it is assumed that half of these occupants will exit directly down the egress stair and off of the floor. The remaining 257 occupants will exit from the floor through the second egress stair and an exit access stairway located in one of the vertical openings between levels 1 and 2 . 
The Hydraulic flow rate is used to calculate required movement time. In this calculation, the exit access stair and egress stair will each egress 129 occupants from the fire floor. The confining element of this egress plan is the doorway into the egress stair which has an effective width of 2 '.

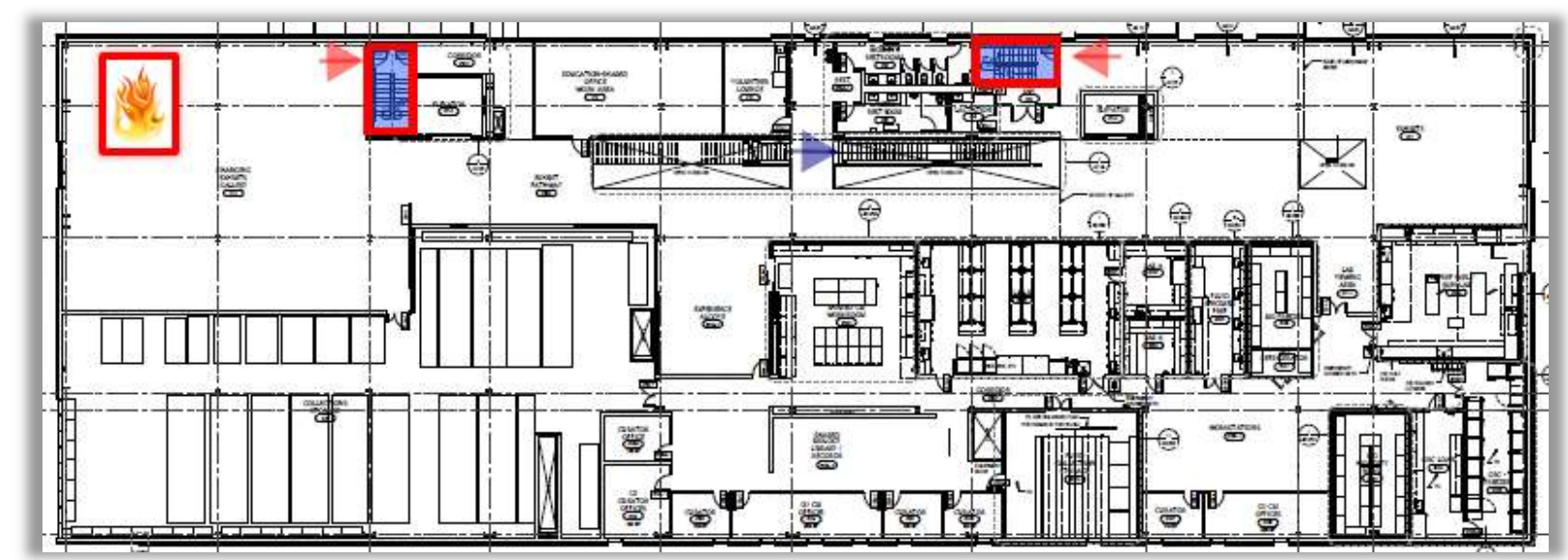

Figure 52: Level 2 floor plan showing location of fire and exits from the level 2

Summary of Calculated Egress (per Section 4.2 of the Fire Protection Handbook):

- Total RSET: 492 seconds

- Time to Notification: 30 seconds

○ Pre-Movement: 90 seconds

- Hydraulic Flow Rate of 296 Occupants Out of Stair 2: 208 seconds

- Time to controlling element: $210^{\prime} / 275(\mathrm{ft} / \mathrm{min})=46$ seconds

- Time through controlling element: $129 / 48=162$ seconds

- Safety Factor: $328 \times 0.5=164$ seconds

\subsubsection{CFD Model Results}

To monitor tenability conditions slice files for Temperature, CO Concentration and Visibility are placed 6 feet above the fire floor. Table 17 provides a summary of conditions at the fire floor and when tenability is lost. Figures 53 thru 55 show slice files of the different conditions $6^{\prime}$ above the fire floor at 492 seconds. Per these results tenability is not maintained. Minimum visibility is exceeded in the room of fire origin at 100 seconds and is lost at the entire fire floor at 253 seconds. Tenability is maintained at the other floors. 
Table 17: Tenability Summary

\begin{tabular}{|l|c|c|c|c|}
\hline & $\begin{array}{c}\text { Minimum Tenability } \\
\text { Conditions at 6' above floor }\end{array}$ & $\begin{array}{c}\text { Conditions at 6' Above } \\
\text { Floor at 492 }(\mathrm{s})\end{array}$ & $\begin{array}{c}\text { Time Tenability } \\
\text { Condition is Lost in } \\
\text { Room of Fire Origin }\end{array}$ & $\begin{array}{c}\text { Time Tenability } \\
\text { Condition is Lost at } \\
\text { Floor of Fire Origin }\end{array}$ \\
\hline Temperature & $100^{\circ} \mathrm{C}$ & $66^{\circ} \mathrm{C}$ & N/A & N/A \\
\hline CO Concentration & $1,000(\mathrm{ppm})$ & $70(\mathrm{ppm})$ & N/A & N/A \\
\hline Visibility & $10(\mathrm{~m})$ & 0.5 & $100(\mathrm{~s})$ & $253(\mathrm{~s})$ \\
\hline
\end{tabular}

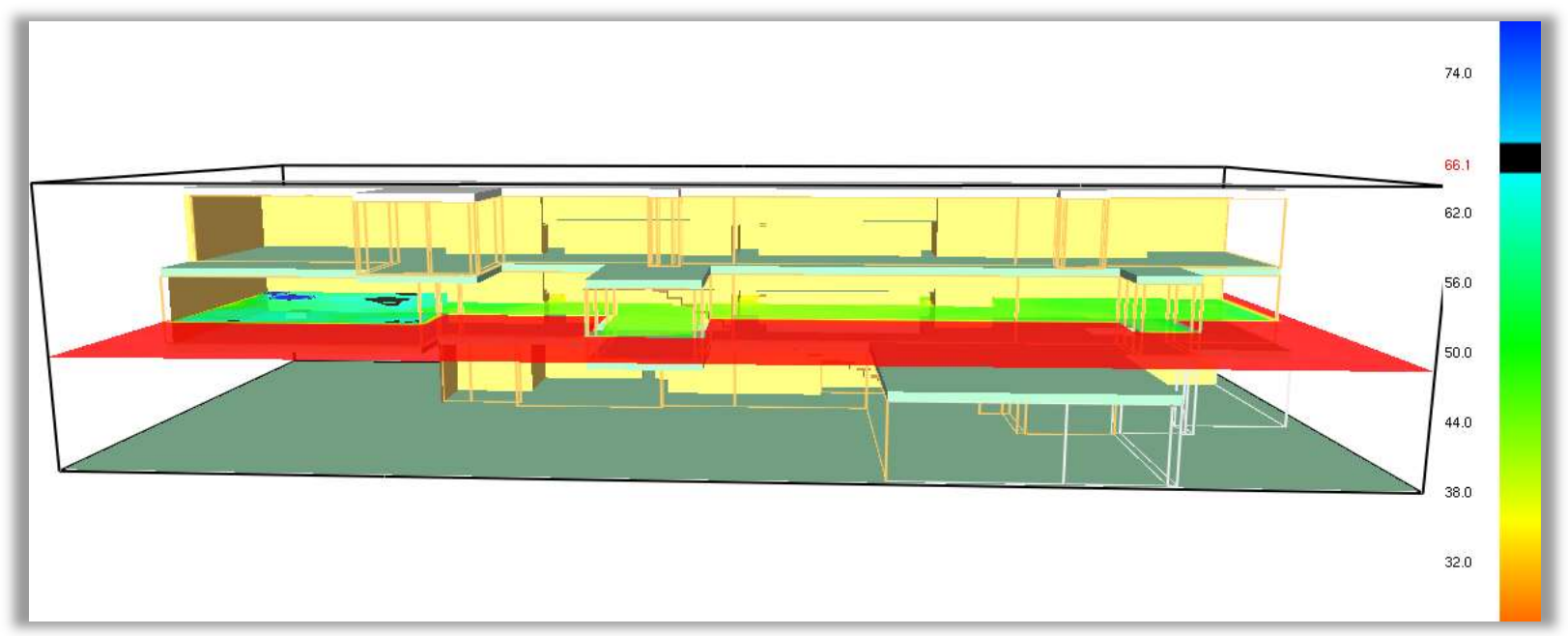

Figure 53: FDS rendering showing temperature slice, 6' above second floor at $\mathbf{4 9 2}$ seconds

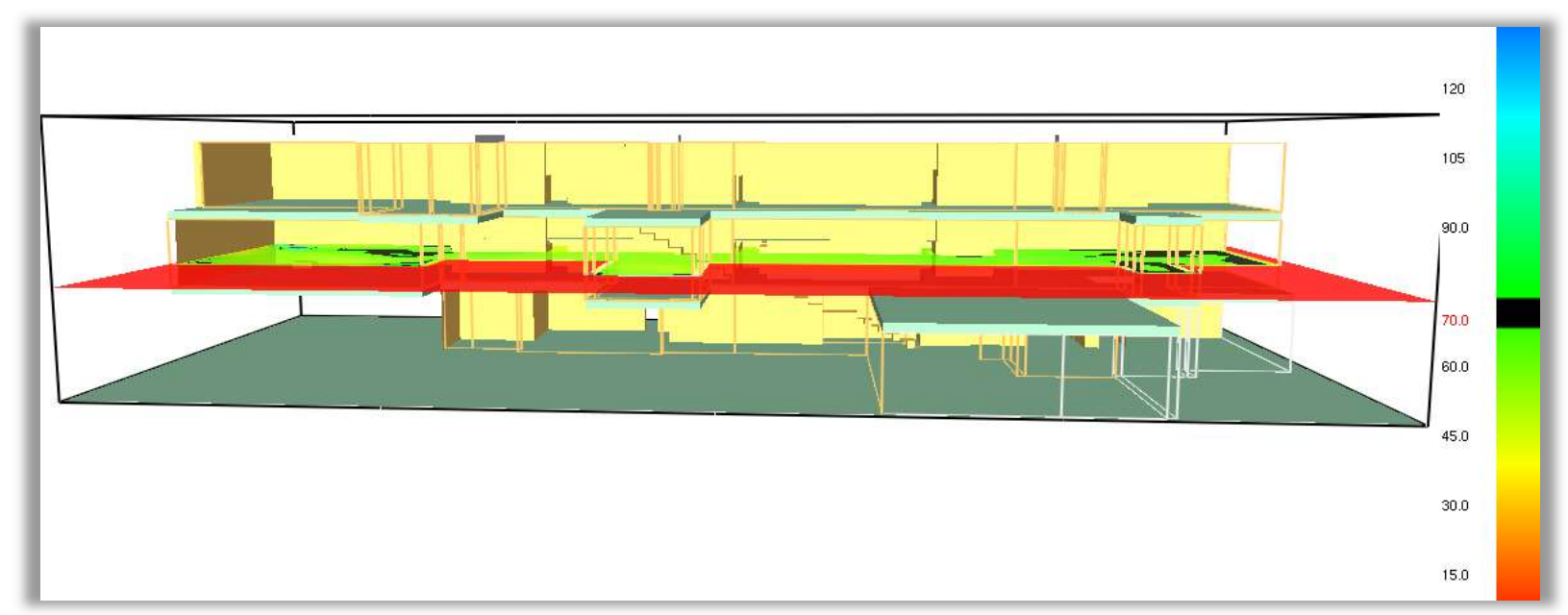

Figure 54: FDS rendering showing CO concentration slice, 6' above second floor at 492 seconds 


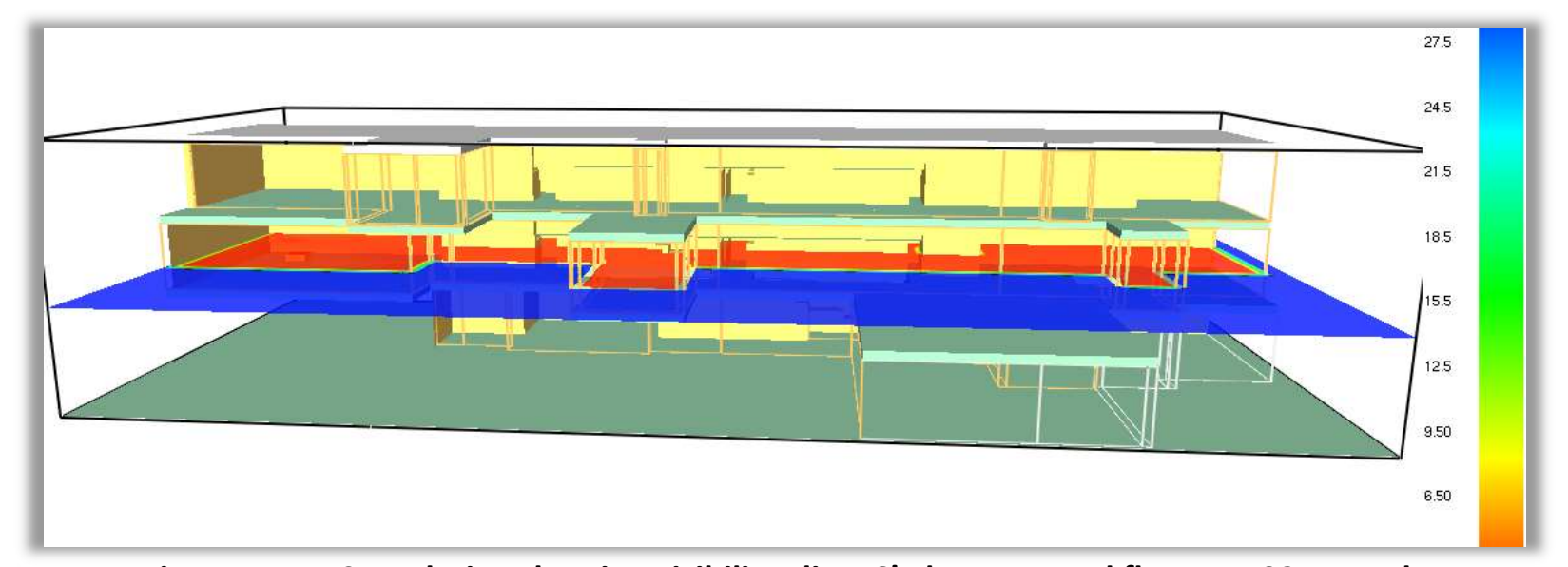

Figure 55: FDS rendering showing visibility slice, 6' above second floor at 492 seconds

\subsection{Atrium Design Comparison}

This section provides a comparison of the two design options provided in this report. The comparison is based on code compliance, impact to the building design and the life safety performance.

Neither of the designs meet the direct prescriptive requirements of the IBC but would typically be approved by the AHJ. The smoke control system in the traditional atrium design was designed to meet tenability requirements per NFPA 92B in lieu of IBC requirement to maintain the smoke layer 6 ' above the highest walking surface. NFPA 92B is referenced in the IBC and this is universally accepted when a CFD modeling is used.

The alternate atrium design uses construction consistent with shaft enclosures to create separations so that only two floors are open to each other. This design approach meets prescriptive IBC requirements however the IBC does not address how the vertical openings in this project are required to be protected. An appeal was provided and approved by the building department to use the proposed UL $10 B$ tested horizontal fire shutters. Per the alternate design criteria in section 104.11, the alternate design meets IBC requirements.

The traditional atrium design would have impacted the building's design much more than the alternate design. The only impact the alternate design had on the building's overall design was the need for the horizontal shutters at the third floor. The coil boxes for these shutters are large and all support structure had to be wrapped in drywall to provide a 1-hour fire rating. Conversely, the smoke control system would require extensive revisions to the building design. Alterations to the floor plans would also be required to meet the rest of the atrium provisions of IBC section 404 .

The traditional atrium design requires a smoke control system be provided to maintain tenability in the atrium space. The traditional atrium design met this requirement and as such met the tenability criteria to allow all occupants to exit the building.

The alternate design does not have this performance based requirement and did not maintain a tenable environment to allow occupants to exit the building when modeled in FDS. Tenable conditions are lost on the fire floor but tenability is maintained at the other floors. It is important to note that the use of a UL $10 \mathrm{~B}$ rated shutter, as approved in the appeal, did not affect the results of the tenability analysis. The 
results would have been the same if a solid floor (no opening between levels) was used in lieu of the horizontal shutter.

\section{$\underline{4 \text { Conclusion }}$}

This report shows that the Burke's design meets current building code requirements. The Burke is a mixed use occupancy with its primary occupancy being A-3. Level 1 has the highest occupant load with 462 occupants. Level 1 also has the highest exit capacity of 1,680. All floors and rooms in the Burke have adequate exit capacities and layouts.

The Burke is Type IIB construction. The IBC allows an A-3 Occupancy, of Type IIB construction with sprinklers to be 75 feet and three stories tall. With allowances for sprinklers and clear frontage, the Burke is allowed to have 35,625 SF of occupied space on any single level. The Burke's height and area are within these parameters.

The Burke has IBC compliant passive and active fire protection features. There is an $\mathrm{H}-3$ separated occupancy on level 2 that is separated with 2-hour fire barriers and is supported by 2-hour rated structure. The stair shafts in the Burke are also enclosed with 2-hour fire barriers. The Burke is equipped with an NFPA 72 compliant fire alarm system and NFPA 13 compliant sprinkler system. These are both requirements of the IBC and University of Washington Life Safety Standards.

The alternate design that uses three horizontal shutters to create separation between floors and eliminates the atrium requirements meets the IBC requirements but would not meet a performance based criteria. The open layout of the atrium space and relatively small openings between floors also make a smoke control system very difficult to design and would require significant changes to the overall building design.

\subsection{Recommendations}

The Burke Museum is IBC compliant but would not meet a performance based design criteria. To better meet a performance based criteria, the ASET would need to increase and/or the RSET would need to decrease.

The exhibit area has high ceilings and the potential for large fuel loads. The high ceilings increase sprinkler activation times which allows fires to grow larger. To reduce the potential fire size in the exhibit areas, I recommend using sprinklers that activate at a lower temperature. Installing sprinklers that activate at $57^{\circ} \mathrm{C}$ in lieu of $68^{\circ} \mathrm{C}$ would reduce a design fire's peak HRR by $600 \mathrm{~kW}$. Reducing the design fire by $600 \mathrm{~kW}$ would greatly increase the ASET.

To reduce the RSET, I recommend adding an exit stair on the lab side of the building. The current design requires all building occupants to travel through the atrium space to reach an exit. The wall separating the exhibit and lab arrears could also be upgraded to a horizontal exit by constructing it as a 2-hour fire barrier. The addition of the stair and upgrading the rating on the wall would nearly triple the exit capacity from each floor greatly decreasing the RSET. 


\section{References}

ICC-ES Report, “ESR-2397, Model WS 5.6 k-K-Factor Specific Application Window Sprinklers," February 2016

Kim, A.K and Lougheed, G.D. "Fire Protection of Windows Using Sprinklers," NRC CNRC, Construction Technology Update No. 12, December 1997

Klote et. al. "Handbook of Smoke Control Engineering," ASHRAE, 2012

NFPA, "Fire Protection Handbook" 20 $0^{\text {th }}$ Edition, National Fire Protection Associations, 2008

Richardson, J.K. and Oleszkiewicz, I. "Fire Tests on Window Assemblies Protected by Automatic Sprinklers," Fire Technology, Vol. 23, No. 2, May 1987

SFPE, "Handbook of Fire Protection Engineering," Fifth Addition, Society of Fire Protection Engineers, 2016

Society of Fire Safety, NSW Chapter, "Practice Note for Tenability Criteria in Building Fires," Version 2.0, March $3^{\text {rd }}, 2014$

University of Washington, "Burke Museum," www.burkemuseum.org, 2016

University of Washington, "Fire Alarm System Design Guide," Environmental Health and Safety, March 2015 


\section{Description of Alternate Modification}

Section 712.1.8 (included below) allows for two story openings that are separated from any other openings by construction conforming to required shaft enclosures. Section 713.2 requires that shaft enclosures be constructed as fire barriers in accordance with Section 707 or Horizontal assemblies in accordance with Section 711 . Section 713.4 requires shaft enclosures to have a fire-resistance rating of not less than 1 hour where connecting less than four stories. Section 711.3 requires the fire-resistance rating of the floor assemblies to be not less than that required by the building type.

The separation between the basement and level 1 is accomplished with a 1-hour fire barrier and 1-hour NFPA 252/UL 10B rated vertical coiling fire doors. This separation is in complete compliance with section 707. This building will be construction type IIB so per section 711.3 , the floor is not required to be rated to conform to shaft enclosure rating requirements.

The separation between level 2 and level 3 is accomplished with the floor and McKeon's H2OO and H250 Horizontal Fire Shutters rated for 2-hours with NFPA 252/UL10B and UL1784.
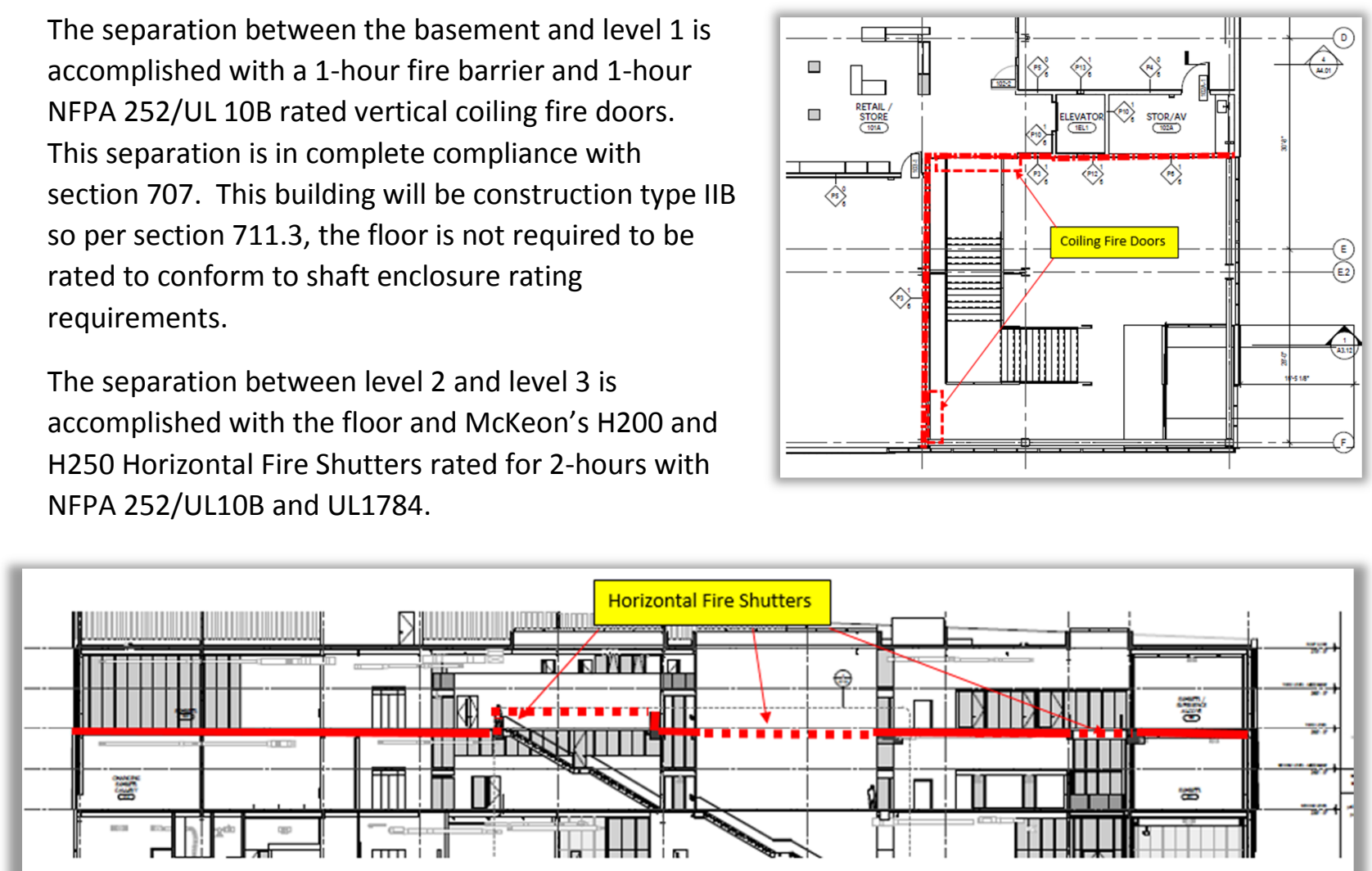

The purpose of this appeal is to get approval to use a McKeon's H200 and H250 Horizontal Fire Shtters tested to NFPA 252/UL10B in the horizontal orientation as part of the separation between level 3 and level 2. 


\section{Relevant Code Sections:}

\subsection{Construction.}

Shaft enclosures shall be constructed as fire barriers in accordance with Section 707 or horizontal assemblies in accordance with Section 711, or both.

\subsection{Openings.}

Openings in a shaft enclosure shall be protected in accordance with Section 716 as required for fire barriers. Doors shall be self- or automatic-closing by smoke detection in accordance with Section 716.5.9.3.

\subsection{Fire-resistance rating.}

The fire-resistance rating of floor and roof assemblies shall not be less than that required by the building type of construction.

\subsection{Floor fire door assemblies.}

Floor fire door assemblies used to protect openings in fire-resistance-rated floors shall be tested in accordance with NFPA 288, and shall achieve a fire-resistance rating not less than the assembly being penetrated. Floor fire door assemblies shall be labeled by an approved agency. The label shall be permanently affixed and shall specify the manufacturer, the test standard and the fire-resistance rating.

\subsubsection{Other types of assemblies.}

Fire door assemblies with other types of doors, including swinging elevator doors and fire shutter assemblies, bottom and side-hinged chute intake doors, and top-hinged chute discharge doors, shall be tested in accordance with NFPA 252 or UL 10B. The pressure in the furnace shall be maintained as nearly equal to the atmospheric pressure as possible. Once established, the pressure shall be maintained during the entire test period.

\section{Justification:}

Section 711.8 requires floor fire door assemblies used to protect openings in fire-resistance-rated floors to be tested with NFPA 288. The Burke Museum is construction type IIB and is not required to have fireresistance-rated floors. Because the floors do not have a fire-resistance-rating, section 711.8 should not apply.

NFPA 288 is a test for a small structural floor fire door assembly designed to accommodate heavy loads such as equipment and people in order to maintain the integrity of a structural assembly. The horizontal fire shutter in this design is not meant to act as part of the floor assembly. Instead, the horizontal shutter acts as a fire and smoke rated protective designed to stop the passage of smoke and fire through the vertical opening. As such, the horizontal shutter is tested as an opening protective with NFPA 252/UL 10B per section 716.5.2. Below is a summary of the pertinent difference between NFPA 288 and NFPA 252/UL 10B.

1. Section 6.3 of NFPA 288 calls for a superimposed load to be applied to the specimen throughout the duration of the test to simulate the maximum load condition. Section 6.3.1 defines this load to be the maximum load allowed by the limiting condition of the design. Section 6.3.2 tempers this requirement by allowing a specific load condition other than the maximum permitted load 
condition to be tested. Considering there is no load requirement on the proposed installation, NFPA 288 would not actually require the door be tested under a load.

2. Section 8.1.3 of NFPA 288 requires that the transmission of heat through the specimen during the classification period shall not raise the average temperature on its unexposed surface more than 250 degrees $F$ above its initial temperature. This is the same requirement for a rated floor or wall assembly and is part of this standard to ensure that a fuel load placed on the unexposed side of the fire door will not be ignited from a fire on the lower floor. The intent of this fire door is to be open under normal conditions and will only activate and close when a fire is detected. This design will prohibit the placement of a fuel load on the unexposed side of the fire door eliminating the need to limit transmission of heat through the door. NFPA 252 does limit flaming on the unexposed side of the specimen which is the purpose of an opening protective

3. Section 6.2 of NFPA 288 requires floor fire doors be tested under combustion pressures of 01 in. wg. NFPA 252 does not have this requirement but the horizontal configuration of the fire door during testing created a condition where the door was exposed to combustion pressures. During the testing of the horizontal shutters, combustion pressures of over .02 in.wg. were measured, exceeding NFPA 288 requirements

4. NFPA 252 has the added requirement of a hose stream test, which is not part of NFPA 288. Per section 6.2.1, Within the 2 minutes immediately following the fire test, the fire-exposed side of the fore door assembly shall be subjected to the impact, erosion and cooling effects of a standard hose stream. Annex Section B-13 adds further commentary on the importance of the hose stream test.

McKeon's H200/H250 is UL and ITS tested as a 2-hour fire and smoke rated assembly to UL1OB (Standard for Fire Tests of Door Assemblies) and UL1784 (Standard for Air Leakage Tests of Door Assemblies). These ratings exceed the minimum requirements as indicated in Sections 713.4 and Table 7.16.5.

The $\mathrm{H} 200$ and $\mathrm{H} 250$ horizontal assemblies self-close mechanically by pre-charged, forced torsion springs which is held in the open position by an electro-magnetic brakes. When activated by a smoke detector, fire alarm and/or loss of power the brake is released and the assembly automatically self closes as it is forced to the closed position by the pre-charged torsion spring at a consistent and safe governed rate of closure of 6 " - 12" per second, NFPA 80 requires a self-closing rate of no less than 6 "and no greater than 24 " per second. Should the building lose power, the electro-magnetic brake releases due to the absence of power to hold it open and the shutter automatically self closes. 
NFPA 92 Calculations, AtriumCalc

\section{Project: Burke Museum Axisymmetric (level 1)}

\section{Routine 1: Atrium Smoke Exhaust with an Axisymmetric Plume}

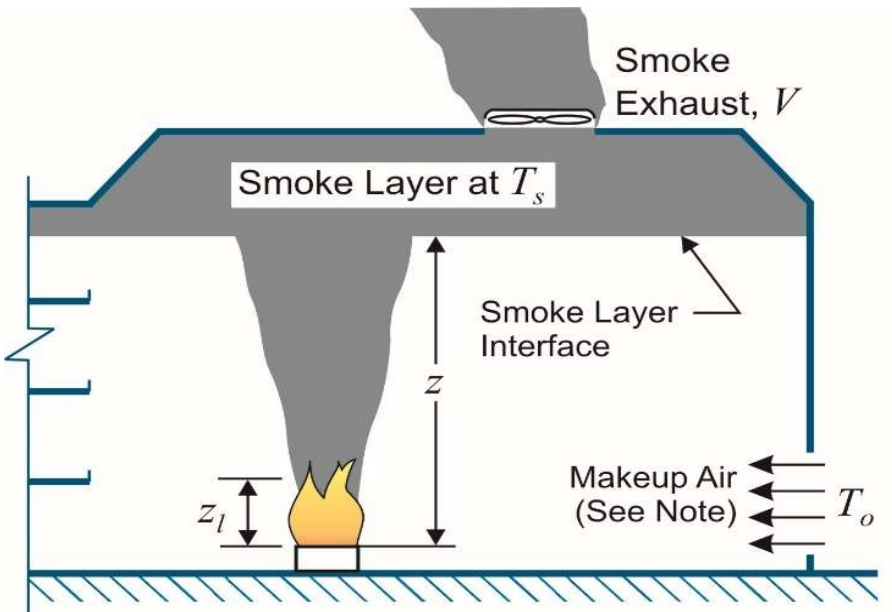

$Q_{c}=\chi Q$

$z_{l}=0.533 Q_{c}^{2 / 5}$

$m=0.022 Q_{c}^{1 / 3} z^{5 / 3}+0.0042 Q_{c} \quad$ for $z>z_{l}$

$m=0.0208 Q_{c}^{3 / 5} z \quad$ for $z \leq z_{l}$

$T_{s}=T_{o}+\frac{K_{s} Q_{c}}{m C_{p}}$

$\rho_{s}=\frac{144 p_{a t m}}{R\left(T_{s}+460\right)}$

$V=60 \mathrm{~m} / \rho_{\mathrm{s}}$

where

$C_{p} \quad=$ specific heat $\left(0.24 \mathrm{Btu} / \mathrm{lb}-{ }^{\circ} \mathrm{F}\right)$.
Notes:

1. Makeup air is shown as being supplied by an opening or openings to the outside, but it can also be supplied by mechanical fans.

2. For calculating the volumetric flow rate of smoke exhaust, a value of $K_{s}=1.0$ needs to be used except when another value of $K_{s}$ is supported by test data or an engineering analysis.

3. For smoke control design, a value of $\chi=0.7$ is almost always used, and other values should be supported by engineering data.

\begin{tabular}{|c|c|c|}
\hline Input: & 2,000 & $\mathrm{Btu} / \mathrm{s}$ \\
\hline$z=$ & 44.00 & $\mathrm{ft}$ \\
\hline$T_{o}=$ & 72.0 & ${ }^{\circ} \mathrm{F}$ \\
\hline$p_{\text {atm }}=$ & 14.70 & psi \\
\hline$K_{s}=$ & 1.0 & (See note 2 above) \\
\hline$\chi=$ & 0.70 & (Almost always 0.70$)$ \\
\hline
\end{tabular}

$Q \quad=$ heat release rate of the fire (Btu/s).

$Q_{c} \quad=$ convective portion of heat release rate of fire $(\mathrm{Btu} / \mathrm{s})$.

$z \quad=$ distance from base of fire to smoke layer interface, $(\mathrm{ft})$.

$z_{l} \quad=$ limiting elevation (ft).

$m \quad=$ exhaust mass flow $(\mathrm{lb} / \mathrm{s})$.

$R \quad=$ gas constant $\left(53.34 \mathrm{ft} \mathrm{lbf} / \mathrm{lbm} /{ }^{\circ} \mathrm{R}\right)$.

$T_{s} \quad=$ smoke layer temperature $\left({ }^{\circ} \mathrm{F}\right)$.

$T_{o} \quad=$ ambient or outdoor temperature $\left({ }^{\circ} \mathrm{F}\right)$.

$K_{s} \quad=$ fraction of convective HRR in smoke layer.

$\rho_{s} \quad=$ smoke density $\left(\mathrm{kg} / \mathrm{m}^{3}\right)$.

$p_{\text {atm }}=$ atmospheric pressure (psi).

$V \quad=$ volumetric flow of smoke exhaust $(\mathrm{cfm})$.

$\chi \quad=$ convective fraction (dimensionless).

Output: $Q_{c}=1,400 \mathrm{Btu} / \mathrm{s}$

$$
\begin{array}{rlrl}
z_{l} & = & & 9.66 \mathrm{ft} \\
m & = & 140.8 \mathrm{lb} / \mathrm{s} \\
T_{s}= & 113.4{ }^{\circ} \mathrm{F} \\
\rho_{s}= & 0.06921 \mathrm{lb} / \mathrm{ft}^{3} \\
V= & 122,105 \mathrm{cfm}
\end{array}
$$


Project: Burke Museum Axisymmetric (level 2)

Routine 1: Atrium Smoke Exhaust with an Axisymmetric Plume

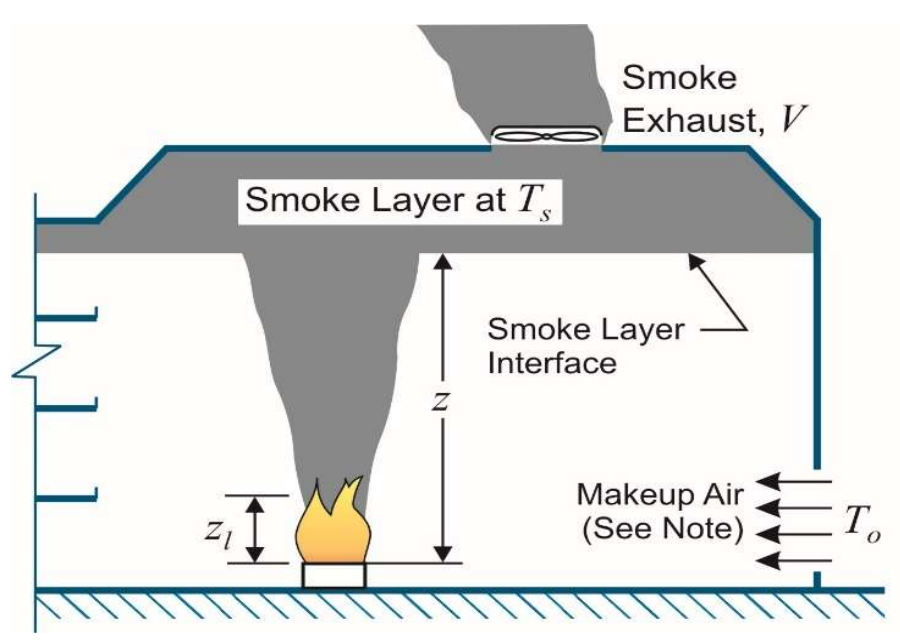

$Q_{c}=\chi Q$

$z_{l}=0.533 Q_{c}^{2 / 5}$

$m=0.022 Q_{c}^{1 / 3} z^{5 / 3}+0.0042 Q_{c} \quad$ for $z>z_{l}$

$m=0.0208 Q_{c}^{3 / 5} z$ for $z \leq z_{l}$

$T_{s}=T_{o}+\frac{K_{s} Q_{c}}{m C_{p}}$

$\rho_{s}=\frac{144 p_{\text {atm }}}{R\left(T_{s}+460\right)}$

$V=60 \mathrm{~m} / \rho_{s}$

where

$C_{p} \quad=$ specific heat $\left(0.24 \mathrm{Btu} / \mathrm{lb}-{ }^{\circ} \mathrm{F}\right)$.
Notes:

1. Makeup air is shown as being supplied by an opening or openings to the outside, but it can also be supplied by mechanical fans.

2. For calculating the volumetric flow rate of smoke exhaust, a value of $K_{s}=1.0$ needs to be used except when another value of $K_{s}$ is supported by test data or an engineering analysis.

3 . For smoke control design, a value of $\chi=0.7$ is almost always used, and other values should be supported by engineering data.

$Q \quad=$ heat release rate of the fire $(\mathrm{Btu} / \mathrm{s})$.

$Q_{c} \quad=$ convective portion of heat release rate of fire $(\mathrm{Btu} / \mathrm{s})$.

$z \quad=$ distance from base of fire to smoke layer interface, (ft).

$z_{l} \quad=$ limiting elevation ( $\left.\mathrm{ft}\right)$.

$m \quad=$ exhaust mass flow (lb/s).

$R \quad=$ gas constant $\left(53.34 \mathrm{ft} \mathrm{lbf} / \mathrm{lbm} /{ }^{\circ} \mathrm{R}\right)$.

$T_{s} \quad=$ smoke layer temperature $\left({ }^{\circ} \mathrm{F}\right)$.

$T_{o} \quad=$ ambient or outdoor temperature $\left({ }^{\circ} \mathrm{F}\right)$.

$K_{s} \quad=$ fraction of convective HRR in smoke layer.

$\rho_{s} \quad=$ smoke density $\left(\mathrm{kg} / \mathrm{m}^{3}\right)$.

$p_{\text {atm }}=$ atmospheric pressure (psi).

$V \quad=$ volumetric flow of smoke exhaust (cfm).

$\chi \quad=$ convective fraction (dimensionless).

Output: $Q_{c}=1,400 \mathrm{Btu} / \mathrm{s}$

$$
z_{l}=\quad 9.66 \mathrm{ft}
$$

$m=\quad 55.0 \mathrm{lb} / \mathrm{s}$

$T_{s}=178.0{ }^{\circ} \mathrm{F}$

$\rho_{s}=0.06220 \mathrm{lb} / \mathrm{ft}^{3}$

$V=\quad 53,078 \mathrm{cfm}$ 
Project: Burke Museum Axisymmetric (level 3)

Routine 1: Atrium Smoke Exhaust with an Axisymmetric Plume

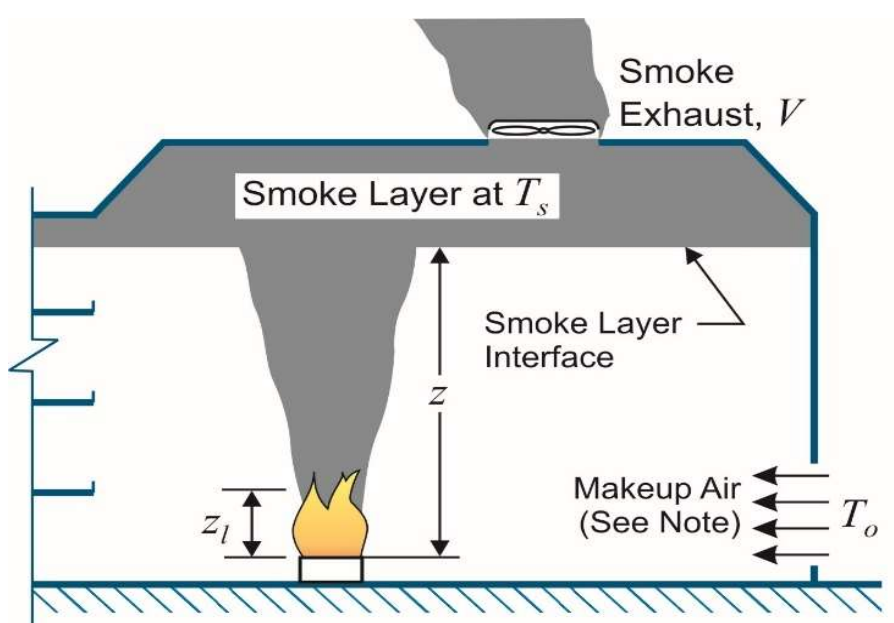

$Q_{c}=\chi Q$

$z_{l}=0.533 Q_{c}^{2 / 5}$

$m=0.022 Q_{c}^{1 / 3} z^{5 / 3}+0.0042 Q_{c} \quad$ for $z>z_{l}$

$m=0.0208 Q_{c}^{3 / 5} z \quad$ for $z \leq z_{l}$

$T_{s}=T_{o}+\frac{K_{s} Q_{c}}{m C_{p}}$

$\rho_{s}=\frac{144 p_{a t m}}{R\left(T_{s}+460\right)}$

$V=60 \mathrm{~m} / \rho_{\mathrm{s}}$

where

$C_{p} \quad=$ specific heat $\left(0.24 \mathrm{Btu} / \mathrm{lb}-{ }^{\circ} \mathrm{F}\right)$.
Notes:

1. Makeup air is shown as being supplied by an opening or openings to the outside, but it can also be supplied by mechanical fans.

2 . For calculating the volumetric flow rate of smoke exhaust, a value of $K_{s}=1.0$ needs to be used except when another value of $K_{s}$ is supported by test data or an engineering analysis.

3 . For smoke control design, a value of $\chi=0.7$ is almost always used, and other values should be supported by engineering data.

$Q \quad=$ heat release rate of the fire $(\mathrm{Btu} / \mathrm{s})$.

$Q_{c} \quad=$ convective portion of heat release rate of fire $(\mathrm{Btu} / \mathrm{s})$.

$z \quad=$ distance from base of fire to smoke layer interface, (ft).

$z_{l} \quad=$ limiting elevation (ft).

$m \quad=$ exhaust mass flow (lb/s).

$R \quad=$ gas constant $\left(53.34 \mathrm{ft} \mathrm{lbf} / \mathrm{lbm} /{ }^{\circ} \mathrm{R}\right)$.

$T_{s} \quad=$ smoke layer temperature $\left({ }^{\circ} \mathrm{F}\right)$.

$T_{o} \quad=$ ambient or outdoor temperature $\left({ }^{\circ} \mathrm{F}\right)$.

$K_{s} \quad=$ fraction of convective HRR in smoke layer.

$\rho_{s} \quad=$ smoke density $\left(\mathrm{kg} / \mathrm{m}^{3}\right)$.

$p_{\text {atm }}=$ atmospheric pressure (psi).

$V \quad=$ volumetric flow of smoke exhaust (cfm).

$\chi \quad=$ convective fraction (dimensionless). 
Project: Burke Museum, Axisymmetric Plume (Exhaust Require for a Single Level) Routine 1: Atrium Smoke Exhaust with an Axisymmetric Plume

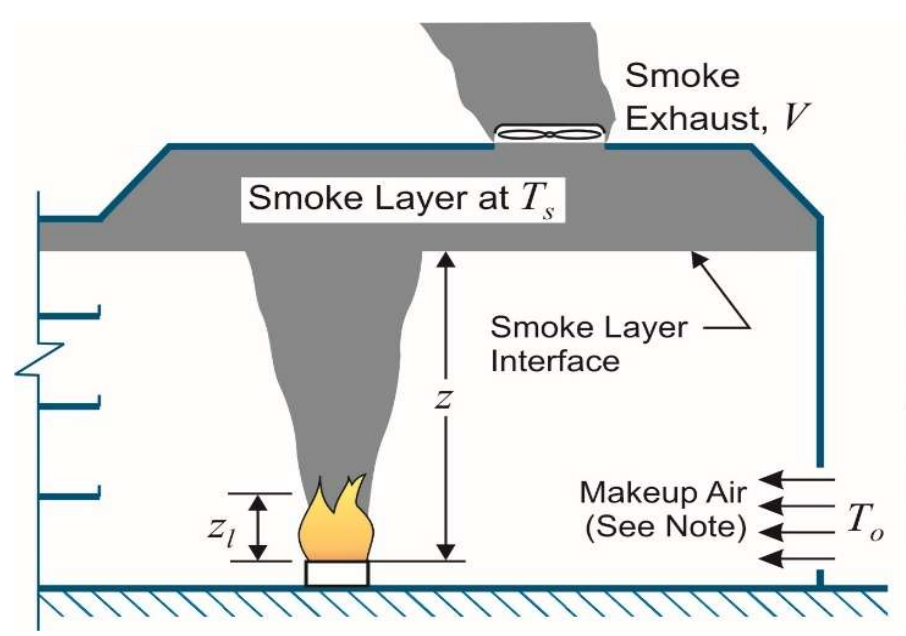

$Q_{c}=\chi Q$

$z_{l}=0.533 Q_{c}^{2 / 5}$

$m=0.022 Q_{c}^{1 / 3} z^{5 / 3}+0.0042 Q_{c} \quad$ for $z>z_{l}$

$m=0.0208 Q_{c}^{3 / 5} z$ for $z \leq z_{l}$

$T_{s}=T_{o}+\frac{K_{s} Q_{c}}{m C_{p}}$

$\rho_{s}=\frac{144 p_{a t m}}{R\left(T_{s}+460\right)}$

$V=60 \mathrm{~m} / \rho_{s}$

where

$C_{p} \quad=$ specific heat $\left(0.24 \mathrm{Btu} / \mathrm{lb}-{ }^{\circ} \mathrm{F}\right)$.
Notes:

1. Makeup air is shown as being supplied by an opening or openings to the outside, but it can also be supplied by mechanical fans.

2 . For calculating the volumetric flow rate of smoke exhaust, a value of $K_{s}=1.0$ needs to be used except when another value of $K_{s}$ is supported by test data or an engineering analysis.

3 . For smoke control design, a value of $\chi=0.7$ is almost always used, and other values should be supported by engineering data.

$Q \quad=$ heat release rate of the fire $(\mathrm{Btu} / \mathrm{s})$.

$Q_{c} \quad=$ convective portion of heat release rate of fire $(\mathrm{Btu} / \mathrm{s})$.

$z \quad=$ distance from base of fire to smoke layer interface, ( $\mathrm{ft})$.

$z_{l} \quad=$ limiting elevation (ft).

$m \quad=$ exhaust mass flow (lb/s).

$R \quad=$ gas constant $\left(53.34 \mathrm{ft} \mathrm{lbf} / \mathrm{lbm} /{ }^{\circ} \mathrm{R}\right)$.

$T_{s} \quad=$ smoke layer temperature $\left({ }^{\circ} \mathrm{F}\right)$.

$T_{o} \quad=$ ambient or outdoor temperature $\left({ }^{\circ} \mathrm{F}\right)$.

$K_{s} \quad=$ fraction of convective HRR in smoke layer.

$\rho_{s} \quad=$ smoke density $\left(\mathrm{kg} / \mathrm{m}^{3}\right)$.

$p_{\text {atm }}=$ atmospheric pressure (psi).

$V \quad=$ volumetric flow of smoke exhaust (cfm).

$\chi \quad=$ convective fraction (dimensionless).

Output: $Q_{c}=1,400 \mathrm{Btu} / \mathrm{s}$

$$
\begin{array}{rcr}
z_{l}= & 9.66 \mathrm{ft} \\
m= & 6.4 \mathrm{lb} / \mathrm{s} \\
T_{s}= & 980.1{ }^{\circ} \mathrm{F} \\
\rho_{s}= & 0.02756 \mathrm{lb} / \mathrm{ft}^{3} \\
V= & 13,986 \mathrm{cfm}
\end{array}
$$


Project: Burke Museum, Balcony Spill Plume (Level 1)

\section{Routine 2: Atrium Smoke Exhaust with a Balcony Spill Plume}

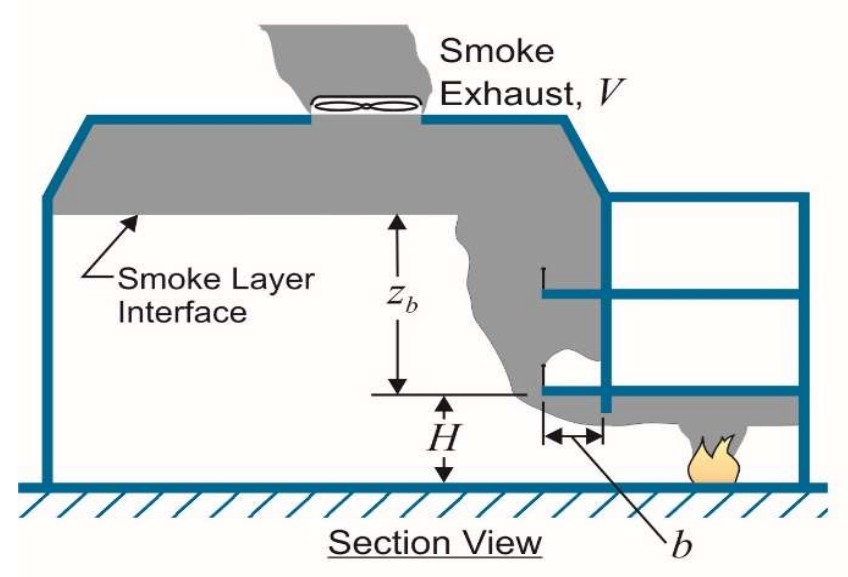

$Q_{c}=\chi Q$

For region $1\left(z_{b}<50 \mathrm{ft}\right)$ :

$$
m=0.12\left(Q W^{2}\right)^{1 / 3}\left(z_{b}+0.25 H\right)
$$

For region $2\left(z_{b} \geq 50 \mathrm{ft}\right.$ and $\left.W<32.8 \mathrm{ft}\right)$ :

$$
\begin{aligned}
m= & 0.32 Q_{c}^{1 / 3} W^{1 / 5} \\
& \left(z_{b}+0.098 W^{7 / 15} H+19.5 W^{7 / 15}-49.2\right)
\end{aligned}
$$

Region $3\left(z_{b} \geq 50 \mathrm{ft}\right.$ and $\left.32.8 \mathrm{ft} \leq W \leq 45.9 \mathrm{ft}\right)$ :

$$
\begin{aligned}
& m=0.062\left(Q_{c} W^{2}\right)^{1 / 3}\left(z_{b}+0.51 H+52\right) \\
& T_{s}=T_{o}+\frac{K_{s} Q_{c}}{m C_{p}} \\
& \rho_{s}=\frac{144 p_{a t m}}{R\left(T_{s}+460\right)} \\
& V=60 m / \rho_{s}
\end{aligned}
$$

Notes:

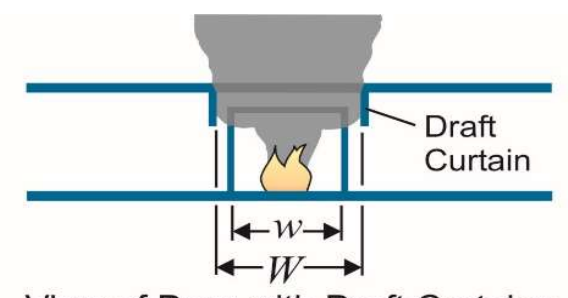

View of Door with Draft Curtains

1. Makeup air is not shown.

2. In the absence of draft curtains, the effective value of $W$ needs to be calculated as $W=w+b$. 3 . For calculating the volumetric flow rate of smoke exhaust, a value of $K_{s}=1.0$ needs to be used except when another value of $K_{s}$ is supported by test data or an engineering analysis.

4. For smoke control design, a value of $\chi=0.7$ is almost always used, and other values should be supported by engineering data.

where

$b \quad=$ distance from the opening to the balcony edge ( $\mathrm{ft}$ ).

$C_{p} \quad=$ specific heat $\left(0.24 \mathrm{Btu} / \mathrm{lb}-{ }^{\circ} \mathrm{F}\right)$.

$H \quad=$ height of balcony above fuel (ft).

$K_{s} \quad=$ fraction of convective HRR in smoke layer.

$m \quad=$ exhaust mass flow $(\mathrm{lb} / \mathrm{s})$.

$p_{\text {atm }}=$ atmospheric pressure (psi).

$Q \quad=$ heat release rate of the fire (Btu/s).

$Q_{c} \quad=$ convective heat release rate of fire $(\mathrm{Btu} / \mathrm{s})$.

$R \quad=$ gas constant $\left(53.34 \mathrm{ft} \mathrm{lbf} / \mathrm{lbm} /{ }^{\circ} \mathrm{R}\right)$.

$T_{o} \quad=$ ambient or outdoor temperature $\left({ }^{\circ} \mathrm{F}\right)$.

$T_{s} \quad=$ smoke layer temperature $\left({ }^{\circ} \mathrm{F}\right)$.

$V \quad=$ volumetric flow of smoke exhaust $(\mathrm{cfm})$.

$W \quad=$ width of the spill (ft).

$w \quad=$ width of the opening from the area of origin (ft).

$z_{b} \quad=$ height of the plume above the balcony edge ( $\mathrm{ft}$ ).

$\chi \quad=$ convective fraction (dimensionless).

$\rho_{s} \quad=$ smoke density $\left(\mathrm{lb} / \mathrm{ft}^{3}\right)$.
Output: $Q_{c}=1,400 \mathrm{Btu} / \mathrm{s}$
$m=\quad 356.5 \mathrm{lb} / \mathrm{s}$
$T_{s}=\quad 88.4{ }^{\circ} \mathrm{F}$
$\rho_{s}=0.07237 \mathrm{lb} / \mathrm{ft}^{3}$
$V=295,543 \mathrm{cfm}$ 


\section{Project: Burke Museum, Balcony Spill Plume (Level 2)}

\section{Routine 2: Atrium Smoke Exhaust with a Balcony Spill Plume}

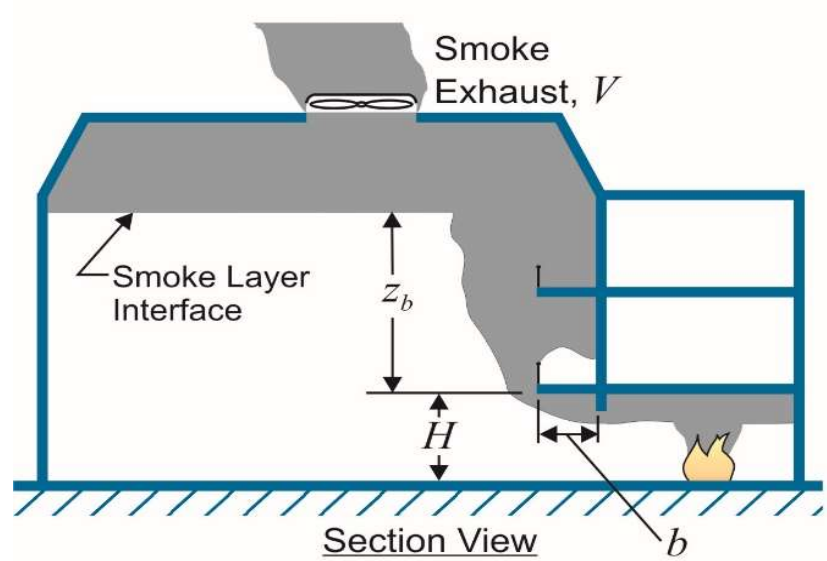

$Q_{c}=\chi Q$

For region $1\left(z_{b}<50 \mathrm{ft}\right)$ :

$m=0.12\left(Q W^{2}\right)^{1 / 3}\left(z_{b}+0.25 H\right)$

For region $2\left(z_{b} \geq 50 \mathrm{ft}\right.$ and $\left.W<32.8 \mathrm{ft}\right)$ :

$$
\begin{aligned}
m= & 0.32 Q_{c}^{1 / 3} W^{1 / 5} \\
& \left(z_{b}+0.098 W^{7 / 15} H+19.5 W^{7 / 15}-49.2\right)
\end{aligned}
$$

Region $3\left(z_{b} \geq 50 \mathrm{ft}\right.$ and $\left.32.8 \mathrm{ft} \leq W \leq 45.9 \mathrm{ft}\right)$ :

$$
\begin{aligned}
& m=0.062\left(Q_{c} W^{2}\right)^{1 / 3}\left(z_{b}+0.51 H+52\right) \\
& T_{s}=T_{o}+\frac{K_{s} Q_{c}}{m C_{p}} \\
& \rho_{s}=\frac{144 p_{a t m}}{R\left(T_{s}+460\right)} \\
& V=60 m / \rho_{s}
\end{aligned}
$$

Notes:

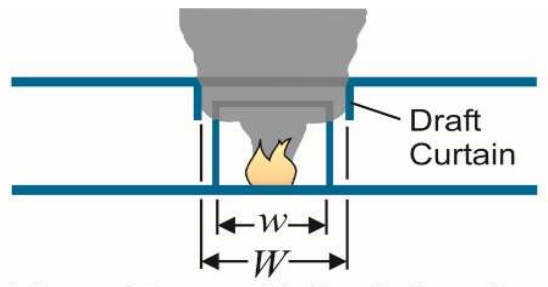

View of Door with Draft Curtains

1. Makeup air is not shown.

2. In the absence of draft curtains, the effective value of $W$ needs to be calculated as $W=w+b$. 3 . For calculating the volumetric flow rate of smoke exhaust, a value of $K_{s}=1.0$ needs to be used except when another value of $K_{s}$ is supported by test data or an engineering analysis.

4. For smoke control design, a value of $\chi=0.7$ is almost always used, and other values should be supported by engineering data.

where

$b \quad=$ distance from the opening to the balcony edge ( $\mathrm{ft}$ ).

$C_{p} \quad=$ specific heat $\left(0.24 \mathrm{Btu} / \mathrm{lb}-{ }^{\circ} \mathrm{F}\right)$.

$H \quad$ = height of balcony above fuel (ft).

$K_{s} \quad=$ fraction of convective HRR in smoke layer.

$m \quad=$ exhaust mass flow $(\mathrm{lb} / \mathrm{s})$.

$p_{\text {atm }}=$ atmospheric pressure (psi).

$Q \quad=$ heat release rate of the fire (Btu/s).

$Q_{c} \quad=$ convective heat release rate of fire $(\mathrm{Btu} / \mathrm{s})$.

$R \quad=$ gas constant $\left(53.34 \mathrm{ft} \mathrm{lbf} / \mathrm{lbm} /{ }^{\circ} \mathrm{R}\right)$.

$T_{o} \quad=$ ambient or outdoor temperature $\left({ }^{\circ} \mathrm{F}\right)$.

$T_{s} \quad=$ smoke layer temperature $\left({ }^{\circ} \mathrm{F}\right)$.

$V \quad=$ volumetric flow of smoke exhaust $(\mathrm{cfm})$.

$W \quad=$ width of the spill (ft).

$w \quad=$ width of the opening from the area of origin (ft).

$z_{b} \quad=$ height of the plume above the balcony edge ( $\mathrm{ft}$ ).

$\chi \quad=$ convective fraction (dimensionless).

$\rho_{s} \quad=$ smoke density $\left(\mathrm{lb} / \mathrm{ft}^{3}\right)$.
Output: $Q_{c}=1,400 \mathrm{Btu} / \mathrm{s}$
$m=133.7 \mathrm{lb} / \mathrm{s}$
$T_{s}=115.6{ }^{\circ} \mathrm{F}$
$\rho_{s}=0.06894 \mathrm{lb} / \mathrm{ft}^{3}$
$V=116,341 \mathrm{cfm}$

Note: Flow is in region 1. 


\section{Project: Burke Museum, Balcony Spill Plume (Level 1)}

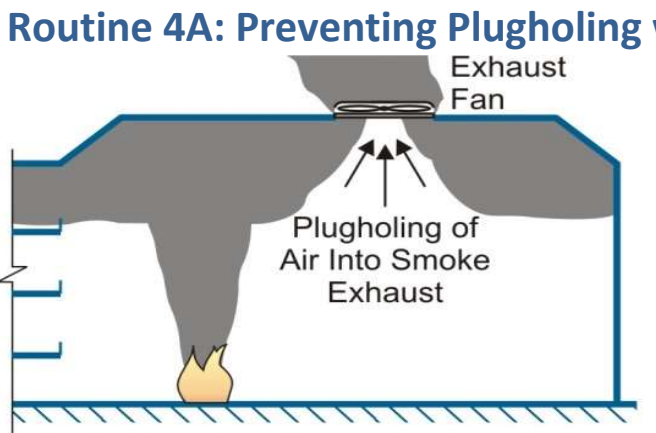

Plugholing Can Cause System Failure
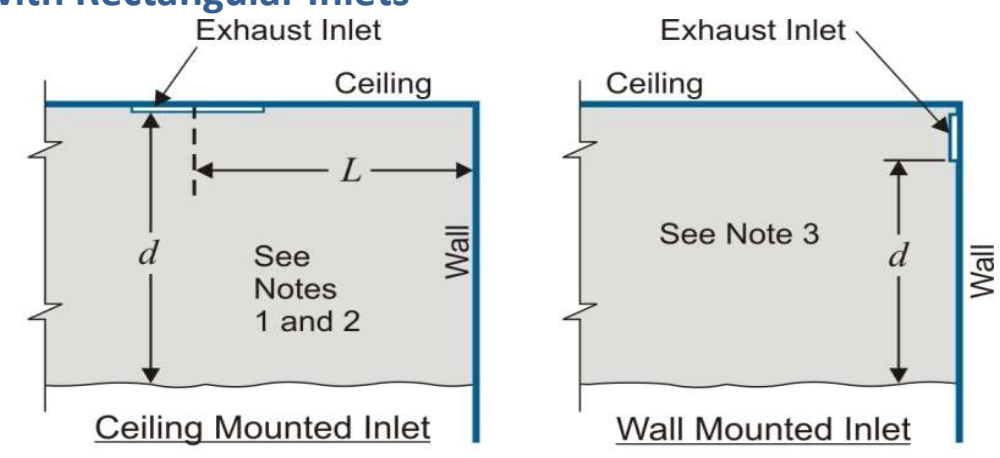

Notes:

1. For a ceiling mounted exhaust inlet with $L<2 D_{i}, \gamma=0.5$.

2. For a ceiling mounted exhaust inlet with $L \geq 2 D_{i}, \gamma=1$.

3. For a wall mounted exhaust inlet, $\gamma=0.5$.

4. $d / D_{i}$ must be greater than 2 .

5. $V_{e}$ must be less than or equal to $V_{\max }$.

6. The edge-to-edge distance between inlets must not be less than $S_{\text {min }}$.

7. For plugholing calculations, a value of $K_{s}=0.5$ needs to be used except

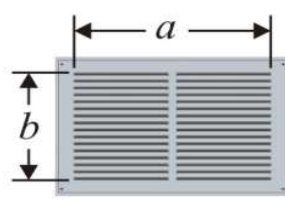

Rectangular Inlet Grille when another value of $K_{s}$ is supported by test data or an engineering analysis.

where

$$
\begin{aligned}
& T_{s}=T_{o}+\frac{K_{s} Q_{c}}{m C_{p}} \quad\left(T_{s} \& T_{o} \text { are in }{ }^{\circ} \mathrm{C}\right) \\
& V_{\max }=452 \gamma d^{5 / 2}\left(\frac{T_{s}-T_{o}}{T_{o}}\right)^{1 / 2} \quad \begin{array}{c}
\left(T_{s} \& T_{o}\right. \\
\text { are in } \left.{ }^{\circ} \mathrm{R}\right)
\end{array} \\
& D_{i}=\frac{2 a b}{a+b} \\
& S_{\min }=0.065 V_{e}^{1 / 2}
\end{aligned}
$$

$$
\begin{array}{ll}
a & =\text { length of the inlet }(\mathrm{ft}) . \\
A_{f} & =\text { free area of inlet grille }\left(A_{f}=a b A_{r}\right)\left(\mathrm{ft}^{2}\right) . \\
A_{r} & =\text { ratio of free area to total grille area. } \\
b & =\text { width of the inlet }(\mathrm{ft}) . \\
C_{p} & =\text { specific heat }\left(0.24 \mathrm{Btu} / \mathrm{lb}-{ }^{\circ} \mathrm{F}\right) . \\
d & =\text { depth of smoke layer below the lowest }
\end{array}
$$

point of the exhaust inlet (ft).

$D_{i} \quad=$ effective diameter of the inlet ( $\mathrm{ft}$ ).

$K_{s} \quad=$ fraction of convective HRR in smoke layer.

$m \quad=$ exhaust mass flow $(\mathrm{lb} / \mathrm{s})$.

$N \quad=$ number of inlets (dimensionless).

$Q_{c} \quad=$ convective heat release rate of fire $(\mathrm{Btu} / \mathrm{s})$.

$S_{\min } \quad=$ minimum edge-to-edge separation between inlets $(\mathrm{ft})$.

$T_{o} \quad=$ ambient temperature $\left({ }^{\circ} \mathrm{F}\right.$ or $\left.{ }^{\circ} \mathrm{R}\right)$.

$T_{s} \quad=$ temperature of smoke layer $\left({ }^{\circ} \mathrm{F}\right.$ or $\left.{ }^{\circ} \mathrm{R}\right)$.

$V \quad=$ volumetric flow of smoke exhaust $(\mathrm{cfm})$.

$V_{e} \quad=$ volumetric flow rate of one exhaust inlet $\left(V_{e}=V / N\right)(\mathrm{cfm})$.

$v_{i} \quad=$ average velocity at inlet $\left(v_{i}=V_{e} / A_{f}\right)$ (fpm).

$V_{\max } \quad=$ maximum volumetric flow rate without plugholing (cfm).

$\gamma \quad=$ exhaust location factor (dimensionless).

$$
\begin{aligned}
& \text { Input: } Q_{c}=2000 \mathrm{Btu} / \mathrm{s} \\
& T_{o}=72.0{ }^{\circ} \mathrm{F} \\
& m=100.30 \mathrm{lb} / \mathrm{s} \\
& V=295,543 \mathrm{cfm} \\
& d=\quad 12.00 \mathrm{ft} \\
& \gamma=1.0(\text { See notes } 1,2 \text { and 3) } \\
& K_{s}=0.5 \text { (See note } 7 \text { above) } \\
& a=\quad 10.00 \mathrm{ft} \\
& b=\quad 40.00 \mathrm{ft} \\
& N=2 \text { Number of Inlets } \\
& A_{r}=0.50 \text { (In the absence of better data, } 0.5 \text { is suggested.) }
\end{aligned}
$$

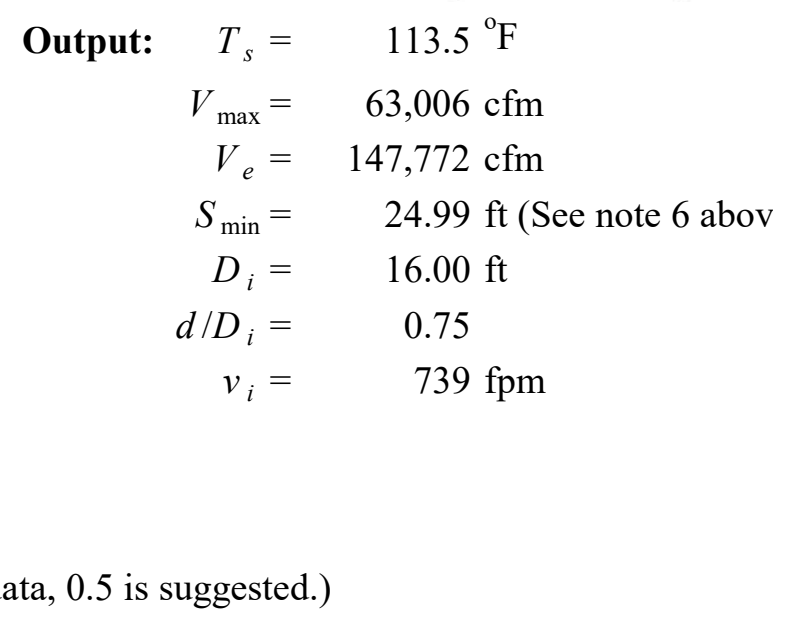

Check 1: CAUTION: The requirement of note 4 above is not satisfied.

Check 2: CAUTION: The requirement of note 5 above is not satisfied. 


\section{Project: Burke Museum, Balcony Spill Plume (Level 2)}

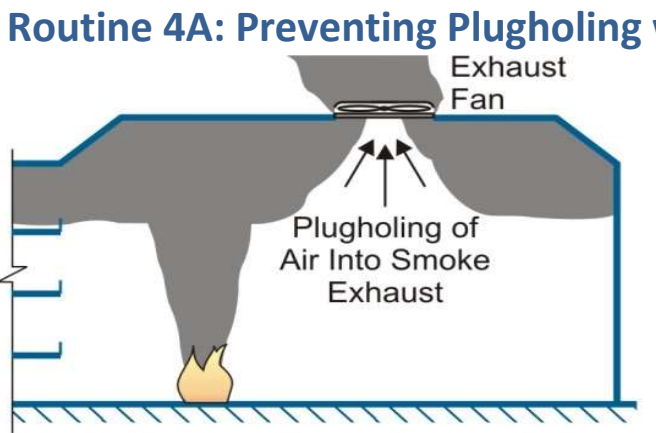

Plugholing Can Cause System Failure
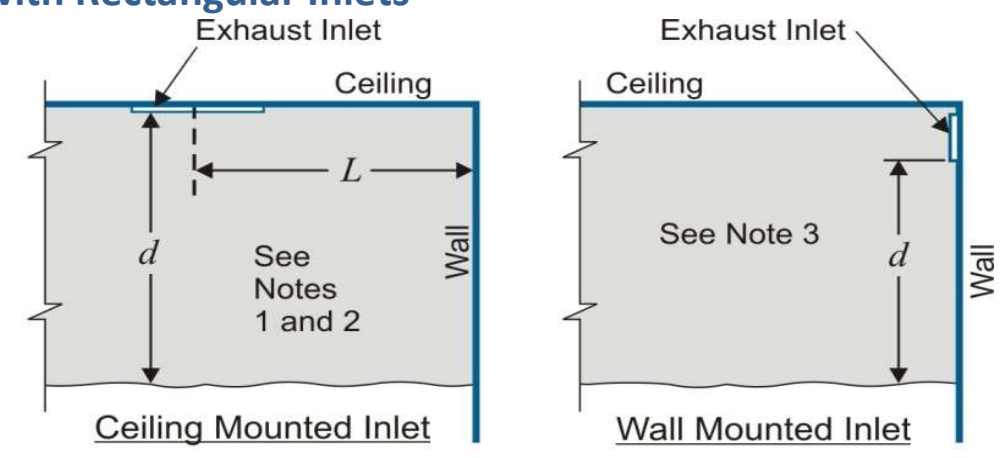

Notes:

1. For a ceiling mounted exhaust inlet with $L<2 D_{i}, \gamma=0.5$.

2. For a ceiling mounted exhaust inlet with $L \geq 2 D_{i}, \gamma=1$.

3. For a wall mounted exhaust inlet, $\gamma=0.5$.

4. $d / D_{i}$ must be greater than 2 .

5. $V_{e}$ must be less than or equal to $V_{\max }$.

6. The edge-to-edge distance between inlets must not be less than $S_{\text {min }}$.

7. For plugholing calculations, a value of $K_{s}=0.5$ needs to be used except

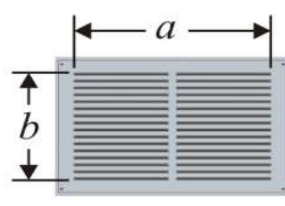

Rectangular Inlet Grille when another value of $K_{s}$ is supported by test data or an engineering analysis.

where

$$
\begin{aligned}
& T_{s}=T_{o}+\frac{K_{s} Q_{c}}{m C_{p}} \quad\left(T_{s} \& T_{o} \text { are in }{ }^{\circ} \mathrm{C}\right) \\
& V_{\max }=452 \gamma d^{5 / 2}\left(\frac{T_{s}-T_{o}}{T_{o}}\right)^{1 / 2} \quad \begin{array}{c}
\left(T_{s} \& T_{o}\right. \\
\text { are in } \left.{ }^{\circ} \mathrm{R}\right)
\end{array} \\
& D_{i}=\frac{2 a b}{a+b} \\
& S_{\min }=0.065 V_{e}^{1 / 2}
\end{aligned}
$$

$$
\begin{array}{ll}
a & =\text { length of the inlet }(\mathrm{ft}) . \\
A_{f} & =\text { free area of inlet grille }\left(A_{f}=a b A_{r}\right)\left(\mathrm{ft}^{2}\right) . \\
A_{r} & =\text { ratio of free area to total grille area. } \\
b & =\text { width of the inlet }(\mathrm{ft}) . \\
C_{p} & =\text { specific heat }\left(0.24 \mathrm{Btu} / \mathrm{lb}-{ }^{\circ} \mathrm{F}\right) . \\
d & =\text { depth of smoke layer below the lowest }
\end{array}
$$

point of the exhaust inlet (ft).

$D_{i} \quad=$ effective diameter of the inlet ( $\mathrm{ft}$ ).

$K_{s} \quad=$ fraction of convective HRR in smoke layer.

$m \quad=$ exhaust mass flow $(\mathrm{lb} / \mathrm{s})$.

$N \quad=$ number of inlets (dimensionless).

$Q_{c} \quad=$ convective heat release rate of fire $(\mathrm{Btu} / \mathrm{s})$.

$S_{\min } \quad=$ minimum edge-to-edge separation between inlets $(\mathrm{ft})$.

$T_{o} \quad=$ ambient temperature $\left({ }^{\circ} \mathrm{F}\right.$ or $\left.{ }^{\circ} \mathrm{R}\right)$.

$T_{s} \quad=$ temperature of smoke layer $\left({ }^{\circ} \mathrm{F}\right.$ or $\left.{ }^{\circ} \mathrm{R}\right)$.

$V \quad=$ volumetric flow of smoke exhaust $(\mathrm{cfm})$.

$V_{e} \quad=$ volumetric flow rate of one exhaust inlet $\left(V_{e}=V / N\right)(\mathrm{cfm})$.

$v_{i} \quad=$ average velocity at inlet $\left(v_{i}=V_{e} / A_{f}\right)$ (fpm).

$V_{\max } \quad=$ maximum volumetric flow rate without plugholing (cfm).

$\gamma \quad=$ exhaust location factor (dimensionless).

$$
\begin{aligned}
& \text { Input: } Q_{c}=2000 \mathrm{Btu} / \mathrm{s} \\
& T_{o}=72.0{ }^{\circ} \mathrm{F} \\
& m=100.30 \mathrm{lb} / \mathrm{s} \\
& V=116,331 \mathrm{cfm} \\
& d=\quad 12.00 \mathrm{ft} \\
& \gamma=1.0(\text { See notes } 1,2 \text { and 3) } \\
& K_{s}=0.5 \text { (See note } 7 \text { above) } \\
& a=\quad 10.00 \mathrm{ft} \\
& b=\quad 40.00 \mathrm{ft} \\
& N=2 \text { Number of Inlets } \\
& A_{r}=0.50 \text { (In the absence of better data, } 0.5 \text { is suggested.) }
\end{aligned}
$$

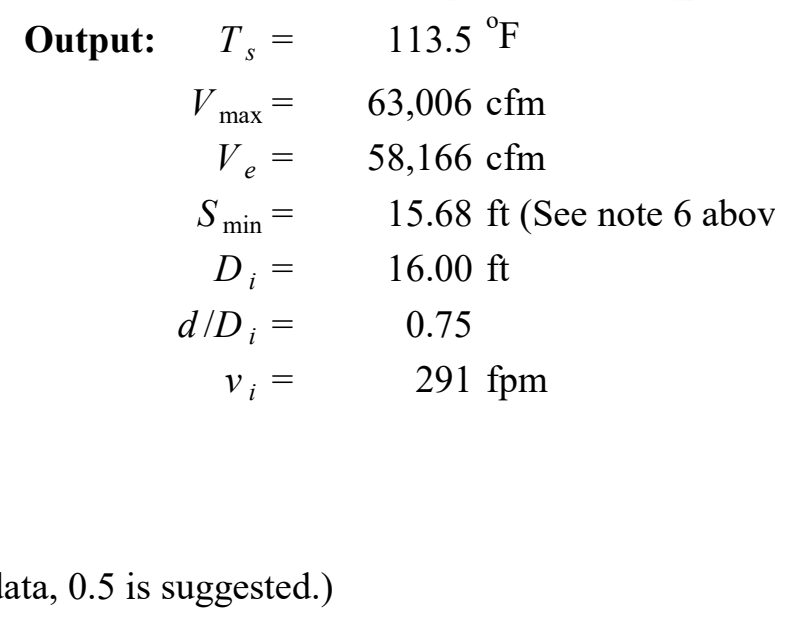

Check 1: CAUTION: The requirement of note 4 above is not satisfied.

Check 2: The requirement of note 5 above is satisfied. 


\section{Project: Burke Museum Plugholing at Top of Atrium}

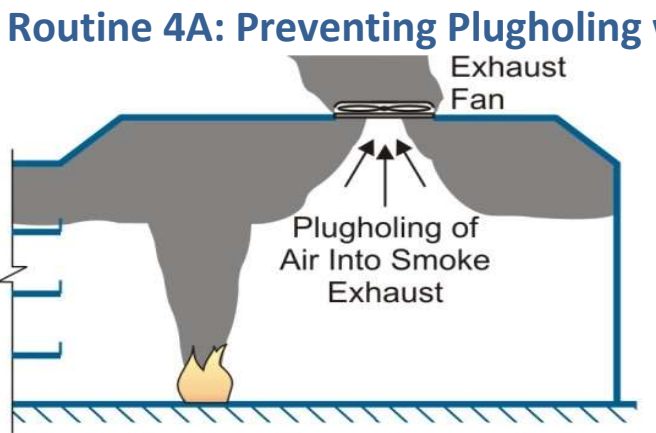

Plugholing Can Cause System Failure
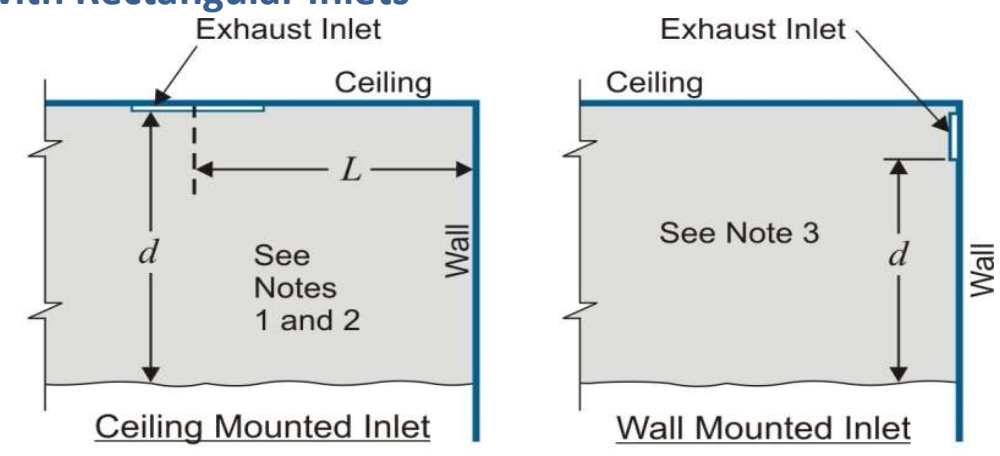

Notes:

1. For a ceiling mounted exhaust inlet with $L<2 D_{i}, \gamma=0.5$.

2. For a ceiling mounted exhaust inlet with $L \geq 2 D_{i}, \gamma=1$.

3. For a wall mounted exhaust inlet, $\gamma=0.5$.

4. $d / D_{i}$ must be greater than 2 .

5. $V_{e}$ must be less than or equal to $V_{\max }$.

6. The edge-to-edge distance between inlets must not be less than $S_{\text {min }}$.

7. For plugholing calculations, a value of $K_{s}=0.5$ needs to be used except when another value of $K_{s}$ is supported by test data or an engineering analysis.

$$
\begin{aligned}
& T_{s}=T_{o}+\frac{K_{s} Q_{c}}{m C_{p}} \quad\left(T_{s} \& T_{o} \text { are in }{ }^{\circ} \mathrm{C}\right) \\
& V_{\max }=452 \gamma d^{5 / 2}\left(\frac{T_{s}-T_{o}}{T_{o}}\right)^{1 / 2} \quad \begin{array}{c}
\left(T_{s} \& T_{o}\right. \\
\text { are in } \left.{ }^{\circ} \mathrm{R}\right)
\end{array} \\
& D_{i}=\frac{2 a b}{a+b} \\
& S_{\min }=0.065 V_{e}^{1 / 2}
\end{aligned}
$$

where

$$
\begin{array}{ll}
a & =\text { length of the inlet }(\mathrm{ft}) . \\
A_{f} & =\text { free area of inlet grille }\left(A_{f}=a b A_{r}\right)\left(\mathrm{ft}^{2}\right) . \\
A_{r} & =\text { ratio of free area to total grille area. } \\
b & =\text { width of the inlet }(\mathrm{ft}) . \\
C_{p} & =\text { specific heat }\left(0.24 \mathrm{Btu} / \mathrm{lb}-{ }^{\circ} \mathrm{F}\right) . \\
d & =\text { depth of smoke layer below the lowest }
\end{array}
$$

point of the exhaust inlet (ft).

$D_{i} \quad=$ effective diameter of the inlet ( $\mathrm{ft}$ ).

$K_{s} \quad=$ fraction of convective HRR in smoke layer.

$m \quad=$ exhaust mass flow $(\mathrm{lb} / \mathrm{s})$.

$N \quad=$ number of inlets (dimensionless).

$Q_{c} \quad=$ convective heat release rate of fire $(\mathrm{Btu} / \mathrm{s})$.

$S_{\min } \quad=$ minimum edge-to-edge separation between inlets (ft).

$T_{o} \quad=$ ambient temperature $\left({ }^{\circ} \mathrm{F}\right.$ or $\left.{ }^{\circ} \mathrm{R}\right)$.

$T_{s} \quad=$ temperature of smoke layer $\left({ }^{\circ} \mathrm{F}\right.$ or $\left.{ }^{\circ} \mathrm{R}\right)$.

$V \quad=$ volumetric flow of smoke exhaust $(\mathrm{cfm})$.

$V_{e} \quad=$ volumetric flow rate of one exhaust inlet $\left(V_{e}=V / N\right)(\mathrm{cfm})$.

$v_{i} \quad=$ average velocity at inlet $\left(v_{i}=V_{e} / A_{f}\right)$ (fpm).

$V_{\max } \quad=$ maximum volumetric flow rate without plugholing (cfm).

$\gamma \quad=$ exhaust location factor (dimensionless).

$$
\text { Output: } \begin{aligned}
T_{s} & =\quad 113.5^{\circ} \mathrm{F} \\
V_{\max } & =\quad 63,006 \mathrm{cfm} \\
V_{e} & =\quad 50,000 \mathrm{cfm} \\
S_{\min } & =\quad 14.53 \mathrm{ft}(\text { See note } 6 \mathrm{abov} \\
D_{i} & =\quad 5.71 \mathrm{ft} \\
d / D_{i} & =\quad 2.10 \\
v_{i} & =2500 \mathrm{fpm}
\end{aligned}
$$

$K_{s}=\quad 0.5($ See note 7 above $)$

$a=\quad 4.00 \mathrm{ft}$

$b=\quad 10.00 \mathrm{ft}$

$N=4$ Number of Inlets

$A_{r}=0.50$ (In the absence of better data, 0.5 is suggested.)

Check 1: The requirement of note 4 above is satisfied.

Check 2: The requirement of note 5 above is satisfied. 


\section{Project: Burke Museum, Axisymmetric Plume (Exhaust Require for a Single Level)}

Routine 4A: Preventing Plugholing with Rectangular Inlets

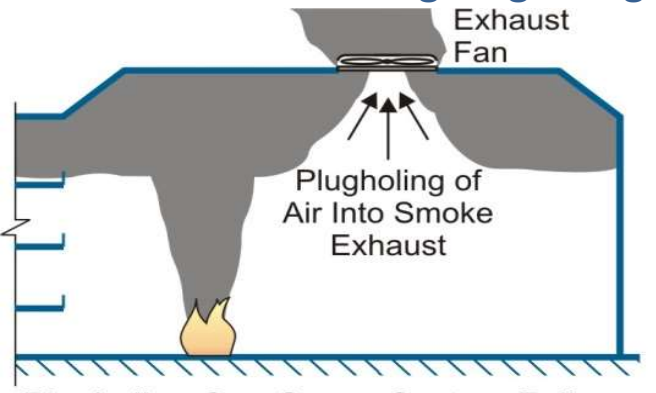

Plugholing Can Cause System Failure

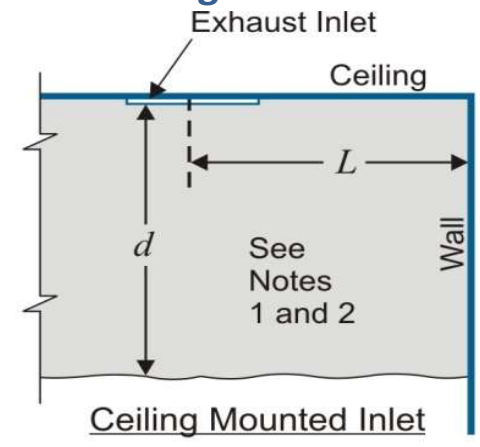

Ceiling Mounted Inlet
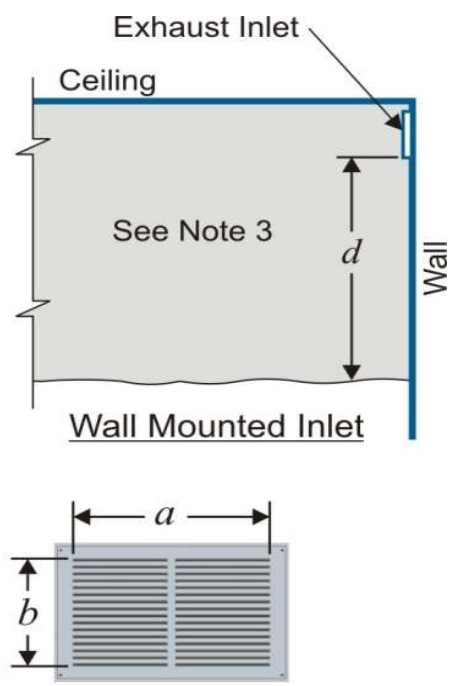

Rectangular Inlet Grille

1. For a ceiling mounted exhaust inlet with $L<2 D_{i}, \gamma=0.5$.

2. For a ceiling mounted exhaust inlet with $L \geq 2 D_{i}, \gamma=1$.

3. For a wall mounted exhaust inlet, $\gamma=0.5$.

4. $d / D_{i}$ must be greater than 2 .

5. $V_{e}$ must be less than or equal to $V_{\max }$.

6. The edge-to-edge distance between inlets must not be less than $S_{\min }$.

7. For plugholing calculations, a value of $K_{s}=0.5$ needs to be used except when another value of $K_{s}$ is supported by test data or an engineering analysis.

$$
\begin{aligned}
& T_{s}=T_{o}+\frac{K_{s} Q_{c}}{m C_{p}} \quad\left(T_{s} \& T_{o} \text { are in }{ }^{\circ} \mathrm{C}\right) \\
& V_{\max }=452 \gamma d^{5 / 2}\left(\frac{T_{s}-T_{o}}{T_{o}}\right)^{1 / 2} \quad \begin{array}{c}
\left(T_{s} \& T_{o}\right. \\
\text { are in } \left.{ }^{\circ} \mathrm{R}\right)
\end{array} \\
& D_{i}=\frac{2 a b}{a+b} \\
& S_{\min }=0.065 V_{e}^{1 / 2}
\end{aligned}
$$

where

$$
\begin{array}{ll}
a & =\text { length of the inlet }(\mathrm{ft}) . \\
A_{f} & =\text { free area of inlet grille }\left(A_{f}=a b A_{r}\right)\left(\mathrm{ft}^{2}\right) . \\
A_{r} & =\text { ratio of free area to total grille area. } \\
b & =\text { width of the inlet }(\mathrm{ft}) . \\
C_{p} & =\text { specific heat }\left(0.24 \mathrm{Btu} / \mathrm{lb}-{ }^{\circ} \mathrm{F}\right) . \\
d & =\text { depth of smoke layer below the lowest }
\end{array}
$$

point of the exhaust inlet (ft).

$D_{i} \quad=$ effective diameter of the inlet $(\mathrm{ft})$.

$K_{s} \quad=$ fraction of convective HRR in smoke layer.

$m \quad=$ exhaust mass flow $(\mathrm{lb} / \mathrm{s})$.

$N \quad=$ number of inlets (dimensionless).

$Q_{c} \quad=$ convective heat release rate of fire $(\mathrm{Btu} / \mathrm{s})$.

$S_{\min } \quad=$ minimum edge-to-edge separation between inlets $(\mathrm{ft})$.

$T_{o} \quad=$ ambient temperature $\left({ }^{\circ} \mathrm{F}\right.$ or $\left.{ }^{\circ} \mathrm{R}\right)$.

$T_{s} \quad=$ temperature of smoke layer $\left({ }^{\circ} \mathrm{F}\right.$ or $\left.{ }^{\circ} \mathrm{R}\right)$.

$V \quad=$ volumetric flow of smoke exhaust (cfm).

$V_{e} \quad=$ volumetric flow rate of one exhaust inlet $\left(V_{e}=V / N\right)(\mathrm{cfm})$.

$v_{i} \quad=$ average velocity at inlet $\left(v_{i}=V_{e} / A_{f}\right)$ (fpm).

$V_{\max }=$ maximum volumetric flow rate without plugholing (cfm).

$\gamma$
Input:
\begin{tabular}{r|r|r|}
$Q_{c}$ & $=2000 \mathrm{Btu} / \mathrm{s}$ \\
$T_{o}$ & $=72.0$ &
\end{tabular}
Output:

$$
\begin{gathered}
T_{s}= \\
V_{\max }=
\end{gathered}
$$$$
113.5^{\circ} \mathrm{F}
$$$$
63,006 \mathrm{cfm}
$$$$
V_{e}=
$$$$
7,000 \mathrm{cfm}
$$$$
S_{\min }=
$$$$
5.44 \mathrm{ft} \text { (See note } 6 \text { abov }
$$$$
D_{i}=
$$$$
16.00 \mathrm{ft}
$$$$
d / D_{i}=
$$$$
0.75
$$$$
v_{i}=
$$$$
35 \mathrm{fpm}
$$
$\begin{array}{rlr}K_{s} & =0.5(\mathrm{~S} \\ a & =10.00 \mathrm{ft}\end{array}$
$b=40.00 \mathrm{ft}$
$N=2$ Number of Inlets
$A_{r}=0.50$ (In the absence of better data, 0.5 is suggested.)

Check 1: CAUTION: The requirement of note 4 above is not satisfied.

Check 2: The requirement of note 5 above is satisfied. 